This document is confidential and is proprietary to the American Chemical Society and its authors. Do not copy or disclose without written permission. If you have received this item in error, notify the sender and delete all copies.

\title{
Comparison of methane combustion mechanisms using shock tube and rapid compression machine ignition delay time measurements
}

\begin{tabular}{|r|l|}
\hline Journal: & Energy \& Fuels \\
\hline Manuscript ID & ef-2020-04277n.R3 \\
\hline Manuscript Type: & Article \\
\hline Author: & 27-Apr-2021 \\
\hline Complete List of Authors: & $\begin{array}{l}\text { Zhang, Peng; Eötvös Loránd Tudományegyetem Kémiai Intézet, } \\
\text { Department of Physical Chemistry } \\
\text { Zsely, Istvan Gyula; Eötvös Loránd Tudományegyetem Kémiai Intézet, } \\
\text { Department of Physical Chemistry } \\
\text { Samu, Viktor; Eötvös Loránd Tudományegyetem Kémiai Intézet, } \\
\text { Department of Physical Chemistry } \\
\text { Nagy, Tibor; Eötvös Loránd Research Network, Institute of Materials and } \\
\text { Environmental Chemistry } \\
\text { Turanyi, Tamás; Eötvös Loránd Tudományegyetem Kémiai Intézet, } \\
\text { Department of Physical Chemistry }\end{array}$ \\
\hline
\end{tabular}

\section{SCHOLARONE Manuscripts}




\title{
Comparison of methane combustion mechanisms
}

\author{
using shock tube and rapid compression machine
}

ignition delay time measurements

\author{
Peng Zhang †, István Gy. Zsély *, †, Viktor Samu †, Tibor Nagy †, Tamás Turányi $\dagger$ \\ $\dagger$ Institute of Chemistry, ELTE Eötvös Loránd University, H-1117 Budapest, Hungary \\ I Institute of Materials and Environmental Chemistry (IMEC), Research Centre for Natural \\ Sciences (RCNS), Eötvös Loránd Research Network, H-1117 Budapest, Hungary
}

Keywords: methane combustion; detailed mechanisms; mechanism testing; mechanism development

\begin{abstract}
Methane is the major component of natural gas, which is one of the most widely used fuels. Large amount of shock tube (ST) and rapid compression machine (RCM) ignition delay measurements are available in the literature for validating its detailed combustion mechanisms. A large set of experimental data was collected for methane combustion: ignition studies in STs (4939 data points in 574 datasets) and in RCMs (582/69). In total, 5521 data points in 643 datasets from 76 publications were collected covering wide ranges of temperature $T$, pressure $p$, equivalence
\end{abstract}


ratio $\varphi$ and diluent concentration. For a quantitative assessment of methane combustion models, a least-squares-function is used to show the agreement between measurements and simulations. 13 recent methane combustion mechanisms were tested against these experimental data, and the dependence of their predictions on the types of experiments and the various experimental conditions was investigated. The mechanism comparison results show that most mechanisms could reproduce well the experimental ignition delay times (IDTs) measured in STs. IDTs measured in RCMs and STs at low temperatures (below $1000 \mathrm{~K}$ ) could also be well predicted by several mechanisms. SanDiego-2014, Caltech-2015, Aramco-II-2016 and Glarborg-2018 were found to be the most accurate mechanisms for the simulation of methane combustion under ST experimental conditions, while Aramco-II-2016 had the smallest prediction error under RCM conditions. Local sensitivity analysis was carried out to determine the effect of reactions on the simulation results obtained under given experimental conditions and to identify the critical reaction steps for improving the methane combustion models. 


\section{Introduction}

Large amount of combustion experimental data was published in the last decades, with continuously improved measurement accuracy. However, most mechanisms were originally developed based on data obtained under narrow ranges of experimental conditions, and the subsequent validation studies of published mechanisms are rare. Therefore, we have investigated a series of detailed reaction mechanisms for the combustion of hydrogen ${ }^{1}$, synthesis gas ${ }^{2}$, methanol ${ }^{3}$ and ethanol ${ }^{4}$. These studies led to building up a comprehensive experimental database 5, and also these works demonstrated that there are excellent mechanisms for the combustion of these fuels. It was also shown that some of the widely used mechanisms poorly reproduce many of the experimental data points. Furthermore, even the best mechanisms may perform surprisingly badly under some specific conditions. This conclusion indicates that it is meaningful to systematically evaluate the combustion mechanisms also for further fuels.

Due to the accumulating knowledge and understanding in combustion chemistry and gas kinetics, and using the increasing power of computers and simulation codes, more and more mechanisms were generated in the recent decades. The study of Lu and Law ${ }^{6}$ indicated that in the last twenty years not only the number of published combustion mechanisms increased, but also there was a significant increase in the numbers of species and reactions in the new mechanisms. However, in many cases the performance of these new mechanisms was not investigated under a wider range of conditions.

One of the most important fuels is natural gas, which is widely utilized for electricity production, heating and transport. The main ingredient of natural gas is methane, and therefore methane combustion is one of the practically most important chemical processes. Knowing the combustion kinetics of methane better, more efficient natural gas engines and gas turbines can be designed. 
Ignition delay time is one of the most important characteristic properties of the combustion of methane containing gas mixtures. Majority of such experiments was carried out in STs, but some others also in RCMs. Jach et al. ${ }^{7}$ recently published a paper on the comparison of the performance of several hydrocarbon combustion mechanisms in reproduction of IDTs of $\mathrm{C}_{1}-\mathrm{C}_{4}$ hydrocarbons, but this study was not comprehensive for methane and the tests were based only on ST measurements. Baigmohammadi et al. ${ }^{8}$ collected experimental data on the ignition of $\mathrm{C}_{1}-\mathrm{C}_{2}$ hydrocarbons covering a wide range of experimental conditions (temperature $\sim 800-2000 \mathrm{~K}$, pressure $\sim 1-80$ bar, equivalence ratio $\sim 0.5-2$, dilution $\sim 75-90 \%$ ), and compared the simulation results obtained by using the $\mathrm{C}_{3}$-NUIG mechanism with the experimental data. However, the amount of data collected for methane ignition was limited and some regions of experimental conditions were not covered, such as initial temperatures above $2000 \mathrm{~K}$, equivalence ratios below 0.5 and above 2.0, and dilution ratios below 75\%. Jach et al. ${ }^{9}$ investigated the performance of 15 detailed reaction mechanisms for the reproduction of ignition delay times of $\mathrm{C} 2-\mathrm{C} 6$ alkenes and acetylene. Lee et al. ${ }^{10}$ tested seven widely used syngas/biogas mechanisms based on a limited amount of IDT experimental data in a wide condition range (907-2030K, 1.24-70 atm), and suggested modified rate parameters for reactions $\mathrm{H}+\mathrm{O}_{2}\left(+\mathrm{CO}_{2}\right)=\mathrm{HO}_{2}\left(+\mathrm{CO}_{2}\right)$ and $\mathrm{CH}_{4}+\mathrm{OH}=$ $\mathrm{CH}_{3}+\mathrm{H}_{2} \mathrm{O}$.

In this paper the general methodology that we have previously developed and applied for the comparison of combustion mechanisms of other fuels ${ }^{1-4}$ is employed for methane combustion based on ST and RCM ignition delay measurements. To support related research in the future, a large amount of experimental data from STs and RCMs was collected in the ReSpechTh database 5, using the latest version of ReSpecTh Kinetics Data Format. Improvement of the method for calculating the standard deviations of experimental datasets was implemented by considering both 
the statistical and experimental errors. The performance of 13 widely used detailed combustion mechanisms was compared according to the reproduction of the ignition delays of methane, and four OHEX submechanisms were compared.

Engineering computational fluid dynamics simulations require accurate mechanisms under specific conditions. This is one of the reasons why in this paper a quantitative assessment of the accuracy of the combustion mechanisms was carried out separately in various ranges of pressure, temperature, equivalence ratio and diluent ratio. Special attention was paid to the performance of the mechanisms at low temperatures $(<1000 \mathrm{~K})$ and the reproducibility of IDTs with different lengths. Local sensitivity analysis was carried out for identifying the most important reactions for the reproduction of IDTs, and the rate coefficients of these reactions used in the best mechanisms were compared. 


\section{Methodology}

Agreement of experimental data and simulation results is investigated here by using the following objective function:

$$
E=\frac{1}{N} \sum_{i=1}^{N} E_{i}
$$

and

$$
E_{i}=\frac{1}{N_{i}} \sum_{j=1}^{N_{i}}\left(\frac{Y_{i j}^{\operatorname{sim}}-Y_{i j}^{\exp }}{\sigma\left(Y_{i j}^{\exp }\right)}\right)^{2}
$$

where

$$
Y_{i j}=\left\{\begin{array}{cl}
y_{i j} & \text { if } \sigma\left(y_{i j}^{\mathrm{exp}}\right) \approx \mathrm{constant} \\
\ln y_{i j} & \text { if } \sigma\left(\ln y_{i j}^{\mathrm{exp}}\right) \approx \mathrm{constant}
\end{array}\right.
$$

Here $N$ is the number of datasets and $N_{\mathrm{i}}$ is the number of data points in the $i$-th dataset. A dataset contains those data points that were measured on the same apparatus at the same time under similar conditions except for one that was systematically changed. Values $y_{i j}^{\exp }$ and $\sigma\left(y_{i j}^{\exp }\right)$ are the $j$-th data point and its standard deviation, respectively, in the $i$-th dataset. The corresponding simulated (modeled) value is $Y_{i j}^{\text {sim }}$ obtained from a simulation using an appropriate detailed mechanism and simulation method. IDT measurement errors are typically relative ones (the scatter is proportional to the value of $\left.y_{i j}\right)$, therefore we used the option $Y_{i j}=\ln y_{i j}$.

Error function values $E_{\mathrm{i}}$ belonging to dataset $i$, and $E$ belonging to all considered $N$ datasets are expected to be near unity if the chemical kinetic model is accurate, and the deviations of the measured and simulated results are caused by the scatter of the experimental data only. Note that due to the squaring in the definition of $E$, a twice as high deviation of the simulated and experimental values leads to a four times higher value of $E$. This objective function has been used 
in our previous studies for assessing the performance of combustion mechanisms in the estimation of rate parameters from experimental data, comparison of reaction mechanisms and mechanism optimization $^{1-4,11-19}$.

In addition to the average error function $E$, the mean $\sigma$-normalized signed deviation $D$ was used to characterize the behavior of the mechanisms:

$$
D=\frac{1}{N} \sum_{i=1}^{N} \frac{1}{N_{i}} \sum_{j=1}^{N_{i}} \frac{Y_{i j}^{\mathrm{sim}}-Y_{i j}^{\exp }}{\sigma\left(Y_{i j}^{\exp }\right)}
$$

using the same transformation $y_{\mathrm{ij}} \rightarrow Y_{\mathrm{ij}}$ as above. In contrast to $E$, the sign of the difference $Y_{\mathrm{ij}}^{\mathrm{sim}}-Y_{\mathrm{ij}}^{\mathrm{exp}}$ is maintained in the definition of $D$, therefore trends such as systematic under- or overprediction are captured in the $D$ values. This is meaningful, if the investigated model results are of the same type, like ignition delay time in this paper. However, mean signed deviation $D$ cannot be used for the characterization of accuracy, since positive and negative deviations belonging to different data points can cancel each other out and the resulting averaged value would erroneously suggest good overall agreement. The $D$ value plots may deliver a better understanding of the trends associated with changes of certain operating conditions and should be interpreted alongside with the corresponding $E$ value plots.

It is possible to characterize the similarity of simulation results for a given data series obtained using two different mechanisms by calculating the Pearson correlation coefficients of local absolute deviations $\left(D_{i}(j)\right)$, which are defined as:

$$
\begin{aligned}
D_{i}^{a}(j) & =Y_{i j}^{\sin \_a}-Y_{i j}^{\exp } \\
D_{i}^{b}(j) & =Y_{i j}^{\operatorname{sim} \_b}-Y_{i j}^{\exp }
\end{aligned}
$$


where simulation results $Y_{i j}^{\operatorname{sim} \_a}$ and $Y_{i j}^{\operatorname{sim} \_b}$ are calculated using reaction mechanisms $a$ and $b$, respectively. Let $\overline{D_{i}^{a}}$ and $\overline{D_{i}^{b}}$ denote the mean of values $D_{i}^{a}(j)$ and $D_{i}^{b}(j)$. The Pearson correlation coefficient for dataset $i$ can be calculated by the formula:

$$
C_{i}^{a b}=\frac{\sum_{j}^{N_{i}}\left(D_{i}^{a}(j)-\bar{D}_{i}^{a}\right)\left(D_{i}^{b}(j)-\bar{D}_{i}^{b}\right)}{\sqrt{\sum_{j}^{N_{i}}\left(D_{i}^{a}(j)-\bar{D}_{i}^{a}\right)^{2}} \sqrt{\sum_{j}^{N_{i}}\left(D_{i}^{b}(j)-\bar{D}_{i}^{b}\right)^{2}}}
$$

In the last step, the correlation coefficients calculated for all $N$ datasets are averaged:

$$
C^{a b}=\frac{1}{N} \sum_{i=1}^{N} C_{i}^{a b}
$$

A discussion on the comparisons of the performance of mechanisms using these correlation coefficients can be found in references ${ }^{1},{ }^{2}$ and ${ }^{9}$.

The standard deviation of a dataset was estimated based on the statistical scatter of the data $\left(\sigma_{\text {stat }, i}\right.$ ) and the reported experimental uncertainty $\left(\sigma_{\exp , i}\right)$, in a way similar to the approach used in ${ }^{3}$ :

$$
\sigma_{i j}=\sqrt{\sigma_{\text {stat }, i}^{2}+\sigma_{\mathrm{exp}, i j}^{2}}
$$

The statistical noise of a data series $\left(\sigma_{\mathrm{stat}, i}\right)$ was determined by finding an optimal trendline $\left(Y^{\mathrm{fit} 1}(\right.$ $x)$ ) for the transformed experimental data series $\left(Y_{i j}^{\exp }=Y_{i}^{\exp }\left(x_{i j}\right), j=1,,, N_{j}\right)$ using code MinimalSplineFit ${ }^{20}$. The idea behind this method is that the transformed values of an experimental dataset $\left(Y_{i j}^{\exp }\right)$ versus the changing condition variable $(x$, e.g. inverse temperature, equivalence ratio) can be considered as a smooth function with a symmetrically distributed noise added. If these data are fitted with flexible functions $\left(y_{i}^{\text {fit1 }}\left(x_{j}\right)\right)$, such as polynomials or spline functions, of increasing complexity (i.e. with more parameters, e.g. higher order, more knots), the fits first reconstruct the underlying smooth function. This way the error reduces steeply, whereas later only the remaining noise is fitted, which cannot be captured efficiently. As a result, an optimal fitting 
curve can be determined, which efficiently approximates the noise-free experimental data series, thus it can be used to give an unbiased estimate to the variance of the statistical noise $\left(\sigma_{\text {stat }}^{2}\right)$ :

$$
\sigma_{\text {stat }, i}^{2}=\frac{\sum_{j=1}^{N_{i}}\left(Y_{i j}^{\exp }-Y_{i}^{\mathrm{fit} 1}\left(x_{i j}\right)\right)^{2}}{N_{\mathrm{DOF}, i}}
$$

Here $Y_{i}^{\mathrm{fit1}}\left(x_{i j}\right)$ is the trendline value that corresponds to the experimental point $Y_{i j}^{\text {exp }}, N_{\mathrm{DOF}, i}=N_{i}$ $-n_{\mathrm{fit} 1, i}$ is the number of degrees of freedom, and $n_{\mathrm{fit} 1, i}$ is the number of parameters in the optimal fitting function. More details are available in ref. ${ }^{20}$.

For the ignition delay measurements, the experimental uncertainty could be expressed ${ }^{21}$ as:

$$
\sigma_{\exp , i j}=\frac{\mathrm{d} y_{i j}^{\exp }}{y_{i j}^{\exp }}
$$

Here $y_{i j}^{e x p}$ and $\mathrm{d} y_{i j}^{e x p}$ are the experimental IDT and the corresponding uncertainty of $i$-th data point in $j$-th dataset.

In the present study, we used the reported experimental uncertainty of IDT whenever it was available in the original article. However, in several publications the uncertainty of IDT was not provided, but the authors indicated the uncertainty of temperature and pressure. In these cases, we derived the IDT uncertainty from the available $P$ and $T$ uncertainty. Usually the relationship between IDT, and pressure and temperature can be expressed by equation:

$$
y_{i j}^{\mathrm{fit} 2}=A_{\mathrm{fit} 2, i} P_{i j} a_{\mathrm{fit} 2, i} e^{\frac{b_{\mathrm{fit} 2, i}}{T_{i j}}}
$$

Here $y_{i j}^{\mathrm{fit} 2}$ is the approximated IDT obtained by two-variate least squares fitting, $P_{i j}$ and $T_{i j}$ are the experimental pressure and temperature, $A_{\mathrm{fit} 2, i}$ is the fitted pre-exponential factor, while $a_{\mathrm{fit} 2, i}$ and $b_{\text {fit } 2, i}$ are fitted parameters related to pressure and temperature, respectively. Description of the fitting process is available in Part 2 of the Supplementary Material. Derivation of the function above yields: 


$$
d y_{i j}^{\exp }=\sqrt{\left(A_{\mathrm{fit} 2, i} a_{\mathrm{fit} 2, i} e^{\frac{b_{\mathrm{fit} 2, i}}{T_{i j}}} P_{i j} a_{\mathrm{fit} 2, i}-1\right)+\frac{1}{T_{i j}}\left(A_{\mathrm{fit} 2, i} b_{\mathrm{fit} 2, i} e^{\frac{b_{\mathrm{fit} 2, i}}{T_{i j}}} P_{i j} a_{\mathrm{fit} 2, i}^{2}\right)}
$$

If the uncertainty of either temperature or pressure is known, then the method can also be used for one variable only. The procedure described above follows the approach of Zhang et al. ${ }^{21}$ for the calculation of the experimental uncertainty of IDT measurements. This procedure results in different standard deviation $\sigma$ for each data point in some datasets, which is available in the Supplementary Material.

If the experimental uncertainty of IDT, temperature, or pressure was not reported by the authors for a dataset, then the standard deviation of the dataset was considered to be identical to $\sigma_{\text {stat }, i}$. In the cases of some measurements, the standard deviation $\sigma_{i j}$ calculated in this way was unrealistically low. Therefore, it was replaced by a minimal assumed standard deviation, which was $10 \%$ relative error for IDTs.

However, it is possible that some experimental data have large systematic uncertainty that could not be captured by either the reported experimental uncertainty or the statistical scatter. This is why data points that could not be reproduced within $3 \sigma$ error by any of the mechanisms were excluded from the mechanism comparison study, thus not all collected data were used at the assessment of the mechanisms. Also, the data were taken into account with different weights, since the equations for the calculation of $E$ and $D$ include that more uncertain data were considered with lower weight. 
3. The investigated mechanisms

Our aim was to test widely used methane combustion mechanisms published in the last two decades. In the forthcoming discussions, an identifier of each mechanism is used, which combines the name of the author or research group and the year of publication.

Table 1. General properties of the collected reaction mechanisms: number of species and reactions involved, the possible inert bath gas (aside from $\mathrm{N}_{2}$ ), and the conditions of methane ignition delay measurements at which the mechanisms were originally validated.

\begin{tabular}{|c|c|c|c|c|c|c|c|c|}
\hline \multirow[t]{2}{*}{ No. } & \multirow[t]{2}{*}{ Mechanisms ID } & \multirow[t]{2}{*}{ Ref. } & \multirow{2}{*}{$\begin{array}{l}\text { Reactions/ } \\
\text { Species } \\
\text { Number }\end{array}$} & \multirow[t]{2}{*}{ Diluents } & \multicolumn{4}{|c|}{ Development and validation conditions } \\
\hline & & & & & Temperature / K & Pressure / atm & $\varphi$ & Dilution Ratio / \% \\
\hline 1 & GRI3.0-1999 & 22 & $325 / 53$ & $\mathrm{Ar} /-$ & $1323-2036$ & $1.6-83.9$ & $0.5-5.01$ & $53.4-99.16$ \\
\hline 2 & Leeds-2001 & 23 & $175 / 37$ & $\mathrm{Ar} /-$ & $1400-2050$ & $1.56-29$ & $0.2-2$ & $66.7-97.8$ \\
\hline 3 & USC-II-2007 & 24 & $784 / 112$ & $\mathrm{Ar} / \mathrm{He}$ & \multicolumn{4}{|c|}{ No validation based on $\mathrm{CH}_{4}$ - IDT experiment. } \\
\hline 4 & Konnov-2009 & 25 & $1231 / 129$ & $\mathrm{Ar} /-$ & $800-2000$ & $1.5-20$ & $0.5-0.75$ & $75.05-99$ \\
\hline 5 & GDF-Kin-2012 & 26 & $1144 / 141$ & $\mathrm{Ar} / \mathrm{He}$ & $886.85-2015$ & $1.87-22.38$ & $0.4-1$ & $71.5-99$ \\
\hline 6 & SanDiego-2014 & 27 & $247 / 50$ & $\mathrm{Ar} / \mathrm{He}$ & $1045-2050$ & $2.96-256.6$ & $0.4-6$ & $33.3-90.9$ \\
\hline 7 & CRECK-2014 & 28 & $2642 / 107$ & $\mathrm{Ar} / \mathrm{He}$ & \multicolumn{4}{|c|}{ No validation based on $\mathrm{CH}_{4}$ - IDT experiment. } \\
\hline 8 & Caltech-2015 & 29 & $1156 / 192$ & $\mathrm{Ar} /-$ & $1348-1881$ & $1.56-4.83$ & $0.2-5$ & $53.4-78.4$ \\
\hline 9 & Aramco-II-2016 & 30 & $2716 / 502$ & $\mathrm{Ar} / \mathrm{He}$ & $1040-2584$ & $1.46-260$ & $0.1-6$ & $33.3-97$ \\
\hline 10 & SanDiego-2016 & 31 & $268 / 57$ & $\mathrm{Ar} / \mathrm{He}$ & $1045-2050$ & $2.96-256.6$ & $0.4-6$ & $33.3-90.9$ \\
\hline 11 & FFCM-I-2016 & 32 & $291 / 38$ & $\mathrm{Ar} / \mathrm{He}$ & $1408.1-2454$ & $1-83.9$ & $0.04-5.01$ & $53.4-99.16$ \\
\hline 12 & Konnov-2017 & 33 & $1236 / 107$ & $\mathrm{Ar} / \mathrm{He}$ & \multicolumn{4}{|c|}{ No validation based on $\mathrm{CH}_{4}$ - IDT experiment. } \\
\hline 13 & Glarborg-2018 & 34 & $1407 / 154$ & $\mathrm{Ar} / \mathrm{He}$ & $908-1665$ & $6.9-456$ & $0.32-3$ & $55-90$ \\
\hline
\end{tabular}

Two mechanisms (GRI3.0-1999 ${ }^{22}$ and Leeds-2001 ${ }^{23}$ ) were originally developed for natural gas combustion, while the other mechanisms were elaborated for the combustion of hydrocarbons or oxygenates ${ }^{24-34}$, but have also been used to interpret methane combustion data. In the order of publishing year, Table 1 lists all the 13 mechanisms and provides further information about size 
and included diluents. Although the Aramco mechanism was continuously updated in the recent years, the methane part was updated in 2016 for the last time, therefore this version is used in the present study. Figure 1 shows the condition ranges (temperature, pressure, equivalence ratio, and diluent ratio) of validating measurements of methane ignition delays used for the development of these mechanisms. Fig.1 indicates that these mechanisms have not been validated under several specific conditions, such as at low pressure $(<1 \mathrm{~atm})$ and low diluent ratio $(<33.3 \%)$. The performance of the 13 mechanisms under these conditions will be presented in Section 6.1.

All mechanisms can handle $\mathrm{N}_{2}$ and Ar bath gases, while only four mechanisms do not include helium as a possible bath gas. For each mechanism, their own thermochemical data were used as published online and/or provided by the authors.
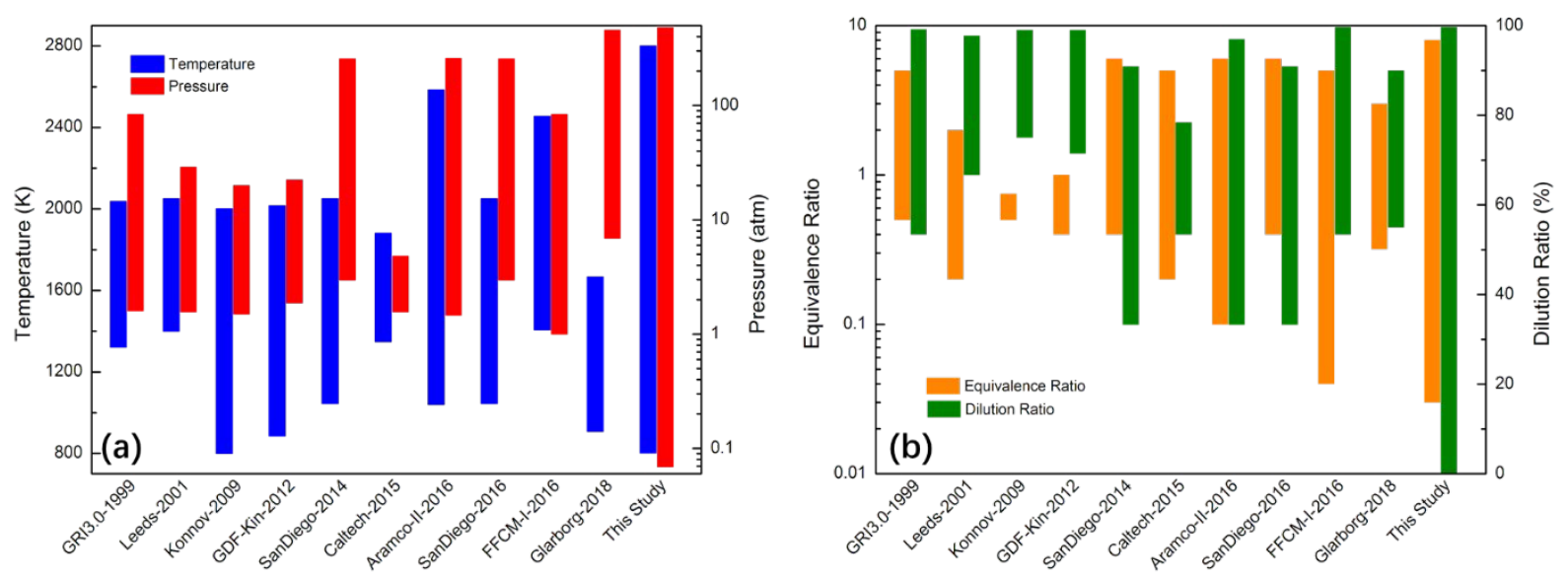

Figure 1. Condition (temperature, pressure, equivalence ratio, and diluent ratio) ranges of methane IDT experimental data originally used for the validation of the mechanisms. The last columns show the experimental condition ranges used for testing the mechanisms in this study. Mechanisms USC-II-2007, CRECK-2014, and Konnov-2017 are not included as they were not validated for methane ignition delay data by their developers 


\section{Collection of experimental data}

The combustion characteristics of mixtures containing methane have been studied extensively. In this work we consider only those experiments in which the reactant mixture contains methane, but no larger hydrocarbons or oxygenated species. This means that mixtures of methane and $\mathrm{H}_{2}$ or $\mathrm{CO}$ are investigated in this paper, but no mixtures containing ethane or methanol. Having this restriction on the initial chemical composition, the datasets to be considered are still numerous, close to two thousand. Therefore, we decided to focus only on ignition delay time measurement in this study. An extensive literature review was performed, and 574 datasets were collected from ST and 69 datasets from RCM measurements, including 5521 data points in total.

The collection of IDT measurements in STs ${ }^{35-103}$ covers a wide range of conditions. The initial temperature and pressure were varied in the range of $803-2800 \mathrm{~K}$ and $0.069-481.4$ atm, respectively; the equivalence ratio was changed between 0.03 and 8.0 ; the mole fraction of diluent concentration was within the interval of 0-99.7\%. In some cases, several different experimental IDTs were deduced from the same experiment in such a way that different profiles, such as pressure, excited $\mathrm{OH}$ radical, or other species profiles were measured simultaneously. In the present study, we added all these kinds of IDT measurements to the database but used only one of them for mechanism comparison. The priority order of IDT definitions was based on excited OH, excited $\mathrm{CH}$, pressure, and other species. Therefore, less data were utilized here than actually collected and encoded in XML files, but the additional experimental data are also available for the combustion community for further studies. Also, measurements with helium bath gas were not used, because there were relatively few such measurements and also we wanted to make a comparison of all mechanisms using the same sets of measurements. Finally, 3403 data points in 484 datasets extracted from 69 publications were used for testing the mechanisms. 
Table 2. A summary of methane experimental data used in the mechanism comparison by type of measurement and experimental facility. The table includes the numbers of datasets and data points used, ranges for pressure $p$, temperature $T$, equivalence ratio $\varphi$, and the combinations of fuels and diluents together with the number of corresponding data points. PRR stands for pressure rise rate.

\begin{tabular}{|c|c|c|c|c|c|c|c|}
\hline Type of measurement & $\begin{array}{l}\text { No. of } \\
\text { datasets }\end{array}$ & $\begin{array}{l}\text { No. of } \\
\text { data points }\end{array}$ & $T / \mathrm{K}$ & $p /$ atm & $\varphi$ & Fuels & Diluents \\
\hline ST without PRR & 387 & 3557 & $803-2800$ & $0.069-481.4$ & $0.03-8$ & $\begin{array}{l}\mathrm{CH}_{4}-\mathbf{2 9 9 7} \\
\mathrm{CH}_{4} / \mathrm{H}_{2}-\mathbf{4 3 2} \\
\mathrm{CH}_{4} / \mathrm{CO}-\mathbf{5 7} \\
\mathrm{CH}_{4} / \mathrm{H}_{2} / \mathrm{CO}-\mathbf{7 1}\end{array}$ & $\begin{array}{l}\mathrm{Ar}-\mathbf{2 2 5 9} \\
\mathrm{Ar} / \mathrm{N}_{2}-\mathbf{8 6} \\
\mathrm{Ar} / \mathrm{N}_{2} / \mathrm{CO}_{2}-\mathbf{2 5} \\
\mathrm{Ar} / \mathrm{CO}_{2}-\mathbf{5 3} \\
\mathrm{Ar} / \mathrm{CO}_{2} / \mathrm{H}_{2} \mathrm{O}-\mathbf{3 3} \\
\mathrm{Ar} / \mathrm{H}_{2} \mathrm{O}-\mathbf{7} \\
\mathrm{N}_{2}-\mathbf{8 7 9} \\
\mathrm{N}_{2} / \mathrm{CO}_{2}-\mathbf{2 7} \\
\mathrm{N}_{2} / \mathrm{CO}_{2} / \mathrm{H}_{2} \mathrm{O}-\mathbf{3 9} \\
\mathrm{N}_{2} / \mathrm{H}_{2} \mathrm{O}-\mathbf{2 3} \\
\mathrm{CO}_{2}-\mathbf{3 9} \\
\mathrm{No} \text { diluent }-\mathbf{8 7}\end{array}$ \\
\hline ST with PRR & 97 & 846 & $1020-2150$ & $0.987-44$ & $0.3-2.0$ & $\begin{array}{l}\mathrm{CH}_{4}-\mathbf{5 9 5} \\
\mathrm{CH}_{4} / \mathrm{H}_{2}-251\end{array}$ & $\begin{array}{l}\mathrm{Ar}-514 \\
\mathrm{~N}_{2}-258 \\
\mathrm{~N}_{2} / \mathrm{CO}_{2}-74\end{array}$ \\
\hline RCM & 69 & 582 & $869.9-1200$ & $9.87-156.62$ & $0.3-2.0$ & $\begin{array}{l}\mathrm{CH}_{4}-467 \\
\mathrm{CH}_{4} / \mathrm{H}_{2}-\mathbf{7 5} \\
\mathrm{CH}_{4} / \mathrm{CO}-\mathbf{1 6} \\
\mathrm{CH}_{4} / \mathrm{H}_{2} / \mathrm{CO}-\mathbf{2 4}\end{array}$ & $\begin{array}{l}\mathrm{Ar}-\mathbf{2 5 7} \\
\mathrm{N}_{2}-\mathbf{2 1} \\
\mathrm{Ar} / \mathrm{N}_{2}-\mathbf{3 0 4}\end{array}$ \\
\hline
\end{tabular}

As for the conditions of RCM experiments $26,43,63,104-107$, the ranges of temperature and pressure were 869.9 - $1200 \mathrm{~K}$, and 9.87 - 156.62 atm, respectively; equivalence ratio and diluent ratio were changed between $0.3-2.0$ and $62.58-90 \%$, respectively. All in all, 582 data points included in 68 datasets were extracted from 7 articles. All detailed information about the ST and RCM experiments can be found in Tables A and B, respectively, of the Supplementary.

An overview of the regions of initial conditions covered and diluents investigated is shown in Table 2. Although the conditions in the listed ranges are not represented uniformly, the provided numbers may serve as an outline for the ranges of conditions. The detailed list of data arranged in datasets with references is given in Tables A and B of the Supplementary Material. 


\section{Simulation of experiments}

All the collected experimental data were encoded in ReSpecTh Kinetics Data Format v2.3 (RKDF2.3) ${ }^{108}$ XML files. The RKD format is an XML data format for the storage of indirect combustion measurements and rate coefficient determinations by direct gas kinetics experiments and theoretical calculations. The RKD format is a modified and extended version of the PrIMe Kinetics Data Format ${ }^{109}$. All the prepared XML files are available in the ReSpecTh Information System ${ }^{5}$.

The RKD files contain all information required for the simulation of the experiments, such as initial compositions, temperature, pressure and IDT definition. Usage of these files allowed the fully automatized run of thousands of simulations. In principle, the complete investigation of a mechanism against several thousand experimental data points can be carried out in a single run using these files and the Optima++ environment ${ }^{110}$. Both simulation packages FlameMaster 111 (FM) and OpenSMOKE++ ${ }^{112,113}$ (OS) were used. For the ST data (shock tubes with constant pressure) all calculations were carried out with both simulation codes and the agreement of the calculated IDTs were always better than $1 \%$. For the simulation of the experiments with pressure/volume profiles, i.e. for the ST-PRR and RCM experiments, FM simulations ran much slower and therefore OS was used routinely. In several points the OS results were checked with FM simulations and again good agreement (within 1\%) was found.

\subsection{Shock tube simulations}

The IDT in a reflected ST experiment is interpreted as the time interval between the arrival of the reflected shock wave and the onset of a well measurable characteristic state. This state was extracted from the simulated pressure or concentration profiles. We found that in the experimental 
papers dealing with ST methane ignition 37 different definitions of IDT have been used. These definitions, and the numbers of the related datasets and data points are listed in Table 3.

Table 3. A summary of various designations of IDTs as defined in the experiments. OHEX and CHEX denote electronically excited $\mathrm{OH}$ and $\mathrm{CH}$ species, respectively.

\begin{tabular}{|c|c|c|c|}
\hline No. & The definition of IDT & $\begin{array}{l}\text { Number of } \\
\text { datasets }\end{array}$ & $\begin{array}{l}\text { Number of data } \\
\text { points }\end{array}$ \\
\hline 1 & Root of the tangent line at the inflection point of $p(t)$ & 111 & 792 \\
\hline 2 & Root of the tangent line at the first inflection point of the $[\mathrm{OH}]$ profile & 3 & 9 \\
\hline 3 & Root of the tangent line at the first inflection point of the $[\mathrm{OHEX}]$ profile & 51 & 472 \\
\hline 4 & Root of the tangent line at the first inflection point of the $[\mathrm{CH}]$ profile & 2 & 3 \\
\hline 5 & Root of the tangent line at the first inflection point of the $[\mathrm{CHEX}]$ profile & 101 & 744 \\
\hline 6 & Root of the tangent line at the inflection point of the $\left[\mathrm{CH}_{4}\right]$ profile & 35 & 201 \\
\hline 7 & Root of the tangent line at the first inflection point of the $\left[\mathrm{CH}_{3}\right]$ profile & 2 & 24 \\
\hline 8 & Root of the tangent line at the inflection point of the $\left[\mathrm{CO}_{2}\right]$ profile & 11 & 91 \\
\hline 9 & Root of the tangent line at the inflection point of the $\left[\mathrm{O}_{2}\right]$ profile & 3 & 31 \\
\hline 10 & Root of the tangent line at the first inflection point of the $\left[\mathrm{H}_{2} \mathrm{O}\right]$ profile & 2 & 14 \\
\hline 11 & Root of the tangent line at the inflection point of the [soot] profile * & 1 & 6 \\
\hline 12 & Time of the first inflection point of $p(t)$ & 73 & 968 \\
\hline 13 & Time of the first inflection point of the $[\mathrm{OHEX}]$ profile & 32 & 346 \\
\hline 14 & Time of the first inflection point of the $[\mathrm{CHEX}]$ profile & 4 & 147 \\
\hline 15 & Time of maximum of $[\mathrm{OH}]$ profile & 9 & 33 \\
\hline 16 & Time of maximum of $[\mathrm{OHEX}]$ profile & 23 & 181 \\
\hline 17 & Time of maximum of $[\mathrm{O}]$ profile & 6 & 44 \\
\hline 18 & Time of maximum of $[\mathrm{O}] \times[\mathrm{CO}]$ profile $* *$ & 5 & 55 \\
\hline 19 & Time of maximum of $\left[\mathrm{CH}_{3}\right]$ profile & 4 & 15 \\
\hline 20 & Time of maximum of $\left[\mathrm{H}_{2} \mathrm{O}\right]$ profile & 2 & 20 \\
\hline 21 & Time of reaching $0.05 \times$ the maximum of $p(t)$ & 6 & 42 \\
\hline 22 & Time of reaching $0.25 \times$ the maximum value in $[\mathrm{OH}]$ profile & 4 & 40 \\
\hline 23 & Time of reaching $0.50 \times$ the maximum value in $[\mathrm{OH}]$ profile & 6 & 48 \\
\hline 24 & Time of reaching $0.75 \times$ the maximum value in $[\mathrm{OH}]$ profile & 4 & 40 \\
\hline 25 & Time of reaching $0.05 \times$ the maximum value in $[\mathrm{OHEX}]$ profile & 13 & 141 \\
\hline 26 & Time of reaching $0.10 \times$ the maximum value in $[\mathrm{OHEX}]$ profile & 6 & 27 \\
\hline 27 & Time of reaching $0.50 \times$ the maximum value in $[\mathrm{OHEX}]$ profile & 16 & 84 \\
\hline 28 & Time of reaching $0.05 \times$ the maximum value in $[\mathrm{CHEX}]$ profile & 6 & 42 \\
\hline 29 & Time of reaching $0.25 \times$ the maximum value in $[\mathrm{CO}]$ profile $* *$ & 4 & 40 \\
\hline 30 & Time of reaching $0.50 \times$ the maximum value in $[\mathrm{CO}]$ profile $* *$ & 4 & 40 \\
\hline 31 & Time of reaching $0.75 \times$ the maximum value in $[\mathrm{CO}]$ profile $* *$ & 4 & 40 \\
\hline 32 & Time of reaching $0.90 \times$ the maximum value in $[\mathrm{CO}]$ profile $* *$ & 2 & 15 \\
\hline 33 & Time of reaching $0.25 \times$ the maximum value in $\left[\mathrm{CO}_{2}\right]$ profile & 2 & 8 \\
\hline 34 & Time of reaching $0.90 \times$ the maximum value in $\left[\mathrm{CO}_{2}\right]$ profile & 7 & 49 \\
\hline 35 & Time of reaching $0.90 \times$ the maximum value in $\left[\mathrm{H}_{2} \mathrm{O}\right]$ profile & 2 & 14 \\
\hline 36 & Time of reaching $0.05 \times$ the maximum value in $\left[\mathrm{C}_{2}\right]$ profile $*$ & 6 & 38 \\
\hline 37 & Time of reaching $\left[\mathrm{CO}_{2}\right]=1.6 \mathrm{E} 14$ molecule $/ \mathrm{cm}^{3} *$ & 2 & 35 \\
\hline
\end{tabular}

* These data points were not used at the comparison of the mechanisms since these IDT definitions are not feasible in this study. 


\footnotetext{
** These data points were not used at the comparison of the mechanisms, since only Ar was used as diluent gas in the measurements, thus the effect of vibration relaxation during CO production was not considered. According to the conclusion of the study of Mathieu et al. 114, if vibration relaxation is not considered, the measurements based on $\mathrm{CO}$ concentrations are not reproducible.
}

1251 IDTs in 141 datasets were determined from excited OH (OHEX) concentration profiles. IDTs derived from simulated OH (ground state) and OHEX (excited state) concentration profiles may or may not agree with each other, and therefore if the experimental IDT was determined based on OHEX profile, then the simulated IDT also has to be based on the OHEX concentration profile. However, only four of the thirteen mechanisms (Aramco-II-2016, FFCM-I-2016, Konnov-2017, Glarborg-2018) contain OHEX chemistry. The OHEX submechanism of the Aramco-II-2016 mechanism was selected and it was added to the nine mechanisms that do not contain OHEX species. The detailed description is available in Part 3 of the Supplementary Material. It was verified that adding the OHEX submechanism to these mechanisms changed the calculation of the concentrations of all other species negligibly. If the IDT definition was based on the calculated OHEX profile, the original Aramco-II-2016, FFCM-I-2016, Konnov-2017, and Glarborg-2018 mechanisms were used, whereas the other mechanisms were used together with the OHEX submechanism of Aramco-II-2016.

The IDTs in 933 data points (included in 111 datasets) were measured based on excited $\mathrm{CH}$ (CHEX) concentrations, from which 19 points of 8 datasets used helium as diluent. Similarly to the case of OH vs. OHEX, the calculated IDT has to be based on calculated CHEX profile, if the experimental IDT was obtained via monitoring the CHEX profile. However, only Aramco-II-2016 and FFCM-I-2016 contain CHEX submechanisms. In a similar way, the CHEX submechanism of Aramco-II-2016 was selected and it was added to the mechanisms without CHEX chemistry. Again, this addition negligibly affected the calculated concentrations of the other species. In the IDT simulations based on CHEX, the original CHEX submechanisms were used with Aramco-II2016 and FFCM-I-2016, but CHEX submechanism of Aramco-II-2016 was added to all other 
mechanisms. We also added the CHEX submechanism of FFCM-I-2016 (instead of Aramco-II2016) to all other mechanisms and found that the calculated IDTs were practically identical to using the Aramco-II-2016 CHEX submechanism.

We investigated the detailed description of experimental conditions in all articles containing ST experimental data. From all 71 articles without published pressure rise rates, 19 articles $35,36,42,45,51,52,58,61,66,71,74,75,77,78,80,84,89,98,99$ declared that the slightly increasing pressure observed before ignition can be neglected. These articles provided several reasons for it, such as (i) the used ST equipment had large diameter that minimized the boundary layer effects, (ii) the measured pressure rise rates before ignition were too small to be considered, (iii) the measured IDTs were very short, (iv) the pressure rise due to reactions could be reproduced by simulations, and (v) no pressure rise was found during the whole reacting process due to the high diluent ratio. Three articles $54,68,88$ took into account the pressure rise at the estimation of the experimental error. The rest of the papers did not comment on the observed slight pressure change before ignition or they did not find pressure rise. For all shock tube measurements without published pressure rise rate the assumption of constant volume and adiabatic conditions was used.

Olm et al. simulated IDTs of hydrogen and syngas mixtures ${ }^{1,2}$ and they excluded data points without detailed pressure-time history if the initial temperature was lower than $1000 \mathrm{~K}$. In the present study, this procedure was not used for the following reasons. The performance of the mechanisms at low initial temperatures $\left(\mathrm{T}_{5} \leq 900 \mathrm{~K}\right)$ using ST measurements was investigated and six mechanisms (Aramco-II-2016, USC-II-2007, Glarborg-2018, Caltech-2015, Konnov-2017, GDF-Kin-2009) were found to have good performance (see Fig. S3). The error values belonging to the other seven mechanisms (FFCM-I-2016, GRI3.0-1999, Konnov-2009, CRECK-2014, Leeds-2001, SanDeigo-2014, and SanDiego-2016) were only slightly higher. Similarly, all data 
points were sorted to five sets according to the length of IDT, and the results in Fig. S4 show that no clear trend of error function values $E$ appear with increasing length of IDTs. The detailed description and figures are available in Part 4 of the Supplementary Material.

In the shock tube measurements of Donohoe et al. ${ }^{43}$, Zhang et al. ${ }^{55,101}$, Burke et al. ${ }^{63}$, Zeng et al..$^{90}$, Merhubi et al. ${ }^{93}$, and Deng et al.${ }^{95,96}$, pressure rise rates during ignition were reported. The details of measurements including pressure rise rates was shown in "ST with PRR" part in Table 2. For the simulation of these ST data, we used the assumptions of constant volume and adiabatic system with the measured pressure rise rate.

\subsection{RCM simulations}

In RCM experiments the compression is never truly adiabatic as from the beginning of the compression stroke heat loss takes place to the walls. The most practical way to take such heat loss into account in homogeneous simulations is based on the adiabatic core approximation ${ }^{115,116}$, which assumes an inner adiabatic core in the chamber by mimicking heat loss with an equivalent adiabatic expansion work. In order to experimentally determine heat loss rate before ignition, an extra, non-reactive experimental measurement is done in an almost identical setup, in which oxygen $\left(\mathrm{O}_{2}\right)$ is replaced with nitrogen $\left(\mathrm{N}_{2}\right)$, thus no chemical heat production can take place. From the corresponding, non-reactive pressure trace the effective volume profile $\left(V_{\text {eff }}(t)\right)$, which also takes heat loss into account within the adiabatic core and frozen-chemistry approximation (i.e. isentropic process), is obtained by the following integral:

$$
V_{\text {eff }}(t)=V\left(t_{0}\right) \exp \left(-\int_{p\left(t_{0}\right)}^{p(t)} \frac{1}{\gamma\left(T\left(p^{\prime}\right)\right) p^{\prime}}\right)
$$


Here, $p\left(t_{0}\right)$ and $V\left(t_{0}\right)$ are the initial pressure and volume, respectively, and $\gamma$ is the adiabatic index:

$$
\gamma(T)=\frac{C_{p}(T)}{C_{V}(T)}=\frac{C_{p}(T)}{C_{p}(T)-R}
$$

which can be calculated using the NASA polynomials of the constant-pressure molar heat capacity $\left(C_{p}\right)$, The momentary temperature $\left(T\left(t^{\prime}\right)\right)$ can be calculated from the initial temperature $\left(T_{0}\right)$, the initial and instantaneous pressures $\left(p\left(t_{0}\right), p\left(t^{\prime}\right)\right)$ and the effective volumes $\left(V\left(t_{0}\right), V^{\text {eff }}\left(t^{\prime}\right)\right)$ using the ideal gas law $(p V / T=$ constant $)$. Applying this equation for the whole period, the simulation of the non-reactive mixture with the obtained volume profile under adiabatic conditions will always precisely follow the measured non-reactive pressure trace if frozen-chemistry approximation holds. This procedure was first applied in the work of Kérmonès et al. ${ }^{117}$, but it was not discussed in details there. Kérmonès et al. ${ }^{117}$ used the code of T. Nagy and this code is available on request. The procedure proposed by He et al. ${ }^{118}$ is very similar, but it determines the effective volume profile for the compression period using the reactive pressure trace. If chemistry (e.g. pyrolysis) takes place already during compression, these methods can provide more realistic simulation results than the procedure proposed by Mittal and Sung ${ }^{116}$, in which the matching of the pressure profile during compression is not achieved precisely. Transferring the determined volume profiles $\left(V^{\text {eff }}(t)\right)$ to reactive simulations, heat loss can be taken into account before ignition, which is necessary to capture the experimentally measured IDT.

For the uniform simulation of all considered RCM experiments, we derived effective volume histories from the non-reactive pressure histories whenever they were available. For the simulation of experiments in papers $43,63,104,107$, we used the provided volume-time profiles as no pressure histories were published. In refs. ${ }^{43,63,104}$, the volume-time profiles were determined based on the method of Mittal and Sung ${ }^{116}$, whereas in paper ${ }^{107}$ they were calculated using the method of He 
et al. ${ }^{118}$. The authors of articles ${ }^{105}$ and ${ }^{106}$ published only reactive pressure histories and assessed heat loss based on them. For these experiments we proceeded in the same way as they did: they truncated each pressure history from when substantial heat release started taking place, extrapolated the preceding heat loss part to the removed period, and then derived the volume-time profile based on the discussed isentropic relations.

Adiabatic simulations of reactive experiments were carried out using the volume-time profiles and all RCM IDTs were defined, in accordance with the experimental papers, as the time of the steepest pressure rise (i.e. time of $\mathrm{d} p / \mathrm{d} t$ maximum) after the end of the compression stroke $(t=0$ ) .

The experimental data used in the present study were obtained from published articles or personal communications with the authors. Some RCM experimental data were not accompanied with published pressure-time or volume-time histories ${ }^{94,119,120}$ and these were excluded from the comparison. 
6 Results and discussion

6.1 Ignition delay times

Table 4 lists the mean squared error and the mean signed deviation function values of all mechanisms. These data are visualized in Figs. 2 and 3. Fig. 2 shows the average error function values of all mechanisms for simulating the shock tube measurements with constant volume assumption (ST group), shock tube experiments with pressure rise rate (ST-PRR group), rapid compression machine measurements (RCM group) and the overall results (Overall group). There are six mechanisms with average error $E$ lower than three times of the estimated experimental error $(E<9)$; these are Aramco-II-2016, Caltech-2015, Glarborg-2018, SanDiego-2014, SanDiego-2016, and GDF-Kin-2012, in the order of increasing error. For the ST group, the simulation error values of Caltech-2015, Glarborg-2018, Aramco-II-2016, and SanDeigo-2014 are the lowest. In the STPRR group, Caltech-2015 and FFCM-I-2016 have obviously lower error values, while for the RCM measurements, Aramco-II-2016 has significantly the best performance among all mechanisms. All mechanisms reproduce the ST-PRR experiments better than the ST experiments. This indicates that providing the pressure rise rate might be important in several cases for the accurate reproduction of the experimental conditions. Two mechanisms, GRI3.0-1999 and FFCMI-2016 do not reproduce well the RCM experimental results, compared to other investigated mechanisms. 
Table 4. The mean squared error function values $E$ and the mean signed deviation function values $D$ for all the mechanisms. The shaded cells indicate those up to six best performing mechanisms in each experimental type that reproduce the measured ignition delay times on average within $3 \sigma$ (i.e. $E<9)$.

\begin{tabular}{llrrrrrrrrr}
\hline \multirow{2}{*}{ No. } & \multirow{2}{*}{ Mechanisms ID } & \multicolumn{4}{c}{ Mean squared error function values } & \multicolumn{5}{c}{ Mean signed deviation function values } \\
\cline { 3 - 9 } & & ST & \multicolumn{2}{c}{ ST-PRR } & \multicolumn{1}{c}{ RCM } & Overall & ST & ST-PRR & RCM & Overall \\
\hline 1 & GRI30-1999 & 8.931 & 3.345 & 560.417 & 58.415 & -0.620 & -0.925 & 15.900 & 0.839 \\
2 & Leeds-2001 & 11.618 & 3.763 & 20.616 & 10.897 & -1.110 & -0.752 & -1.860 & -1.110 \\
3 & USC-II-2007 & 9.418 & 2.652 & 54.025 & 12.178 & 0.442 & -0.236 & 5.110 & 0.737 \\
4 & Konnov-2009 & 16.861 & 16.411 & 92.951 & 23.751 & -2.850 & -3.480 & -7.670 & -3.420 \\
5 & GDF-Kin-2012 & 7.558 & 5.740 & 22.646 & 8.584 & -1.330 & -1.490 & -2.060 & -1.430 \\
6 & SanDiego-2014 & 5.742 & 2.932 & 24.848 & 6.941 & 0.128 & -0.016 & -2.740 & -0.164 \\
7 & CRECK-2014 & 23.147 & 9.586 & 127.636 & 30.061 & -2.900 & -0.977 & 4.880 & -1.810 \\
8 & Caltech-2015 & 4.644 & 1.851 & 19.099 & 5.420 & 0.044 & 0.285 & 2.500 & 0.317 \\
9 & Aramco-II-2016 & 5.458 & 4.205 & 6.029 & 5.264 & 0.823 & 1.280 & 0.589 & 0.891 \\
10 & SanDiego-2016 & 5.924 & 3.214 & 25.517 & 7.188 & 0.324 & 0.193 & -2.770 & 0.015 \\
11 & FFCM-I-2016 & 9.160 & 2.016 & 600.867 & 62.026 & 0.366 & -0.176 & 18.000 & 1.880 \\
12 & Konnov-2017 & 8.056 & 7.445 & 23.103 & 9.316 & 1.410 & 1.020 & 3.680 & 1.540 \\
13 & Glarborg-2018 & 5.258 & 3.786 & 12.613 & 5.643 & 1.070 & 1.180 & 1.800 & 1.160 \\
\hline
\end{tabular}




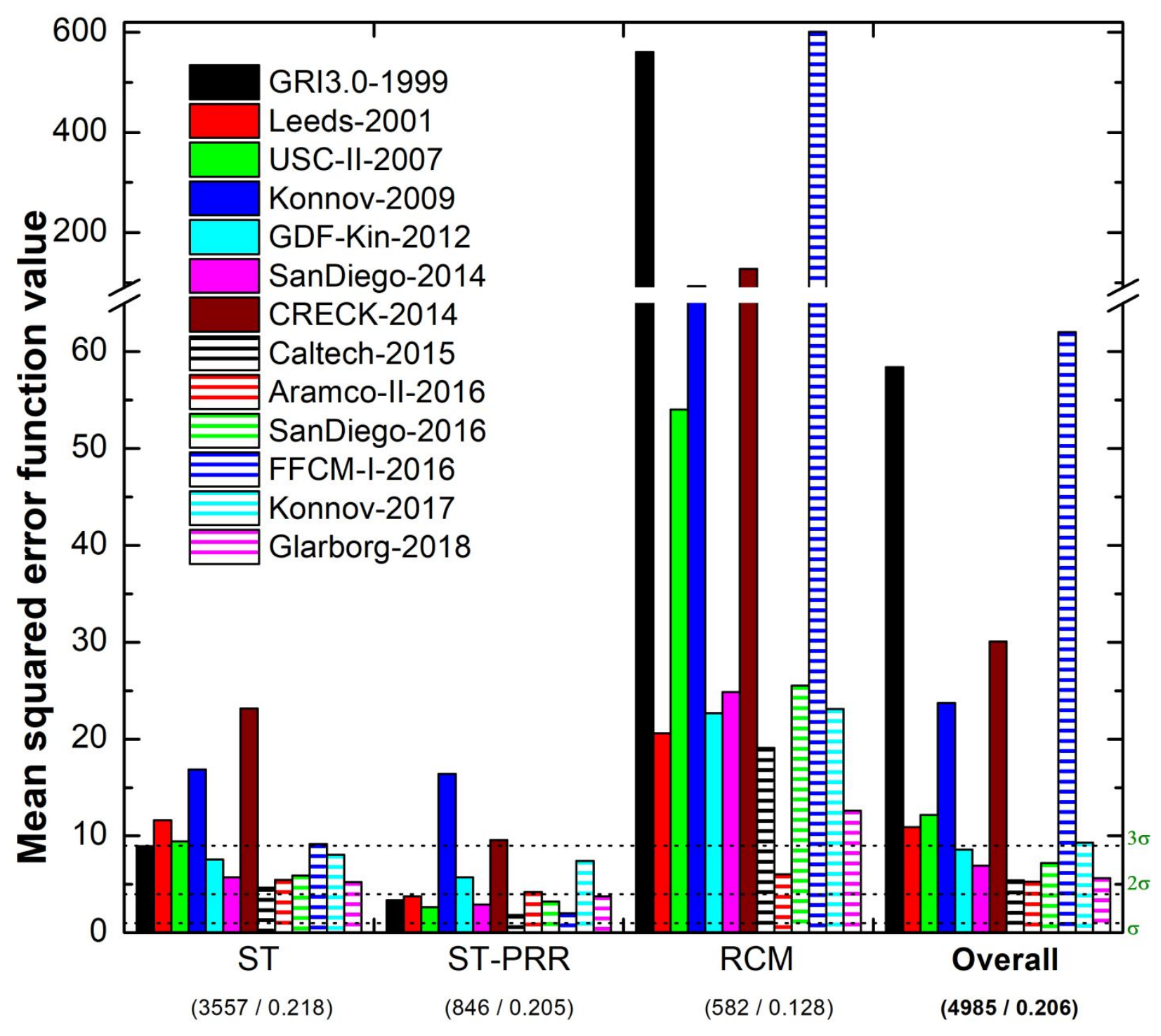

Ignition delay time: Influence of experimental method

Figure 2. Errors of the reproductions of IDTs according to the different types of experiments. The number given in the parentheses are the number of data points used and the average of the estimated $\sigma$ of the $\ln \tau$ values. 


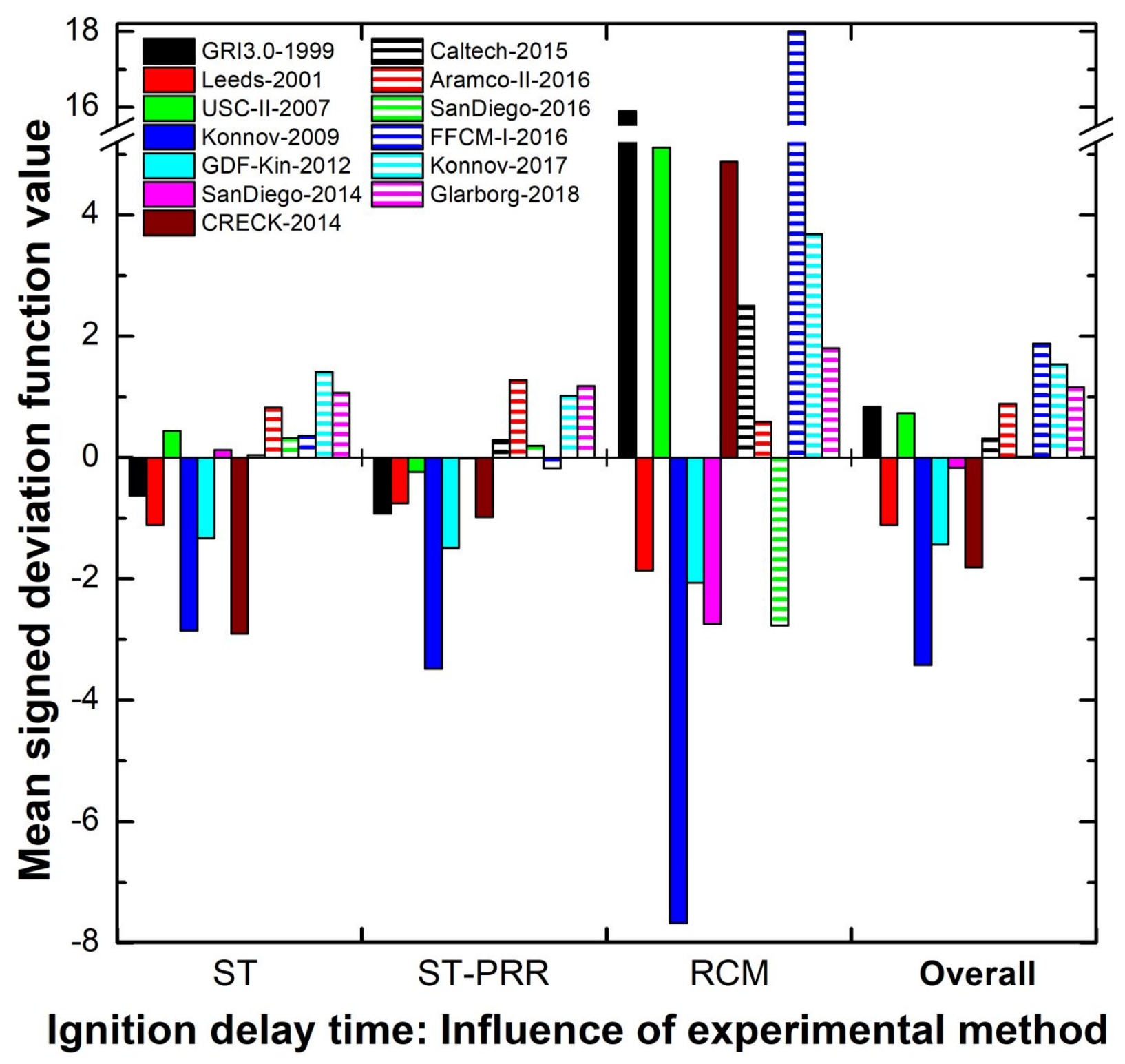

Figure. 3. Mean signed deviation values for all mechanisms according to the different types of experiments.

Fig. 3 displays the mean signed deviations for all mechanisms for the different types of experiments. Four mechanisms (Caltech-2015, Aramco-II-2016, Konnov-2017 and Glarborg2018) generally overpredict the IDTs, which means that the simulated IDTs are longer than the experimental ones. Three mechanisms (Leeds-2001, Konnov-2009, and GDF-Kin-2012) 
underpredict IDTs. The other mechanisms do not show an obvious trend in the signed deviation values.

\begin{tabular}{|c|c|c|c|c|c|c|c|c|c|c|c|c|c|}
\hline$\# 1$ & \#2 & \#3 & \#4 & \#5 & \#6 & $\# 7$ & \#8 & \#9 & $\# 10$ & $\# 11$ & \#12 & $\# 13$ & \\
\hline 1.00 & 0.83 & 0.96 & 0.87 & 0.85 & 0.84 & 0.57 & 0.96 & 0.84 & 0.83 & 0.94 & 0.92 & 0.91 & $\# 1$ \\
\hline & 1.00 & 0.76 & 0.77 & 0.74 & 0.84 & 0.68 & 0.82 & 0.82 & 0.83 & 0.83 & 0.89 & 0.89 & \#2 \\
\hline & & 1.00 & 0.88 & 0.85 & 0.82 & 0.47 & 0.93 & 0.79 & 0.82 & 0.93 & 0.89 & 0.86 & \#3 \\
\hline & & & 1.00 & 0.79 & 0.91 & 0.39 & 0.83 & 0.71 & 0.91 & 0.84 & 0.81 & 0.87 & \#4 \\
\hline & & & & 1.00 & 0.73 & 0.60 & 0.87 & 0.86 & 0.73 & 0.84 & 0.79 & 0.81 & $\# 5$ \\
\hline & & & & & 1.00 & 0.45 & 0.82 & 0.74 & 1.00 & 0.81 & 0.85 & 0.90 & \#6 \\
\hline & & & & & & 1.00 & 0.59 & 0.72 & 0.42 & 0.55 & 0.61 & 0.58 & \#7 \\
\hline & & & & & & & 1.00 & 0.88 & 0.80 & 0.95 & 0.93 & 0.91 & \#8 \\
\hline & & & & & & & & 1.00 & 0.72 & 0.83 & 0.88 & 0.87 & $\# 9$ \\
\hline & & & & & & & & & 1.00 & 0.80 & 0.83 & 0.89 & $\# 10$ \\
\hline i. Sho & ock Tuk & abe & & & & & & & & 1.00 & 0.93 & 0.89 & \#11 \\
\hline simul & lations & & & & & & & & & & 1.00 & 0.92 & $\# 12$ \\
\hline (3557 & data $\mathrm{p}$ & points) & & & & & & & & & & 1.00 & $\# 13$ \\
\hline$\# 1$ & \#2 & \#3 & \#4 & \#5 & \#6 & \#7 & \#8 & $\# 9$ & \#10 & \#11 & \#12 & $\# 13$ & \\
\hline 1.00 & 0.25 & 0.49 & 0.34 & 0.33 & 0.49 & 0.60 & 0.40 & 0.11 & 0.49 & 0.79 & 0.36 & 0.40 & $\# 1$ \\
\hline & 1.00 & 0.75 & 0.76 & 0.69 & 0.78 & 0.47 & 0.74 & 0.68 & 0.78 & 0.49 & 0.60 & 0.80 & \#2 \\
\hline & & 1.00 & 0.64 & 0.71 & 0.83 & 0.63 & 0.74 & 0.59 & 0.83 & 0.57 & 0.76 & 0.83 & $\# 3$ \\
\hline & & & 1.00 & 0.68 & 0.78 & 0.47 & 0.60 & 0.56 & 0.78 & 0.48 & 0.43 & 0.65 & \#4 \\
\hline & & & & 1.00 & 0.87 & 0.54 & 0.69 & 0.55 & 0.87 & 0.39 & 0.50 & 0.72 & $\# 5$ \\
\hline & & & & & 1.00 & 0.65 & 0.75 & 0.57 & 0.99 & 0.50 & 0.59 & 0.82 & \#6 \\
\hline & & & & & & 1.00 & 0.64 & 0.29 & 0.66 & 0.51 & 0.40 & 0.62 & \#7 \\
\hline & & & & & & & 1.00 & 0.69 & 0.75 & 0.50 & 0.63 & 0.91 & \#8 \\
\hline & & & & & & & & 1.00 & 0.56 & 0.38 & 0.64 & 0.73 & $\# 9$ \\
\hline & & & & & & & & & 1.00 & 0.50 & 0.60 & 0.81 & $\# 10$ \\
\hline \multirow{2}{*}{\multicolumn{3}{|c|}{$\begin{array}{l}\text { iii. RCM } \\
\text { simulations }\end{array}$}} & & & & & & & & 1.00 & 0.53 & 0.54 & $\# 11$ \\
\hline & & & & & & & & & & & 1.00 & 0.75 & $\# 12$ \\
\hline \multicolumn{3}{|c|}{ (582 data points) } & & & & & & & & & & 1.00 & \#13 \\
\hline
\end{tabular}

\begin{tabular}{|c|c|c|c|c|c|c|c|c|c|c|c|c|c|}
\hline \#1 & \#2 & \#3 & \#4 & \#5 & \#6 & \#7 & \#8 & \#9 & \#10 & \#11 & \#12 & \#13 & \\
\hline 1.00 & 0.88 & 0.91 & 0.81 & 0.82 & 0.79 & 0.49 & 0.90 & 0.89 & 0.77 & 0.93 & 0.84 & 0.90 & \#1 \\
\hline & 1.00 & 0.73 & 0.77 & 0.69 & 0.79 & 0.53 & 0.80 & 0.88 & 0.75 & 0.85 & 0.82 & 0.94 & \#2 \\
\hline & & 1.00 & 0.82 & 0.85 & 0.75 & 0.42 & 0.90 & 0.81 & 0.73 & 0.90 & 0.80 & 0.80 & \#3 \\
\hline & & & 1.00 & 0.70 & 0.87 & 0.17 & 0.74 & 0.67 & 0.87 & 0.75 & 0.72 & 0.79 & \#4 \\
\hline & & & & 1.00 & 0.52 & 0.61 & 0.91 & 0.84 & 0.50 & 0.88 & 0.91 & 0.73 & $\# 5$ \\
\hline & & & & & 1.00 & 0.14 & 0.66 & 0.63 & 1.00 & 0.71 & 0.59 & 0.83 & \#6 \\
\hline & & & & & & 1.00 & 0.65 & 0.71 & 0.10 & 0.61 & 0.63 & 0.51 & \#7 \\
\hline & & & & & & & 1.00 & 0.94 & 0.63 & 0.96 & 0.91 & 0.87 & \#8 \\
\hline & & & & & & & & 1.00 & 0.59 & 0.93 & 0.91 & 0.89 & $\# 9$ \\
\hline & & & & & & & & & 1.00 & 0.68 & 0.56 & 0.81 & $\# 10$ \\
\hline ii. Sh & ock Tu & abe & & & & & & & & 1.00 & 0.90 & 0.92 & $\# 11$ \\
\hline simul & ations & 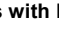 & PRR & & & & & & & & 1.00 & 0.83 & $\# 12$ \\
\hline (846 c & data $p c$ & oints) & & & & & & & & & & 1.00 & $\# 13$ \\
\hline \#1 & \#2 & \#3 & \#4 & \#5 & \#6 & \#7 & \#8 & \#9 & $\# 10$ & \#11 & \#12 & $\# 13$ & \\
\hline 1.00 & 0.79 & 0.90 & 0.81 & 0.79 & 0.80 & 0.56 & 0.89 & 0.78 & 0.79 & 0.92 & 0.85 & 0.86 & \#1 \\
\hline & 1.00 & 0.75 & 0.77 & 0.72 & 0.82 & 0.63 & 0.81 & 0.82 & 0.81 & 0.80 & 0.85 & 0.89 & \#2 \\
\hline & & 1.00 & 0.84 & 0.84 & 0.81 & 0.47 & 0.91 & 0.78 & 0.80 & 0.89 & 0.86 & 0.85 & \#3 \\
\hline & & & 1.00 & 0.77 & 0.89 & 0.35 & 0.79 & 0.69 & 0.89 & 0.79 & 0.76 & 0.83 & \#4 \\
\hline & & & & 1.00 & 0.70 & 0.60 & 0.86 & 0.83 & 0.69 & 0.81 & 0.78 & 0.79 & \#5 \\
\hline & & & & & 1.00 & 0.40 & 0.78 & 0.70 & 1.00 & 0.76 & 0.77 & 0.88 & \#6 \\
\hline & & & & & & 1.00 & 0.61 & 0.68 & 0.38 & 0.56 & 0.59 & 0.57 & \#7 \\
\hline & & & & & & & 1.00 & 0.88 & 0.76 & 0.91 & 0.90 & 0.90 & \#8 \\
\hline & & & & & & & & 1.00 & 0.68 & 0.81 & 0.86 & 0.86 & \#9 \\
\hline \multirow{4}{*}{\multicolumn{4}{|c|}{$\begin{array}{l}\text { iv. Overall } \\
\text { ignition delay times } \\
\text { simulations } \\
\text { ( } 4985 \text { data points) }\end{array}$}} & & & & & & 1.00 & 0.74 & 0.76 & 0.87 & $\# 10$ \\
\hline & & & & & & & & & & 1.00 & 0.89 & 0.86 & $\# 11$ \\
\hline & & & & & & & & & & & 1.00 & 0.88 & $\# 12$ \\
\hline & & & & & & & & & & & & 1.00 & $\# 13$ \\
\hline
\end{tabular}

Figure. 4. Matrix of Pearson correlation coefficients for all types of simulations. The \#n numbers refer to the mechanism indices shown in Table 1.

In Fig. 4, the average Pearson correlation coefficients between the IDTs calculated by each two mechanisms are displayed. Among the weak correlations, CRECK-2014 (\#7) has small correlation coefficients with all other 12 mechanisms in all the four groups, and GRI3.0-1999 (\#1) has this feature only for the RCM measurements. In Fig. 4 panel iii (RCM experiments), FFCM-I-2016 (\#11) and Konnov-2017 (\#12) have weak correlations with the other mechanisms overall. SanDiego-2014 (\#6) and SanDiego-2016 (\#10) have the highest correlation at all types of measurements, since the latter was developed from the former one, and their simulated values for most of the data points are very close. Except for the two San Diego mechanisms, the highest 
correlations exist for mechanism pairs GRI3.0-1999 (\#1) / USC-II-2007 (\#3) and GRI3.0-1999 (\#1) / Caltech-2015 (\#8) in the ST subset, Caltech-2015 (\#8) / FFCM-I-2016 (\#11) in the ST-PRR subset, Caltech-2015 (\#8) / Glarborg-2018 (\#13) in the RCM subset, and GRI3.0-1999 (\#1) / FFCM-I-2016 (\#11) for all IDTs. In ST and ST-PRR parts, any of the pairs between GRI3.0-1999 (\#1), USC-II-2007 (\#3), Caltech-2015 (\#8), FFCM-I-2016 (\#11) has a correlation coefficient higher than or equal to 0.9. In addition, simulation results of Caltech-2015 (\#8) and Glarborg-2018 (\#13) have correlation higher than average with several mechanisms in the four panels. The correlation coefficients of each two mechanisms are larger for ST experiments than for the STPRR and RCM ones. The correlation coefficients indicate that most mechanisms were calibrated considering the ST without PRR datasets, while the generally more recent ST-PRR and RCM datasets were less used. High correlation coefficients are usually in good accordance with the known development history of the mechanisms. Olm et al. had a similar observation for the hydrogen ${ }^{1}$ and syngas ${ }^{2}$ mechanisms. 


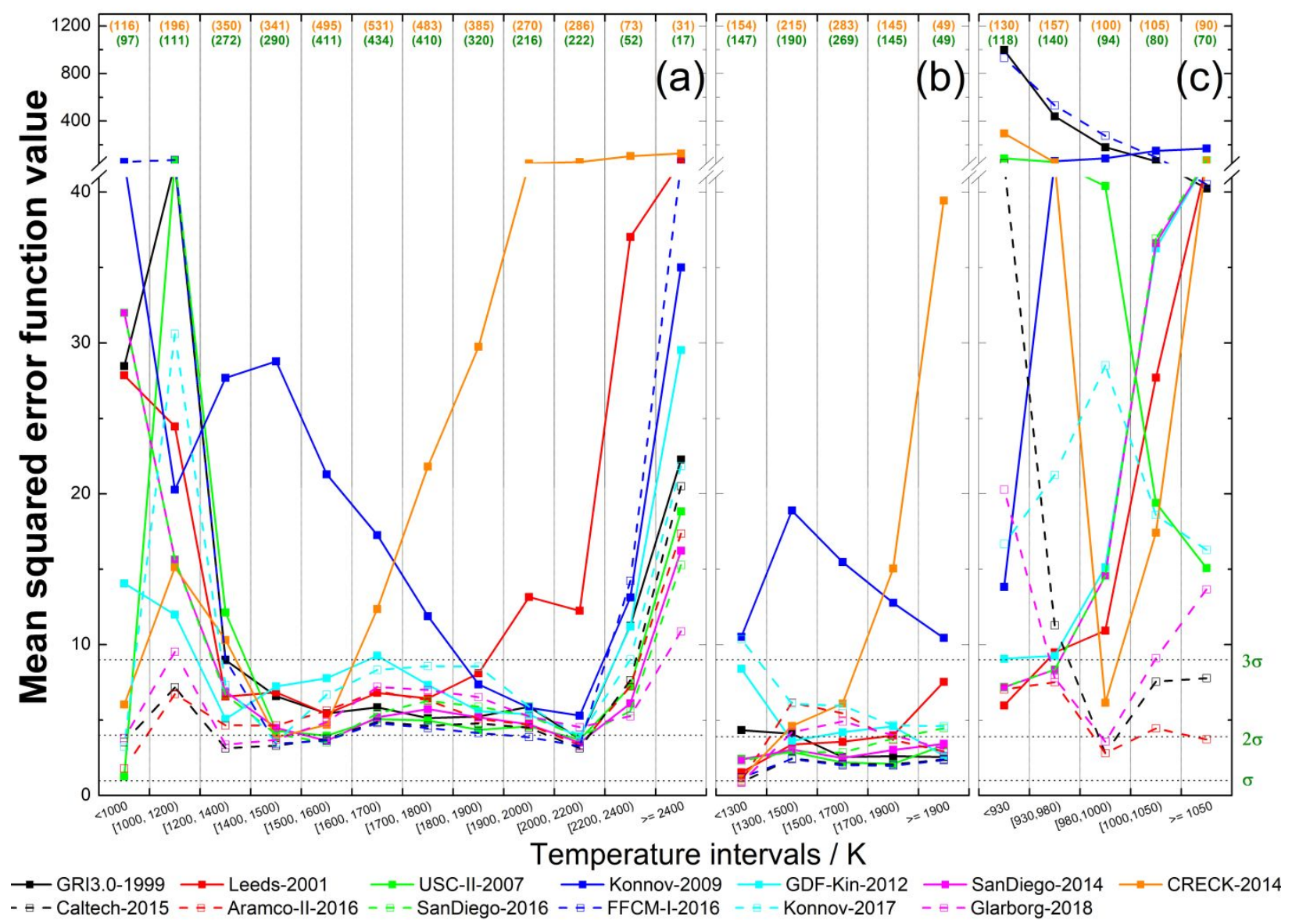

Figure. 5. Performance of the mechanisms in the various intervals of temperature with respect to IDT. The panels show the results for STs without PRR (a), STs with PRR (b) and RCM (c). The orange and green numbers at the top of the figure give the number of data points in each interval before and after excluding data points. Data points that could not be reproduced within $3 \sigma$ error by any of the mechanisms were not used.

In Figs. 5 to 10, the performance of the mechanisms in reproducing IDTs is shown in the various intervals of experimental conditions, like temperature, pressure, equivalence ratio, and diluent ratio. In these figures, the intervals were selected by ensuring statistically enough data points within each interval. The number of data points used in each range is shown at the top of the corresponding intervals. 
Fig. 5 shows the dependence of $E$ values of the mechanisms on the initial temperature. In Fig. 5(a) for ST measurements without PRR, the overall trend is that most mechanisms can reproduce the experiments with better accuracy in the middle temperature range, $(1200 \mathrm{~K}-2200 \mathrm{~K})$ except for mechanisms Leeds-2001, Konnov-2009, and CRECK-2014. The $E$ values of these three mechanisms follow a similar trend, but with higher values. In this middle temperature range, Caltech-2015 and FFCM-I-2017 have the lowest error values. However, the $E$ values of FFCM-I2017 increase dramatically towards lower and higher temperatures, while Caltech-2015 has stable performance in the whole temperature range. Similarly, Aramco-II-2016 and Glarborg-2018 are accurate at all initial temperatures.

As Fig. 5(b) shows, for the reproduction of the ST with PRR experimental data, five mechanisms (Leeds-2001, Konnov-2009, GDF-Kin-2012, CRECK-2014, and Konnov-2017) have large errors in all or in some temperature ranges. Surprisingly, Aramco-II-2016 has a somewhat larger error in the temperature range of $1300 \mathrm{~K}$ to $1700 \mathrm{~K}$, where most other mechanisms have very low error.

According to Fig. 5(c), the majority of mechanisms reproduce the RCM experimental data poorly, while Aramco-II-2016 is the only one which has $E$ values lower than 9 (i.e. below on average $3 \sigma$ deviation) at all initial temperatures. Konnov-2017 and Glarborg-2018 have error values larger than those of Aramco-II-2016, but these are better than the other mechanisms. The error value $E$ of Caltech-2015 is less than 9 above $980 \mathrm{~K}$, while below this temperature $E$ is increasing significantly with decreasing temperature.

Fig. S5 (panels (a) and (b) for initial temperature and pressure, respectively) in the Supplementary Material shows that there is no trend for under- or overprediction of the ST experimental data (with or without PRR) for most of the mechanisms. At high temperature, CRECK-2014 and Leeds-2001 strongly underpredicts the ignition delay times. At low temperature, 
Konnov-2009 underpredicts the IDTs. Konnov-2017 overpredicts IDTs in the whole pressure range, while CRECK-2014 and Konnov-2009 underpredicts the ignition delay times at low and high pressures, respectively. For the RCM experimental data (see Fig. S5 (c)) all mechanisms, except for Konnov-2009, trend to predict relatively longer IDTs at lower initial temperatures, while simulate relatively shorter IDTs at higher temperatures.

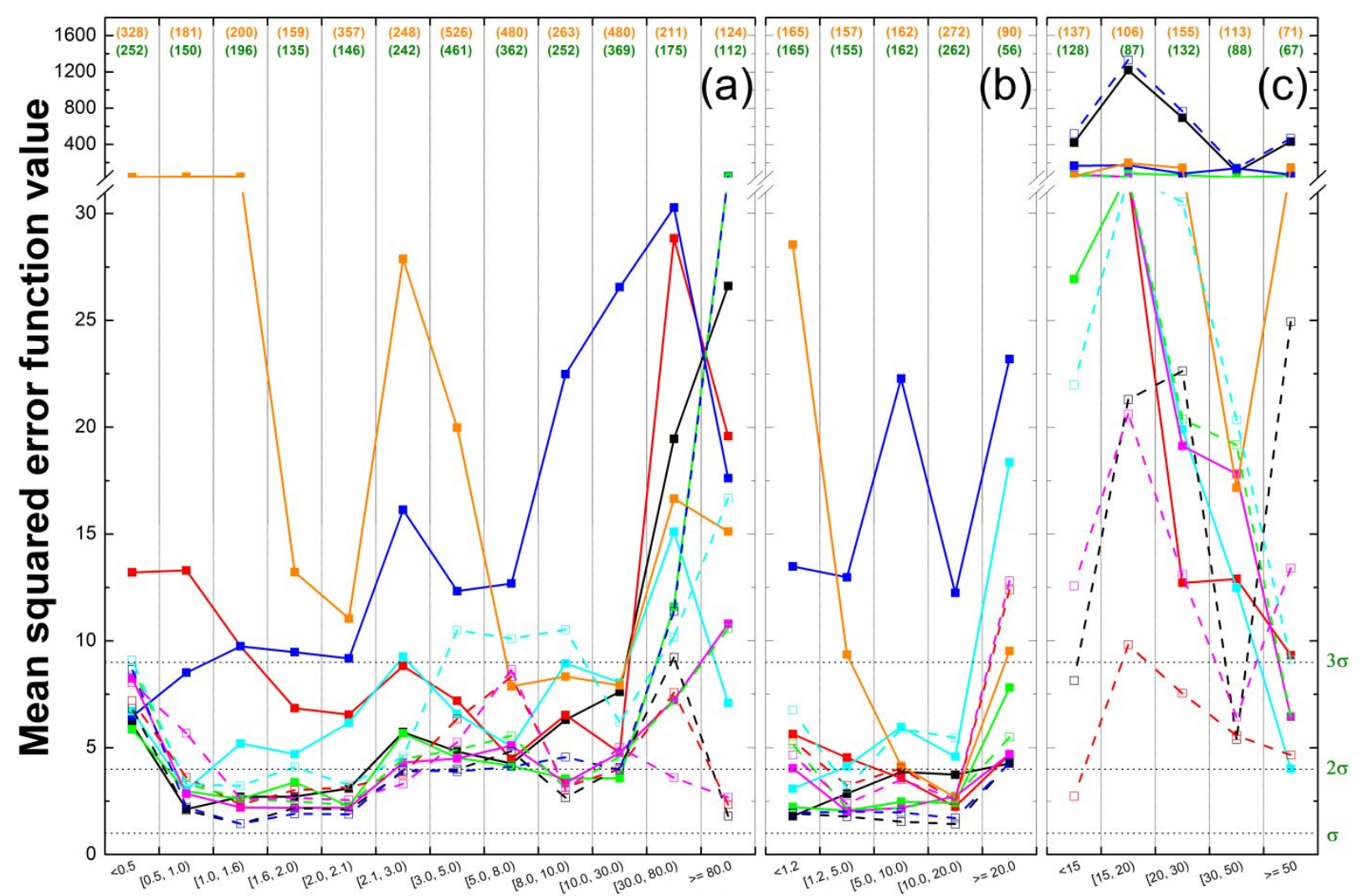

Pressure intervals / atm

$\rightarrow$ GRI3.0-1999 - Leeds-2001 -USC-II-2007 $\rightarrow$ Konnov-2009 -GDF-Kin-2012 —-SanDiego-2014 - - CRECK-2014 - $\Xi$ - Caltech-2015 - - - Aramco-II-2016 - - -SanDiego-2016 - - - FFCM-I-2016 - - - Konnov-2017 - - - Glarborg-2018

Figure. 6. Performance of the mechanisms for various intervals of pressure with respect to IDT. Each plot shows the results for STs without PRR (a), STs with PRR (b) and RCM (c).

Although Table 1 and Fig. 1 show that the mechanisms have not been validated considering the low pressure $(<1 \mathrm{~atm})$ experiments, Fig. 6(a) shows that all mechanisms can reproduce the ST experiments without PRR data well in the low and middle pressure range, but their performance 
is not as good at pressures higher than 30 atm, except for Glarborg-2018, Aramco-II-2016 and Clatech-2015. As shown in Fig. 6(b) for the ST-PRR data, Konnov-2009, GDF-Kin-2012, and CRECK-2014 have significant change of $E$ values for all ranges of pressure, while the other mechanisms are satisfactory for reproducing all datasets. In Fig. 6(c), Aramco-II-2016 is the most accurate mechanism for the reproduction of the RCM data in all pressure ranges and the deviations of Caltech-2015 and Glarborg-2018 are also within the reasonable range. However, the predicting capability of all other mechanisms are much poorer.

Figure 7 shows the $\log \tau-1000 / T$ plots and indicates the deviations of the various simulation results compared to the experimental IDT uncertainty. Note that neither the experimental data nor the simulation results fit to a straight line, because pressure was not identical in these experiments.

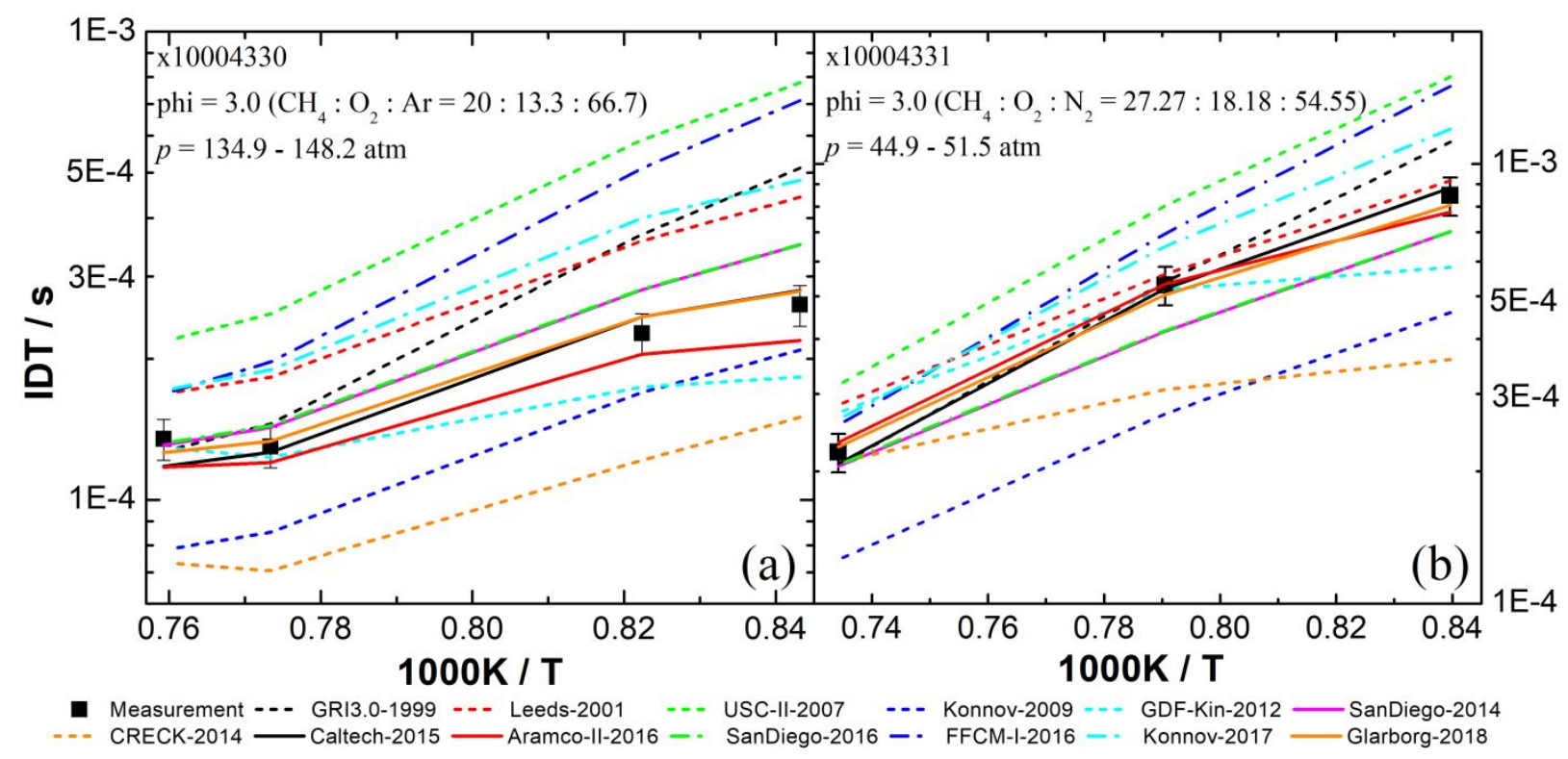

Figure. 7. Measured and simulated ignition delay times of methane mixtures at high pressures. The detailed information on experimental data x10004330 and x10004331 ${ }^{71}$ is shown in Table A in the Supplementary Material. 


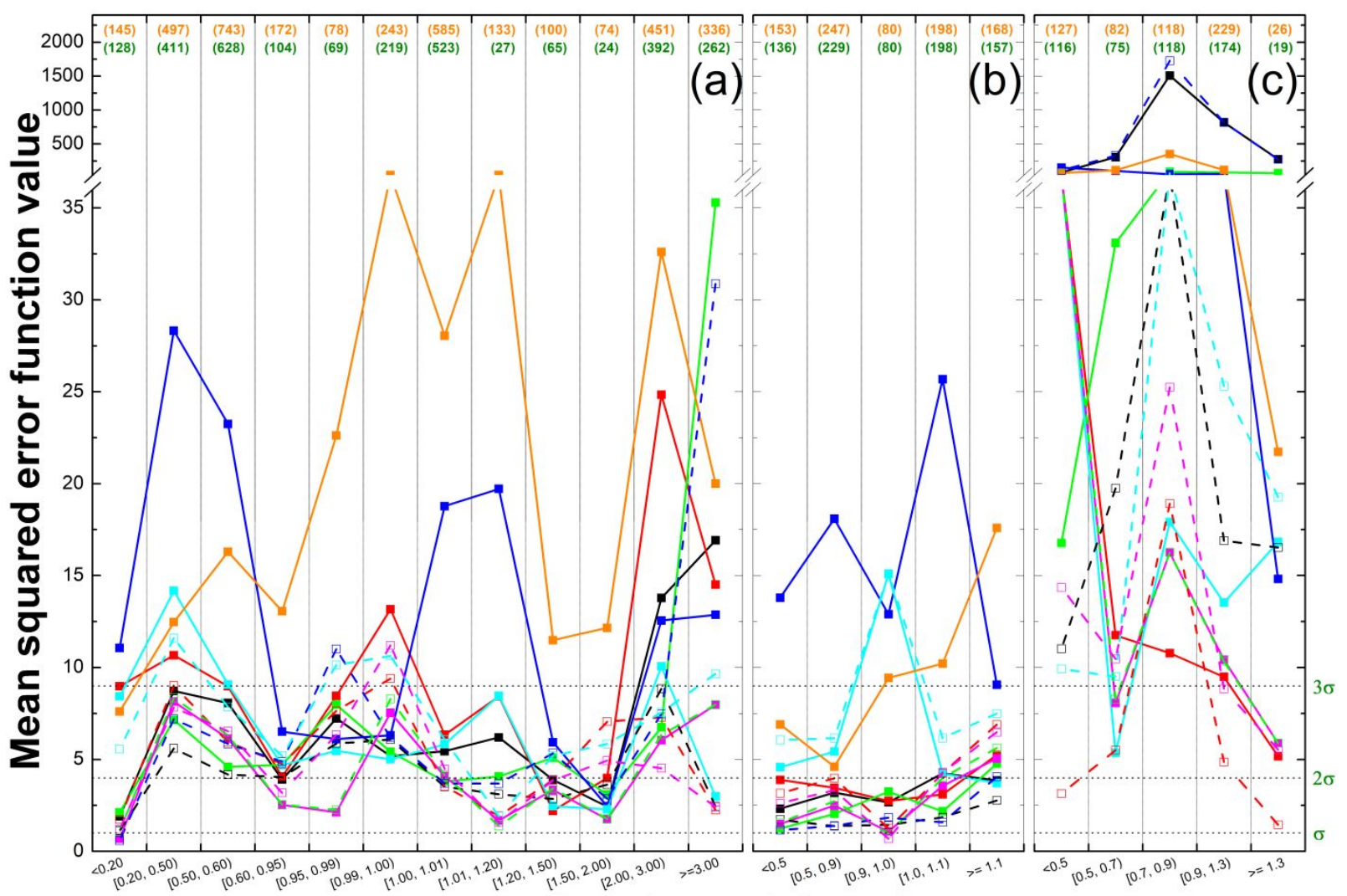

Equivalence ratio intervals

$\rightarrow$ GRI3.0-1999 $\rightarrow$ Leeds-2001 $\rightarrow$ USC-II-2007 $\rightarrow$ Konnov-2009 "-GDF-Kin-2012 $\rightarrow$ SanDiego-2014 $\rightarrow$ CRECK-2014

Figure. 8. Performance of the mechanisms for various intervals of equivalence ratio with respect

to IDT. Each plot shows the results for STs without PRR (a), STs with PRR (b) and RCM (c).

Fig. 8(a) shows that at the reproduction of ST data without PRR there is no clear trend for changing the error function values with equivalence ratios. However, in the low equivalence ratio range SanDiego-2014, SanDiego-2016, and Caltech-2015 have the lowest error. Table 1 and Fig. 1 indicate that all mechanisms but FFCM-I-2016 were validated only at equivalence ratios larger than 0.1. In Fig. 8(a) it is shown that all mechanisms can predict the experiments within $2 \sigma$ at low equivalence ratio $\varphi<0.2$, except for Leeds-2001, GDF-Kin-2012, CRECK-2014 and the two Konnov mechanisms. For the reproduction of ST data with PRR (Fig. 8(b)), Caltech-2015 and FFCM-I-2016 are the most accurate mechanisms, and Glarborg-2018 has low error (less than $1 \sigma$ ) 
at stoichiometric equivalence ratio. For reproducing the RCM data (Fig. 8(c)), most mechanisms are less accurate under slightly lean $(0.7<\varphi<0.9)$ conditions compared to both the lean and rich mixtures. Aramco-II-2016 has the same trend, but its error is the lowest at most equivalence intervals.

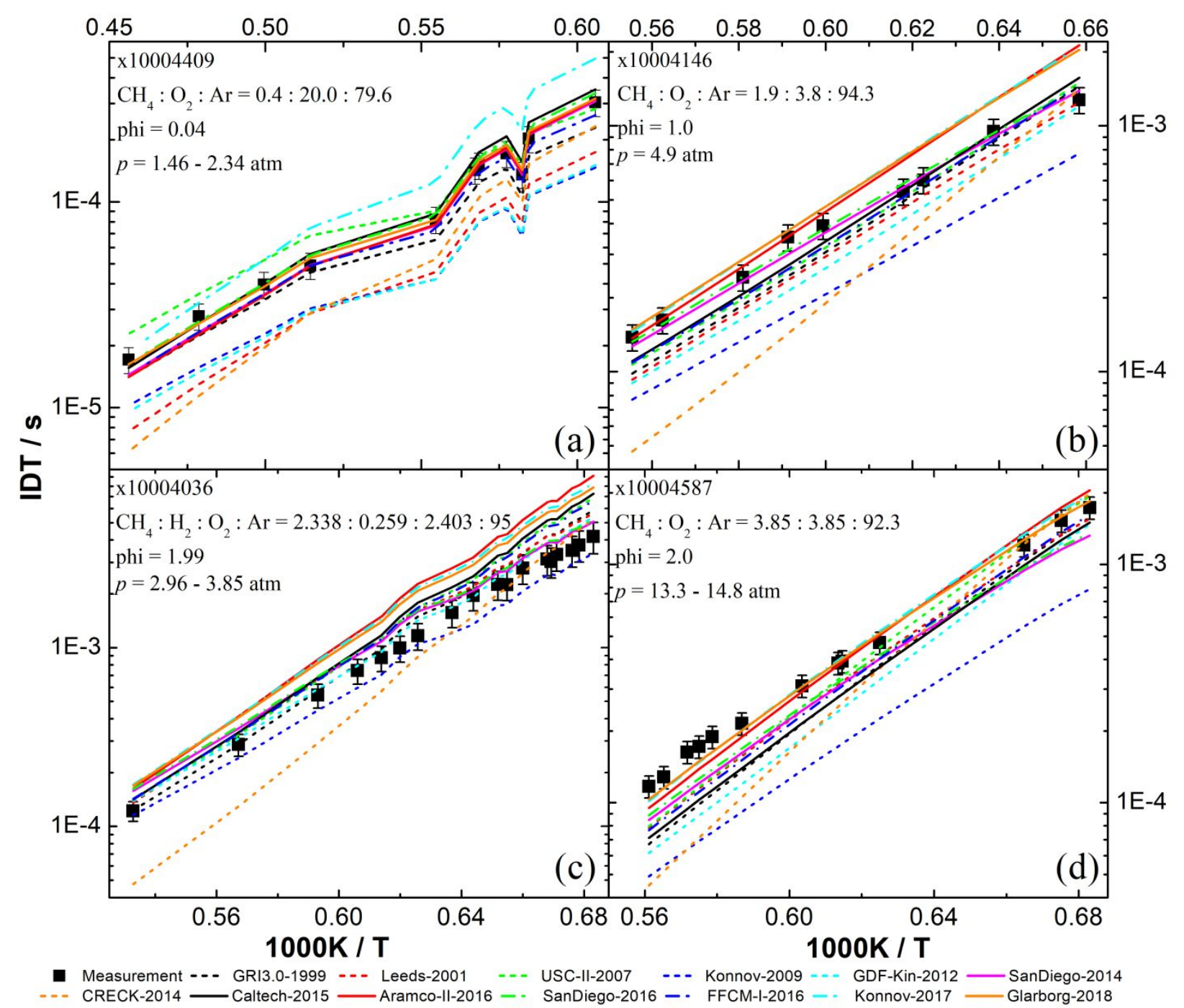

Figure. 9. Measured and simulated ignition delay times of the methane mixtures with various equivalence ratios. The detailed information of the experimental data $\left(\mathrm{x} 10004036^{91}, \mathrm{x} 10004146^{52}\right.$, $\mathrm{x} 10004409^{81}, \mathrm{x} 10004587^{100}$ ) is shown on the Table A in the Supplementary Material. 
Figure 9(a) provides a related comparison of the experimental data and the simulation results on a $\log \tau-1000 \mathrm{~K} / T$ plot. Near the stoichiometric equivalence ratio, the errors of most mechanisms are low, except for CRECK-2014 and Konnov-2009, as seen in Fig 9(b). In the range of moderately rich equivalence ratio $(1.2<\varphi<2.0)$, the GDF-Kin-2012 mechanism has relatively lower error compared to other mechanisms, as shown in Fig 9(c). For mixtures even richer in fuel $(2.0 \leq \varphi)$, Glarborg-2018 could reproduce the experimental data the best, as shown in Fig 9(d).

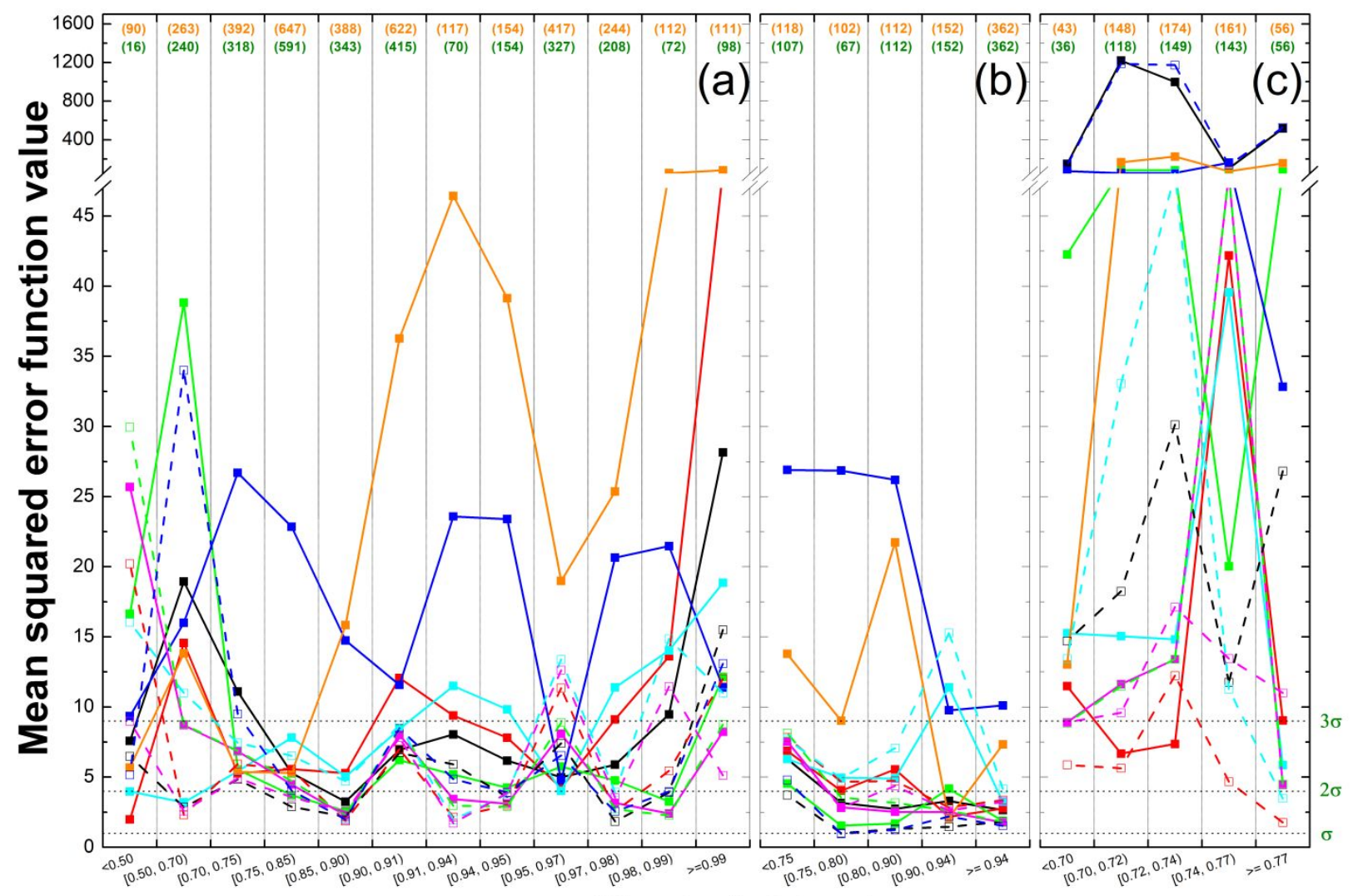

Diluent ratio intervals

$\rightarrow$ GRI3.0-1999 $\rightarrow$ Leeds-2001 - USC-II-2007 $\rightarrow$ Konnov-2009 - - GDF-Kin-2012 - - SanDiego-2014 - CRECK-2014 $-\nexists-$ Caltech-2015 - - - Aramco-II-2016 - - -SanDiego-2016 - - - FFCM-I-2016 - - Konnov-2017 - - - Glarborg-2018

Figure. 10. Performance of the mechanisms for various intervals of diluent ratio with respect to IDT. Each plot shows the results for STs without PRR (a), STs with PRR (b) and RCM (c). 
The lowest diluent ratio used for the original validation of mechanisms is $33.3 \%$ (see Table 1), which means that the performance of these mechanisms below diluent ratio $33.3 \%$ was not investigated. In the present study, however, even combustion of undiluted mixtures was also considered (diluent ratio 0, oxy-fuel combustion). Figure 10 shows the performance of the mechanisms for various intervals of diluent ratio. For the ST data without PRR (Fig. 10(a)), Glarborg-2018 and Caltech-2015 are advantageous in predicting experiments in the full condition range. Caltech-2015 and FFCM-I-2016 are the most accurate mechanisms for reproducing the ST experimental data with PRR, as shown in Fig. 10(b). Fig. 10, panels (a), (b), and (c) show that Leeds-2001, Caltech-2015 and Aramco-II-2016 are the best performing mechanisms, respectively, under low diluent ratio conditions.

For the prediction of RCM data (Fig. 10(c)), Aramco-II-2016 is the best mechanism again, although its error is slightly higher in the diluent ratio range $72 \%$ to $74 \%$. As shown in Fig. S6 (f) of the Supplementary Material, Aramco-II-2016 overpredicts the IDTs measured with RCM in most ranges of diluent ratio. 


\subsection{Sensitivity analysis results}

Sensitivity analysis was carried out using the four mechanisms with the best predicting ability (SanDiego-2014, Clatech-2015, Aramco-II-2016 and Glarborg-2018) under each of the conditions of the collected IDT measurements. The local sensitivity coefficients were calculated in such a way that Arrhenius parameters $A$ of the reactions were increased by $5 \%$ and the ignition delay times were recalculated. Sensitivity coefficients $\mathrm{d} \tau / \mathrm{d} A_{\mathrm{j}}$ were calculated by finite differences and then converted to normalized sensitivities $\mathrm{d} \ln \tau / \mathrm{d} \ln A_{\mathrm{j}}=\left(A_{\mathrm{j}} / \tau\right) \mathrm{d} \tau / \mathrm{d} A_{\mathrm{j}}$. The normalized sensitivity coefficients were scaled to values between -1 and +1 by dividing them by the largest absolute sensitivity coefficients. The most sensitive reactions were identified based on the order of the average of the absolute values of the scaled sensitivity coefficient obtained in the investigated intervals. Furthermore, range $[-1,+1]$ was divided to ten equidistant intervals, and the relative frequency of the reactions in each interval was counted. This analysis was carried out for each experimental type (ST, ST with PRR, RCM).

In Table 5, for the selected four mechanisms the fifteen most sensitive reactions and their mean absolute scaled sensitivity coefficients $\overline{S_{a b s}}$ are shown. The order of the sensitivity is meaningful within one mechanism, and the values belonging to different mechanisms cannot be compared. 
Table 5. The top 15 most sensitive reactions for the selected four mechanisms based on the average absolute values $\overline{a_{a b s}}($ scale: 0 - 1$)$

\begin{tabular}{|c|c|c|c|c|c|c|c|c|}
\hline \multicolumn{9}{|c|}{ Subset 1: Shock tube ignition delay times with constant pressure } \\
\hline Rank & SanDiego-2014 & $\overline{S_{a b s}}$ & Caltech-2015 & $\overline{S_{a b s}}$ & Aramco-II-2016 & $\overline{S_{a b s}}$ & Glarborg-2018 & $\overline{S_{a b s}}$ \\
\hline 1 & $\mathrm{H}+\mathrm{O}_{2}=\mathrm{O}+\mathrm{OH}$ & 0.738 & $\mathrm{H}+\mathrm{O}_{2}=\mathrm{O}+\mathrm{OH}$ & 0.678 & $\mathrm{H}+\mathrm{O}_{2}=\mathrm{O}+\mathrm{OH}$ & 0.836 & $\mathrm{H}+\mathrm{O}_{2}=\mathrm{O}+\mathrm{OH}$ & 0.855 \\
\hline 2 & $\mathrm{CH}_{3}+\mathrm{O}_{2}=\mathrm{CH}_{2} \mathrm{O}+\mathrm{OH}$ & 0.650 & $\mathrm{CH}_{3}+\mathrm{O}_{2}=\mathrm{CH}_{2} \mathrm{O}+\mathrm{OH}$ & 0.362 & $\mathrm{CH}_{3}+\mathrm{O}_{2}=\mathrm{CH}_{2} \mathrm{O}+\mathrm{OH}$ & 0.506 & $\mathrm{CH}_{3}+\mathrm{O}_{2}=\mathrm{CH}_{2} \mathrm{O}+\mathrm{OH}$ & 0.413 \\
\hline 3 & $\mathrm{CH}_{3}+\mathrm{O}_{2}=\mathrm{CH}_{3} \mathrm{O}+\mathrm{O}$ & 0.467 & $\mathrm{CH}_{4}+\mathrm{H}=\mathrm{CH}_{3}+\mathrm{H}_{2}$ & 0.356 & $\mathrm{CH}_{4}+\mathrm{H}=\mathrm{CH}_{3}+\mathrm{H}_{2}$ & 0.441 & $\mathrm{CH}_{4}+\mathrm{H}=\mathrm{CH}_{3}+\mathrm{H}_{2}$ & 0.410 \\
\hline 4 & $\mathrm{CH}_{4}+\mathrm{H}=\mathrm{CH}_{3}+\mathrm{H}_{2}$ & 0.412 & $\mathrm{CH}_{3}+\mathrm{CH}_{3}=\mathrm{C}_{2} \mathrm{H}_{5}+\mathrm{H}$ & 0.279 & $\mathrm{CH}_{3}+\mathrm{HO}_{2}=\mathrm{CH}_{3} \mathrm{O}+\mathrm{OH}$ & 0.344 & $\mathrm{CH}_{3}+\mathrm{HO}_{2}=\mathrm{CH}_{3} \mathrm{O}+\mathrm{OH}$ & 0.389 \\
\hline 5 & $\mathrm{CH}_{3}+\mathrm{H}+\mathrm{M}=\mathrm{CH}_{4}+\mathrm{M}^{\mathrm{LP}}$ & 0.361 & $\mathrm{CH}_{3}+\mathrm{HO}_{2}=\mathrm{CH}_{3} \mathrm{O}+\mathrm{OH}$ & 0.253 & $\mathrm{CH}_{3}+\mathrm{O}_{2}=\mathrm{CH}_{3} \mathrm{O}+\mathrm{O}$ & 0.299 & $\mathrm{CH}_{3}+\mathrm{CH}_{3}=\mathrm{C}_{2} \mathrm{H}_{5}+\mathrm{H}$ & 0.282 \\
\hline 6 & $\mathrm{CH}_{3}+\mathrm{CH}_{3}=\mathrm{C}_{2} \mathrm{H}_{5}+\mathrm{H}$ & 0.213 & $\mathrm{CH}_{3}+\mathrm{O}_{2}=\mathrm{CH}_{3} \mathrm{O}+\mathrm{O}$ & 0.205 & $\mathrm{CH}_{3}+\mathrm{CH}_{3}+\mathrm{M}=\mathrm{C}_{2} \mathrm{H}_{6}+\mathrm{M}$ & 0.254 & $\mathrm{CH}_{3}+\mathrm{O}_{2}=\mathrm{CH}_{3} \mathrm{O}+\mathrm{O}$ & 0.279 \\
\hline 7 & $\mathrm{CH}_{3}+\mathrm{CH}_{3}+\mathrm{M}=\mathrm{C}_{2} \mathrm{H}_{6}+\mathrm{M}$ & 0.193 & $\mathrm{C}_{2} \mathrm{H}_{6}+\mathrm{M}=\mathrm{CH}_{3}+\mathrm{CH}_{3}+\mathrm{M}$ & 0.203 & $\mathrm{CH}_{3}+\mathrm{H}+\mathrm{M}=\mathrm{CH}_{4}+\mathrm{M}^{\mathrm{LP}}$ & 0.226 & $\mathrm{CH}_{4}+\mathrm{O}_{2}=\mathrm{CH}_{3}+\mathrm{HO}_{2}$ & 0.192 \\
\hline 8 & $\mathrm{CH}_{4}+\mathrm{OH}=\mathrm{CH}_{3}+\mathrm{H}_{2} \mathrm{O}$ & 0.173 & $\mathrm{CH}_{3}+\mathrm{H}+\mathrm{M}=\mathrm{CH}_{4}+\mathrm{M}^{\mathrm{LP}}$ & 0.163 & $\mathrm{CH}_{4}+\mathrm{OH}=\mathrm{CH}_{3}+\mathrm{H}_{2} \mathrm{O}$ & 0.179 & $\mathrm{CH}_{3}+\mathrm{CH}_{3}+\mathrm{M}=\mathrm{C}_{2} \mathrm{H}_{6}+\mathrm{M}$ & 0.184 \\
\hline 9 & $\mathrm{CH}_{2} \mathrm{O}+\mathrm{O}_{2}=\mathrm{HCO}+\mathrm{HO}_{2}$ & 0.152 & $\mathrm{CH}_{3}+\mathrm{HO}_{2}=\mathrm{CH}_{4}+\mathrm{O}_{2}$ & 0.151 & $\mathrm{CH}_{2} \mathrm{O}+\mathrm{O}_{2}=\mathrm{HCO}+\mathrm{HO}_{2}$ & 0.178 & $\mathrm{CH}_{3}+\mathrm{H}+\mathrm{M}=\mathrm{CH}_{4}+\mathrm{M}^{\mathrm{LP}}$ & 0.182 \\
\hline 10 & $\mathrm{CH}_{3}+\mathrm{CH}_{3}+\mathrm{M}=\mathrm{C}_{2} \mathrm{H}_{6}+\mathrm{M}^{\mathbf{L P}}$ & 0.127 & $\mathrm{CH}_{3}+\mathrm{H}_{2} \mathrm{O}_{2}=\mathrm{CH}_{4}+\mathrm{HO}_{2}$ & 0.124 & $\mathrm{CH}_{4}+\mathrm{HO}_{2}=\mathrm{CH}_{3}+\mathrm{H}_{2} \mathrm{O}_{2}$ & 0.171 & $\mathrm{CH}_{3}+\mathrm{CH}_{3}+\mathrm{M}=\mathrm{C}_{2} \mathrm{H}_{6}+\mathrm{M}^{\mathbf{L P}}$ & 0.129 \\
\hline 11 & $\mathrm{CH}_{2} \mathrm{O}+\mathrm{OH}=\mathrm{HCO}+\mathrm{H}_{2} \mathrm{O}$ & 0.111 & $\mathrm{CH}_{2} \mathrm{O}+\mathrm{O} 2=\mathrm{HCO}+\mathrm{HO}_{2}$ & 0.114 & $\mathrm{CH}_{3}+\mathrm{HO}_{2}=\mathrm{CH}_{4}+\mathrm{O}_{2}$ & 0.161 & $\mathrm{HCO}+\mathrm{O}_{2}=\mathrm{CO}+\mathrm{HO}_{2}$ & 0.120 \\
\hline 12 & $\mathrm{CH}_{3}+\mathrm{HO}_{2}=\mathrm{CH}_{3} \mathrm{O}+\mathrm{OH}$ & 0.111 & $\mathrm{C}_{2} \mathrm{H}_{6}+\mathrm{M}=\mathrm{CH}_{3}+\mathrm{CH}_{3}+\mathrm{M}^{\mathrm{LP}}$ & 0.105 & $\mathrm{HCO}+\mathrm{M}=\mathrm{H}+\mathrm{CO}+\mathrm{M}$ & 0.107 & $\mathrm{CH}_{4}+\mathrm{OH}=\mathrm{CH}_{3}+\mathrm{H}_{2} \mathrm{O}$ & 0.116 \\
\hline 13 & $\mathrm{CH}_{3}+\mathrm{O}=\mathrm{CH}_{2} \mathrm{O}+\mathrm{H}$ & 0.105 & $\mathrm{CH}_{4}+\mathrm{OH}=\mathrm{CH}_{3}+\mathrm{H}_{2} \mathrm{O}$ & 0.101 & $\mathrm{CH}_{3}+\mathrm{O}=\mathrm{CH}_{2} \mathrm{O}+\mathrm{H}$ & 0.093 & $\mathrm{HCO}+\mathrm{M}=\mathrm{H}+\mathrm{CO}+\mathrm{M}^{\mathrm{LP}}$ & 0.102 \\
\hline 14 & $\mathrm{HCO}+\mathrm{M}=\mathrm{CO}+\mathrm{H}+\mathrm{M}$ & 0.092 & $\mathrm{HCO}+\mathrm{M}=\mathrm{CO}+\mathrm{H}+\mathrm{M}$ & 0.098 & $\mathrm{HCO}+\mathrm{O}_{2}=\mathrm{CO}+\mathrm{HO}_{2}$ & 0.092 & $\mathrm{CH}_{4}+\mathrm{HO}_{2}=\mathrm{CH}_{3}+\mathrm{H}_{2} \mathrm{O}_{2}$ & 0.101 \\
\hline 15 & $\mathrm{CH}_{2} \mathrm{O}+\mathrm{HO}_{2}=\mathrm{HCO}+\mathrm{H}_{2} \mathrm{O}_{2}$ & 0.089 & $\mathrm{HCO}+\mathrm{O}_{2}=\mathrm{CO}+\mathrm{HO}_{2}$ & 0.083 & $\mathrm{CH}_{4}+\mathrm{O}=\mathrm{CH}_{3}+\mathrm{OH}$ & 0.085 & $\mathrm{CH}_{3}+\mathrm{O}=\mathrm{CH}_{2} \mathrm{O}+\mathrm{H}$ & 0.095 \\
\hline \multicolumn{9}{|c|}{ Subset 2: Shock tube ignition delay times with pressure rise rate } \\
\hline Rank & SanDiego-2014 & $\overline{S_{a b s}}$ & Caltech-2015 & $\overline{S_{a b s}}$ & Aramco-II-2016 & $\overline{S_{a b s}}$ & Glarborg-2018 & $\overline{S_{a b s}}$ \\
\hline 1 & $\mathrm{H}+\mathrm{O}_{2}=\mathrm{O}+\mathrm{OH}$ & 0.858 & $\mathrm{H}+\mathrm{O}_{2}=\mathrm{O}+\mathrm{OH}$ & 0.964 & $\mathrm{H}+\mathrm{O}_{2}=\mathrm{O}+\mathrm{OH}$ & 0.963 & $\mathrm{H}+\mathrm{O}_{2}=\mathrm{O}+\mathrm{OH}$ & 0.903 \\
\hline 2 & $\mathrm{CH}_{3}+\mathrm{O}_{2}=\mathrm{CH}_{2} \mathrm{O}+\mathrm{OH}$ & 0.652 & $\mathrm{CH}_{3}+\mathrm{O}_{2}=\mathrm{CH}_{2} \mathrm{O}+\mathrm{OH}$ & 0.438 & $\mathrm{CH}_{3}+\mathrm{O}_{2}=\mathrm{CH}_{2} \mathrm{O}+\mathrm{OH}$ & 0.509 & $\mathrm{CH}_{3}+\mathrm{O}_{2}=\mathrm{CH}_{2} \mathrm{O}+\mathrm{OH}$ & 0.394 \\
\hline 3 & $\mathrm{CH}_{3}+\mathrm{O}_{2}=\mathrm{CH}_{3} \mathrm{O}+\mathrm{O}$ & 0.416 & $\mathrm{CH}_{4}+\mathrm{H}=\mathrm{CH}_{3}+\mathrm{H}_{2}$ & 0.413 & $\mathrm{CH}_{4}+\mathrm{H}=\mathrm{CH}_{3}+\mathrm{H}_{2}$ & 0.388 & $\mathrm{CH}_{3}+\mathrm{HO}_{2}=\mathrm{CH}_{3} \mathrm{O}+\mathrm{OH}$ & 0.374 \\
\hline 4 & $\mathrm{CH}_{4}+\mathrm{H}=\mathrm{H}_{2}+\mathrm{CH}_{3}$ & 0.378 & $\mathrm{CH}_{3}+\mathrm{HO}_{2}=\mathrm{CH}_{3} \mathrm{O}+\mathrm{OH}$ & 0.297 & $\mathrm{CH}_{3}+\mathrm{HO}_{2}=\mathrm{CH}_{3} \mathrm{O}+\mathrm{OH}$ & 0.335 & $\mathrm{CH}_{4}+\mathrm{H}=\mathrm{CH}_{3}+\mathrm{H}_{2}$ & 0.337 \\
\hline 5 & $\mathrm{CH}_{3}+\mathrm{H}+\mathrm{M}=\mathrm{CH}_{4}+\mathrm{M}^{\mathrm{LP}}$ & 0.216 & $\mathrm{CH}_{3}+\mathrm{CH}_{3}=\mathrm{C}_{2} \mathrm{H} 5+\mathrm{H}$ & 0.280 & $\mathrm{CH}_{3}+\mathrm{O}_{2}=\mathrm{CH}_{3} \mathrm{O}+\mathrm{O}$ & 0.262 & $\mathrm{CH}_{3}+\mathrm{O}_{2}=\mathrm{CH}_{3} \mathrm{O}+\mathrm{O}$ & 0.213 \\
\hline 6 & $\mathrm{CH}_{4}+\mathrm{OH}=\mathrm{H}_{2} \mathrm{O}+\mathrm{CH}_{3}$ & 0.213 & $\mathrm{C}_{2} \mathrm{H}_{6}+\mathrm{M}=\mathrm{CH}_{3}+\mathrm{CH}_{3}+\mathrm{M}$ & 0.214 & $\mathrm{CH}_{3}+\mathrm{CH}_{3}+\mathrm{M}=\mathrm{C}_{2} \mathrm{H}_{6}+\mathrm{M}$ & 0.236 & $\mathrm{CH}_{3}+\mathrm{CH}_{3}=\mathrm{C}_{2} \mathrm{H}_{5}+\mathrm{H}$ & 0.188 \\
\hline 7 & $\mathrm{CH}_{3}+\mathrm{CH}_{3}+\mathrm{M}=\mathrm{C}_{2} \mathrm{H}_{6}+\mathrm{M}$ & 0.196 & $\mathrm{CH}_{3}+\mathrm{O}_{2}=\mathrm{CH}_{3} \mathrm{O}+\mathrm{O}$ & 0.208 & $\mathrm{CH}_{4}+\mathrm{OH}=\mathrm{CH}_{3}+\mathrm{H}_{2} \mathrm{O}$ & 0.207 & $\mathrm{CH}_{3}+\mathrm{CH}_{3}+\mathrm{M}=\mathrm{C}_{2} \mathrm{H}_{6}+\mathrm{M}$ & 0.170 \\
\hline 8 & $\mathrm{CH}_{3}+\mathrm{CH}_{3}=\mathrm{C}_{2} \mathrm{H} 5+\mathrm{H}$ & 0.163 & $\mathrm{CH}_{4}+\mathrm{OH}=\mathrm{CH}_{3}+\mathrm{H}_{2} \mathrm{O}$ & 0.184 & $\mathrm{CH}_{2} \mathrm{O}+\mathrm{O}_{2}=\mathrm{HCO}+\mathrm{HO}_{2}$ & 0.160 & $\mathrm{CH}_{4}+\mathrm{OH}=\mathrm{CH}_{3}+\mathrm{H}_{2} \mathrm{O}$ & 0.159 \\
\hline 9 & $\mathrm{CH}_{3}+\mathrm{CH}_{3}+\mathrm{M}=\mathrm{C}_{2} \mathrm{H}_{6}+\mathrm{M}^{\mathbf{L P}}$ & 0.150 & $\mathrm{OH}+\mathrm{H}_{2}=\mathrm{H}+\mathrm{H}_{2} \mathrm{O}$ & 0.147 & $\mathrm{H}_{2}+\mathrm{OH}=\mathrm{H}+\mathrm{H}_{2} \mathrm{O}$ & 0.124 & $\mathrm{CH}_{4}+\mathrm{O}_{2}=\mathrm{CH}_{3}+\mathrm{HO}_{2}$ & 0.136 \\
\hline
\end{tabular}




\begin{tabular}{|c|c|c|c|c|c|c|c|c|}
\hline 10 & $\mathrm{CH}_{2} \mathrm{O}+\mathrm{O}_{2}=\mathrm{HCO}+\mathrm{HO}_{2}$ & 0.137 & $\mathrm{CH}_{3}+\mathrm{HO}_{2}=\mathrm{CH}_{4}+\mathrm{O}_{2}$ & 0.143 & $\mathrm{CH}_{3}+\mathrm{HO}_{2}=\mathrm{CH}_{4}+\mathrm{O}_{2}$ & 0.104 & $\mathrm{CH}_{3}+\mathrm{CH}_{3}+\mathrm{M}=\mathrm{C}_{2} \mathrm{H}_{6}+\mathrm{M}^{\mathbf{L P}}$ & 0.129 \\
\hline 11 & $\mathrm{CH}_{3}+\mathrm{HO}_{2}=\mathrm{CH}_{3} \mathrm{O}+\mathrm{OH}$ & 0.123 & $\mathrm{C}_{2} \mathrm{H}_{6}+\mathrm{M}=\mathrm{CH}_{3}+\mathrm{CH}_{3}+\mathrm{M}^{\mathrm{LP}}$ & 0.138 & $\mathrm{CH}_{3}+\mathrm{H}+\mathrm{M}=\mathrm{CH}_{4}+\mathrm{M}^{\mathrm{LP}}$ & 0.104 & $\mathrm{OH}+\mathrm{H}_{2}=\mathrm{H}+\mathrm{H}_{2} \mathrm{O}$ & 0.128 \\
\hline 12 & $\mathrm{H}_{2}+\mathrm{OH}=\mathrm{H}_{2} \mathrm{O}+\mathrm{H}$ & 0.111 & $\mathrm{CH}_{2} \mathrm{O}+\mathrm{O}_{2}=\mathrm{HCO}+\mathrm{HO}_{2}$ & 0.113 & $\mathrm{CH}_{4}+\mathrm{HO}_{2}=\mathrm{CH}_{3}+\mathrm{H}_{2} \mathrm{O}_{2}$ & 0.101 & $\mathrm{H}+\mathrm{O}_{2}+\mathrm{M}=\mathrm{HO}_{2}+\mathrm{M}^{\mathbf{L P}}$ & 0.112 \\
\hline 13 & $\mathrm{H}+\mathrm{O}_{2}+\mathrm{M}=\mathrm{HO}_{2}+\mathrm{M}^{\mathrm{LP}}$ & 0.104 & $\mathrm{CH}_{3}+\mathrm{H}_{2} \mathrm{O}_{2}=\mathrm{CH}_{4}+\mathrm{HO}_{2}$ & 0.100 & $\mathrm{H}+\mathrm{O}_{2}+\mathrm{M}=\mathrm{HO}_{2}+\mathrm{M}^{\mathbf{L P}}$ & 0.097 & $\mathrm{CH}_{3}+\mathrm{H}+\mathrm{M}=\mathrm{CH}_{4}+\mathrm{M}^{\mathrm{LP}}$ & 0.081 \\
\hline 14 & $\mathrm{CH}_{2} \mathrm{O}+\mathrm{OH}=\mathrm{HCO}+\mathrm{H}_{2} \mathrm{O}$ & 0.096 & $\mathrm{CH}_{3}+\mathrm{H}+\mathrm{M}=\mathrm{CH}_{4}+\mathrm{M}^{\mathrm{LP}}$ & 0.095 & $\mathrm{HCO}+\mathrm{M}=\mathrm{H}+\mathrm{CO}+\mathrm{M}$ & 0.073 & $\mathrm{HCO}+\mathrm{O}_{2}=\mathrm{CO}+\mathrm{HO}_{2}$ & 0.078 \\
\hline 15 & $\mathrm{CH}_{3}+\mathrm{O}=\mathrm{CH}_{2} \mathrm{O}+\mathrm{H}$ & 0.088 & $\mathrm{H}+\mathrm{O}_{2}+\mathrm{M}=\mathrm{HO}_{2}+\mathrm{M}^{\mathrm{LP}}$ & 0.092 & $\mathrm{CH}_{2} \mathrm{O}+\mathrm{H}=\mathrm{HCO}+\mathrm{H}_{2}$ & 0.065 & $\mathrm{HCO}+\mathrm{M}=\mathrm{H}+\mathrm{CO}+\mathrm{M}^{\mathrm{LP}}$ & 0.076 \\
\hline \multicolumn{9}{|c|}{ Subset 3: RCM measurements } \\
\hline Rank & SanDiego-2014 & $\overline{S_{a b s}}$ & Caltech-2015 & $\overline{S_{a b s}}$ & Aramco-II-2016 & $\overline{S_{a b s}}$ & Glarborg-2018 & $\overline{S_{a b s}}$ \\
\hline 1 & $\mathrm{CH}_{3}+\mathrm{O}_{2}=\mathrm{CH}_{2} \mathrm{O}+\mathrm{OH}$ & 0.720 & $\mathrm{OH}+\mathrm{OH}+\mathrm{M}=\mathrm{H}_{2} \mathrm{O}_{2}+\mathrm{M}^{\mathrm{LP}}$ & 0.623 & $\mathrm{CH}_{4}+\mathrm{O}=\mathrm{CH}_{3}+\mathrm{OH}$ & 0.761 & $\mathrm{CH}_{3}+\mathrm{H}=\mathrm{CH}_{2}+\mathrm{H}_{2}$ & 0.733 \\
\hline 2 & $\mathrm{OH}+\mathrm{OH}+\mathrm{M}=\mathrm{H}_{2} \mathrm{O}_{2}+\mathrm{M}^{\mathrm{LP}}$ & 0.398 & $\mathrm{CH}_{3}+\mathrm{H}_{2} \mathrm{O}_{2}=\mathrm{CH}_{4}+\mathrm{HO}_{2}$ & 0.619 & $\mathrm{C}_{2} \mathrm{H}_{5} \mathrm{OH}+\mathrm{CH}_{3} \mathrm{O}_{2}=\mathrm{C}_{2} \mathrm{H}_{5} \mathrm{O}+\mathrm{CH}_{3} \mathrm{O}_{2} \mathrm{H}$ & 0.699 & $\mathrm{CH}_{2} \mathrm{CHO}+\mathrm{CH}_{2}=\mathrm{C}_{2} \mathrm{H}_{4}+\mathrm{HCO}$ & 0.682 \\
\hline 3 & $\mathrm{CH}_{2} \mathrm{O}+\mathrm{HO}_{2}=\mathrm{HCO}+\mathrm{H}_{2} \mathrm{O}_{2}$ & 0.398 & $\mathrm{C}_{2} \mathrm{H}_{6}+\mathrm{M}=\mathrm{CH}_{3}+\mathrm{CH}_{3}+\mathrm{M}$ & 0.467 & $\mathrm{CH}_{4}+\mathrm{OH}=\mathrm{CH}_{3}+\mathrm{H}_{2} \mathrm{O}$ & 0.579 & $\mathrm{HCO}+\mathrm{O}_{2}=\mathrm{CO}+\mathrm{HO}_{2}$ & 0.653 \\
\hline 4 & $\mathrm{CH}_{4}+\mathrm{HO}_{2}=\mathrm{CH}_{3}+\mathrm{H}_{2} \mathrm{O}_{2}$ & 0.362 & $\mathrm{CH}_{2} \mathrm{O}+\mathrm{HO}_{2}=\mathrm{HCO}+\mathrm{H}_{2} \mathrm{O}_{2}$ & 0.356 & $\mathrm{CH}_{4}+\mathrm{HO}_{2}=\mathrm{CH}_{3}+\mathrm{H}_{2} \mathrm{O}_{2}$ & 0.554 & $\mathrm{HCO}+\mathrm{HO}_{2}=\mathrm{CO}_{2}+\mathrm{OH}+\mathrm{H}$ & 0.644 \\
\hline 5 & $\mathrm{CH}_{3}+\mathrm{CH}_{3}+\mathrm{M}=\mathrm{C}_{2} \mathrm{H}_{6}+\mathrm{M}$ & 0.344 & $\mathrm{CH}_{3}+\mathrm{O}_{2}=\mathrm{CH}_{2} \mathrm{O}+\mathrm{OH}$ & 0.343 & $\mathrm{HOCHO}+\mathrm{H}=>\mathrm{H}_{2}+\mathrm{CO}+\mathrm{OH}$ & 0.469 & $\mathrm{CH}_{2} \mathrm{O}+\mathrm{H}=\mathrm{HCO}+\mathrm{H}_{2}{ }^{\text {DUP2 }}$ & 0.554 \\
\hline 6 & $\mathrm{CH}_{2} \mathrm{O}+\mathrm{O}_{2}=\mathrm{HCO}+\mathrm{HO}_{2}$ & 0.208 & $\mathrm{CH}_{3} \mathrm{O}_{2}+\mathrm{CH}_{3}=\mathrm{CH}_{3} \mathrm{O}+\mathrm{CH}_{3} \mathrm{O}$ & 0.341 & $\mathrm{HCOH}+\mathrm{OH}=\mathrm{HCO}+\mathrm{H}_{2} \mathrm{O}$ & 0.464 & $\mathrm{CH}_{3} \mathrm{OOH}+\mathrm{H}=\mathrm{CH}_{2} \mathrm{OOH}+\mathrm{H}_{2}$ & 0.474 \\
\hline 7 & $\mathrm{OH}+\mathrm{OH}+\mathrm{M}=\mathrm{H}_{2} \mathrm{O}_{2}+\mathrm{M}$ & 0.192 & $\mathrm{HO}_{2}+\mathrm{HO}_{2}=\mathrm{H}_{2} \mathrm{O}_{2}+\mathrm{O}_{2}$ Dup2 & 0.340 & $\mathrm{CH}_{3}+\mathrm{O}=\mathrm{CH}_{2} \mathrm{O}+\mathrm{H}$ & 0.452 & $\mathrm{HCO}+\mathrm{OH}=\mathrm{CO}+\mathrm{H}_{2} \mathrm{O}$ & 0.457 \\
\hline 8 & $\mathrm{CH}_{4}+\mathrm{OH}=\mathrm{H}_{2} \mathrm{O}+\mathrm{CH}_{3}$ & 0.184 & $\mathrm{H}+\mathrm{O}_{2}=\mathrm{O}+\mathrm{OH}$ & 0.320 & $\mathrm{H}+\mathrm{O}_{2}=\mathrm{O}+\mathrm{OH}$ & 0.349 & $\mathrm{CH}_{3}+\mathrm{M}=\mathrm{CH}+\mathrm{H}_{2}+\mathrm{M}$ & 0.398 \\
\hline 9 & $\mathrm{HO}_{2}+\mathrm{HO}_{2}=\mathrm{H}_{2} \mathrm{O}_{2}+\mathrm{O}_{2}$ DUP2 & 0.164 & $\mathrm{CH}_{3}+\mathrm{HO}_{2}=\mathrm{CH}_{3} \mathrm{O}+\mathrm{OH}$ & 0.301 & $\mathrm{CH}_{2} \mathrm{O}+\mathrm{H}=\mathrm{HCO}+\mathrm{H}_{2}$ & 0.346 & $\mathrm{CH}_{3} \mathrm{O}+\mathrm{CH}_{3}=\mathrm{CH}_{2} \mathrm{O}+\mathrm{CH}_{4}$ & 0.391 \\
\hline 10 & $\mathrm{CH}_{2} \mathrm{O}+\mathrm{OH}=\mathrm{HCO}+\mathrm{H}_{2} \mathrm{O}$ & 0.148 & $\mathrm{OH}+\mathrm{OH}+\mathrm{M}=\mathrm{H}_{2} \mathrm{O}_{2}+\mathrm{M}$ & 0.254 & $\mathrm{CH}_{3}+\mathrm{OH}=\mathrm{CH}_{2}+\mathrm{H}_{2} \mathrm{O}$ & 0.315 & $\mathrm{H}+\mathrm{O}_{2}=\mathrm{O}+\mathrm{OH}$ & 0.372 \\
\hline 11 & $\mathrm{H}+\mathrm{O}_{2}=\mathrm{OH}+\mathrm{O}$ & 0.132 & $\mathrm{H}+\mathrm{O}_{2}+\mathrm{M}=\mathrm{HO}_{2}+\mathrm{M}^{\mathrm{LP}}$ & 0.232 & $\mathrm{H}_{2} \mathrm{O}_{2}+\mathrm{M}=\mathrm{OH}+\mathrm{OH}+\mathrm{M}$ & 0.280 & $\mathrm{CH}_{3} \mathrm{OO}+\mathrm{CH}_{2} \mathrm{O}=\mathrm{CH}_{3} \mathrm{OOH}+\mathrm{HCO}$ & 0.351 \\
\hline 12 & $\mathrm{HO}_{2}+\mathrm{HO}_{2}=\mathrm{H}_{2} \mathrm{O}_{2}+\mathrm{O}_{2}$ DUP1 & 0.123 & $\begin{array}{l}\mathrm{CH}_{3} \mathrm{O}_{2}+\mathrm{CH}_{2} \mathrm{O} \Rightarrow \mathrm{CH}_{3} \mathrm{O}+\mathrm{OH}+ \\
\mathrm{HCO}\end{array}$ & 0.216 & $\mathrm{HO}_{2}+\mathrm{HO}_{2}=\mathrm{H}_{2} \mathrm{O}_{2}+\mathrm{O}_{2}$ DUP2 & 0.275 & $\mathrm{H}_{2} \mathrm{O}_{2}+\mathrm{M}=\mathrm{OH}+\mathrm{OH}+\mathrm{M}$ & 0.303 \\
\hline 13 & $\mathrm{H}+\mathrm{O}_{2}+\mathrm{M}=\mathrm{HO}_{2}+\mathrm{M}^{\mathbf{L P}}$ & 0.104 & $\mathrm{CH}_{3}+\mathrm{HO}_{2}=\mathrm{CH}_{4}+\mathrm{O}_{2}$ & 0.193 & $\mathrm{C}_{2} \mathrm{H}_{5} \mathrm{OH}+\mathrm{C}_{2} \mathrm{H}_{5}=\mathrm{P}-\mathrm{C}_{2} \mathrm{H}_{4} \mathrm{OH}+\mathrm{C}_{2} \mathrm{H}_{6}$ & 0.255 & $\mathrm{HO}_{2}+\mathrm{HO}_{2}=\mathrm{H}_{2} \mathrm{O}_{2}+\mathrm{O}_{2}$ DUP1 & 0.294 \\
\hline 14 & $\mathrm{CH}_{3}+\mathrm{O}_{2}=\mathrm{CH}_{3} \mathrm{O}+\mathrm{O}$ & 0.104 & $\mathrm{CH}_{2} \mathrm{O}+\mathrm{O}_{2}=\mathrm{HCO}+\mathrm{HO}_{2}$ & 0.160 & $\mathrm{CH}_{3}+\mathrm{O}_{2}+\mathrm{M}=\mathrm{CH}_{3} \mathrm{O}_{2}+\mathrm{M}$ & 0.246 & $\mathrm{CH}_{2} \mathrm{CHO}+\mathrm{O}_{2}=\mathrm{CH}_{2} \mathrm{O}+\mathrm{CO}+\mathrm{OH}$ & 0.274 \\
\hline 15 & $\mathrm{CH}_{3}+\mathrm{HO}_{2}=\mathrm{CH}_{3} \mathrm{O}+\mathrm{OH}$ & 0.093 & $\mathrm{HO}_{2}+\mathrm{HO}_{2}=\mathrm{H}_{2} \mathrm{O}_{2}+\mathrm{O}_{2}$ DuPI & 0.151 & $\mathrm{CH}_{4}+\mathrm{H}=\mathrm{CH}_{3}+\mathrm{H}_{2}$ & 0.242 & $\mathrm{HCCO}+\mathrm{HCCO}=\mathrm{C}_{2} \mathrm{H}_{2}+\mathrm{CO}+\mathrm{CO}$ & 0.213 \\
\hline
\end{tabular}

LP Low-pressure limit rate parameters.

DUP1-2 Duplicate reaction; the numbering is in the order of the reactions in the mechanism.

Red shading: six reactions with the highest average absolute scaled sensitivity coefficients.

Yellow shading: six reactions with the next highest average absolute scaled sensitivity coefficients. 
Six reactions, R1: $\mathrm{H}+\mathrm{O}_{2}=\mathrm{O}+\mathrm{OH}, \mathrm{R} 2: \mathrm{CH}_{3}+\mathrm{O}_{2}=\mathrm{CH}_{2} \mathrm{O}+\mathrm{OH}$, R3: $\mathrm{CH}_{4}+\mathrm{H}=\mathrm{CH}_{3}+\mathrm{H}_{2}$, R4: $\mathrm{CH}_{3}+\mathrm{O}_{2}=\mathrm{CH}_{3} \mathrm{O}+\mathrm{O}, \mathrm{R} 5: \mathrm{HO}_{2}+\mathrm{HO}_{2}=\mathrm{H}_{2} \mathrm{O}_{2}+\mathrm{O}_{2}$ (Duplicate 1), R6: $\mathrm{HO}_{2}+\mathrm{HO}_{2}=\mathrm{H}_{2} \mathrm{O}_{2}$ $+\mathrm{O}_{2}$ (Duplicate 2), are the most sensitive elementary reactions. This list indicates that both channels of reaction $\mathrm{HO}_{2}+\mathrm{HO}_{2}=\mathrm{H}_{2} \mathrm{O}_{2}+\mathrm{O}_{2}$ are important. The following analysis investigates the sum of the rate coefficients of channels R5 and R6. These six reactions are highlighted by red in Table 5. The first four reaction steps, R1 to R4, were defined as the most sensitive elementary reactions since they have the highest average absolute scaled sensitivity coefficients $\left.\left(\overline{S_{a b s}}\right)_{a v g}\right)$ in the two shock tube subsets of Table 5. The two channels of the elementary reaction, $\mathrm{HO}_{2}+\mathrm{HO}_{2}$ $=\mathrm{H}_{2} \mathrm{O}_{2}+\mathrm{O}_{2}$, were further identified as the most sensitive reaction steps by the RCM subset of Table 5.

Another group of six reactions is listed as second-level sensitive reactions: $\mathrm{R} 7: \mathrm{CH}_{4}+\mathrm{OH}=\mathrm{CH}_{3}$ $+\mathrm{H}_{2} \mathrm{O}, \mathrm{R} 8: \mathrm{CH}_{3}+\mathrm{H}+\mathrm{M}=\mathrm{CH}_{4}+\mathrm{M}(\mathrm{LP}), \mathrm{R} 9: \mathrm{OH}+\mathrm{H}_{2}=\mathrm{H}+\mathrm{H}_{2} \mathrm{O}, \mathrm{R} 10: \mathrm{H}+\mathrm{O}_{2}+\mathrm{M}=\mathrm{HO}_{2}+$ $\mathrm{M}$ (LP), R11: $\mathrm{CH}_{4}+\mathrm{O}=\mathrm{CH}_{3}+\mathrm{OH}, \mathrm{R} 12: \mathrm{CH}_{4}+\mathrm{HO}_{2}=\mathrm{CH}_{3}+\mathrm{H}_{2} \mathrm{O}_{2}$. These are highlighted by yellow in Table 5. The $\left(\overline{S_{a b s}}\right)_{a v g}$ values of R7 and R8 in ST measurements and R7-R10 in ST-PRR experiments are between 0.1 and 0.25 .

For the most sensitive reactions of the RCM subset, the inconsistency between the four best mechanisms is significant, as shown in Table 5. Since Aramco-II-2016 is the only mechanism that had a good performance under RCM conditions, the top four sensitive reactions of Aramco-II2016 for RCM subset $\left(\overline{S_{a b s}}>0.5\right)$ are definitely important. However, reaction $\mathrm{C}_{2} \mathrm{H}_{5} \mathrm{OH}+\mathrm{CH}_{3} \mathrm{O}_{2}$ $=\mathrm{C}_{2} \mathrm{H}_{5} \mathrm{O}+\mathrm{CH}_{3} \mathrm{O}_{2} \mathrm{H}$ is not present in the other mechanisms, therefore the rate coefficient of this reaction cannot be used in comparisons. Considering that reaction $\mathrm{CH}_{4}+\mathrm{OH}=\mathrm{CH}_{3}+\mathrm{H}_{2} \mathrm{O}$ has been identified as the most important reaction in the two subsets of the shock tube measurements, 
reactions $\mathrm{CH}_{4}+\mathrm{O}=\mathrm{CH}_{3}+\mathrm{OH}(\mathrm{R} 11)$ and $\mathrm{CH}_{4}+\mathrm{HO}_{2}=\mathrm{CH}_{3}+\mathrm{H}_{2} \mathrm{O}_{2}(\mathrm{R} 12)$ are added to the list of the second-level sensitive reactions.

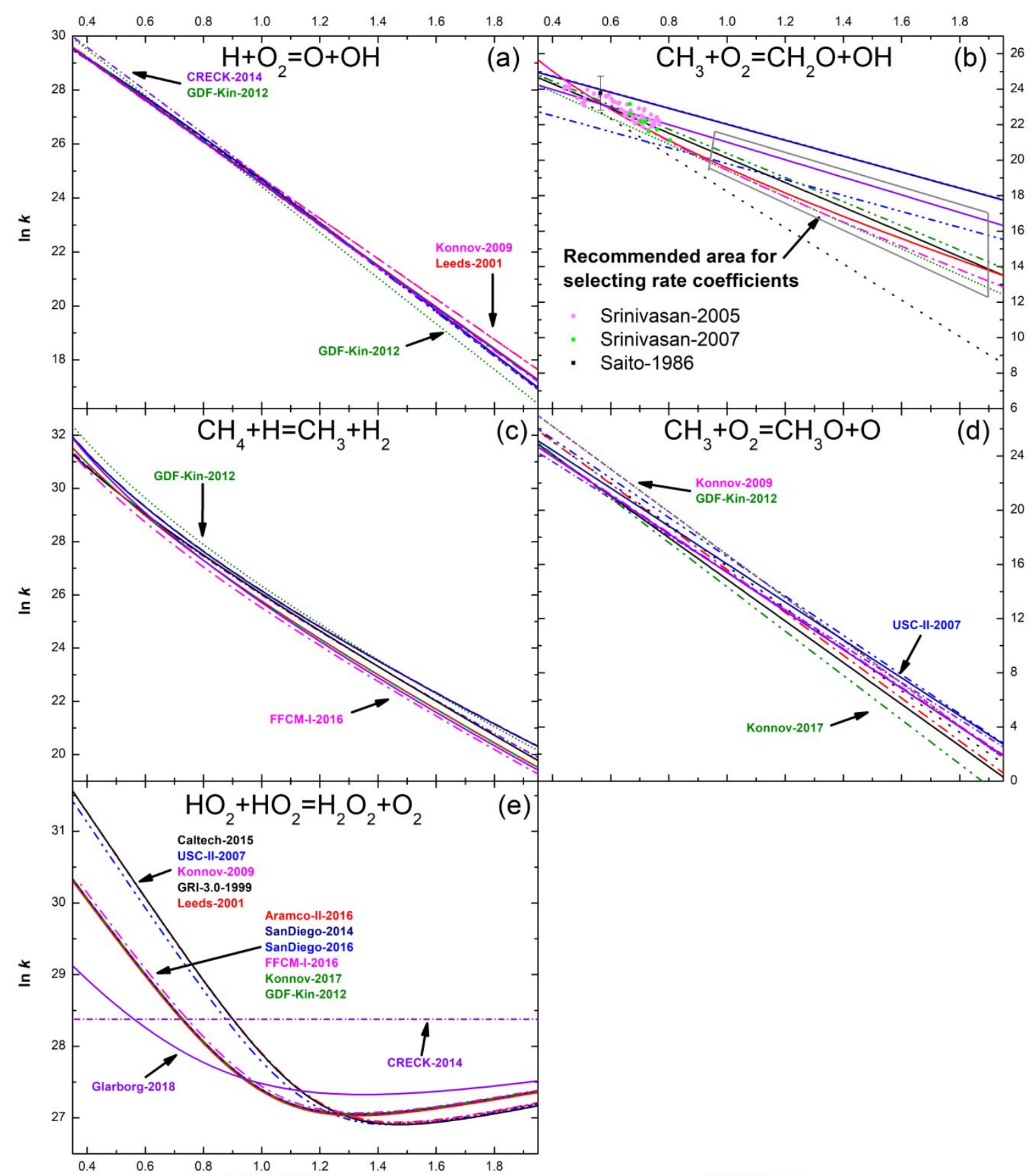

$1000 \mathrm{~K} / \mathrm{T}$

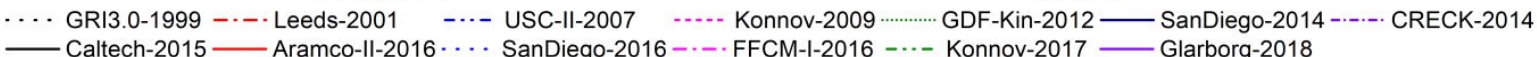

Figure. 11. Comparison of the rate coefficients of the five most sensitive reactions: $\mathrm{R} 1: \mathrm{H}+\mathrm{O}_{2}=$ $\mathrm{O}+\mathrm{OH}(\mathrm{a}), \mathrm{R} 2: \mathrm{CH}_{3}+\mathrm{O}_{2}=\mathrm{CH}_{2} \mathrm{O}+\mathrm{OH}(\mathrm{b}), \mathrm{R} 3: \mathrm{CH}_{4}+\mathrm{H}=\mathrm{CH}_{3}+\mathrm{H}_{2}$ (c), $\mathrm{R} 4: \mathrm{CH}_{3}+\mathrm{O}_{2}=\mathrm{CH}_{3} \mathrm{O}$ 
$+\mathrm{O}$ (d), R5 + R6: $\mathrm{HO}_{2}+\mathrm{HO}_{2}=\mathrm{H}_{2} \mathrm{O}_{2}+\mathrm{O}_{2}$ (e). Panel (b) contains the direct measurement results of the R2 rate coefficients from the studies of Srinivasan ${ }^{121} 122$ and Saito ${ }^{123}$ (only a single point with error bar). The units of the rate coefficients are in $\mathrm{cm}$, mol, $\mathrm{s}$.

Figure 11 gives the Arrhenius plots of the five most sensitive reactions as used in the 13 mechanisms. Rate coefficients of the four best mechanisms are drawn by solid lines for an added emphasis. For R1, $\mathrm{H}+\mathrm{O}_{2}=\mathrm{O}+\mathrm{OH}$ (Fig. 11(a)), most mechanisms have similar trends, except for CRECK-2014 at middle and high temperatures (>1100K) and Leeds-2001 and Konnov-2009 at low temperature $(<890 \mathrm{~K})$. GDF-Kin-2012 has slight deviation from the other mechanisms in the whole temperature range. In the case of $\mathrm{R} 2, \mathrm{CH}_{3}+\mathrm{O}_{2}=\mathrm{CH}_{2} \mathrm{O}+\mathrm{OH}(\mathrm{b})$, the rate coefficients used in the various mechanisms are very different. The $\ln k$ curves of the four best mechanisms have four different trends, although Caltech-2015 and Aramco-II-2016 are close to each other. Considering that the Arrhenius parameters of reaction R2 are very different in the various mechanisms, we investigated the origin of the Arrhenius parameters of this reaction in each mechanism. The findings are given in Table E of the Supplementary Material. Srinivasan et al. ${ }^{121}$ ${ }^{122}$ and Saito et al. ${ }^{123}$ published direct measurement results for the R2 rate coefficient. These experimental data are also plotted in the Fig. 11. The available direct measurement data are in the high temperature range (above $1250 \mathrm{~K}$ ) and such data are not available at lower temperatures which are more critical for the modelling. For reaction $\mathrm{R} 3, \mathrm{CH}_{4}+\mathrm{H}=\mathrm{CH}_{3}+\mathrm{H}_{2}$ (c), the rate coefficients for all the mechanisms have a similar trend. The rate coefficients of GDF-Kin-2012 and FFCM-I2016 are the highest and lowest ones, respectively. $\mathrm{R} 4, \mathrm{CH}_{3}+\mathrm{O}_{2}=\mathrm{CH}_{3} \mathrm{O}+\mathrm{O}$ (d), is the second channel of the reaction between $\mathrm{CH}_{3}$ and $\mathrm{O}_{2}$ in the present study. Unlike of the first channel, $\mathrm{R} 2$, the rate coefficients of R4 for all mechanisms have a similar Arrhenius curve. For the four best mechanisms, only the rate coefficient of Caltech-2015 deviates significantly at low temperatures 
$(<820 \mathrm{~K})$. R5 and R6 are two duplicate channels of reaction $\mathrm{HO}_{2}+\mathrm{HO}_{2}=\mathrm{H}_{2} \mathrm{O}_{2}+\mathrm{O}_{2}$. The sum of these two rate coefficients is plotted in Fig 11(e). At high temperatures channel R5 dominates the rate coefficient. Caltech-2015, USC-II-2007, Konnov-2009, GRI3.0-1999, Leed-2001 have the highest $\mathrm{R} 5$ rate coefficients and thus the highest overall $k$ of this reaction, while these mechanisms have the lowest R6 rate coefficients and thus the lowest overall $k$ at low temperatures. The Arrhenius plot of (R5+R6) of Glarborg-2018 is significantly different from all other mechanisms. CRECK-2014 uses temperature independent rate coefficient for reaction $(\mathrm{R} 5+\mathrm{R} 6) \mathrm{HO}_{2}+\mathrm{HO}_{2}=$ $\mathrm{H}_{2} \mathrm{O}_{2}+\mathrm{O}_{2}$

Similarly, the Arrhenius plots of the second-level sensitive reactions, R7-R12, are displayed in Fig. 12. For $\mathrm{R} 7, \mathrm{CH}_{4}+\mathrm{OH}=\mathrm{CH}_{3}+\mathrm{H}_{2} \mathrm{O}$, the rate coefficient of Aramco-II-2016 is significantly higher than those of other mechanisms at high temperature, while it decreases rapidly with decreasing temperature. The Arrhenius plot of reaction $\mathrm{R} 8 \mathrm{CH}_{3}+\mathrm{H}+\mathrm{M}=\mathrm{CH}_{4}+\mathrm{M}$ (LP) shows that mechanisms GRI3.0-1999, USC-II-2007, GDF-Kin-2012, SanDiego-2014, Caltech-2015, Aramco-II-2016, SanDiego-2016 have identical rate coefficients, while all the other mechanisms use alternative ones. Konnov-2009 used significantly higher rate coefficient for R8 at low temperature than the other mechanisms, and in the newer version (Konnov-2017) the rate coefficient was shifted to a lower level below $1000 \mathrm{~K}$. R9 is a sensitive reaction for ST-PRR measurements and the Arrhenius plots for all mechanisms are similar, except for Aramco-II-2016; its rate coefficient is significantly lower than those of other mechanisms. Reaction $\mathrm{R} 10, \mathrm{H}+\mathrm{O}_{2}+$ $\mathrm{M}=\mathrm{HO}_{2}+\mathrm{M}(\mathrm{LP})$, is relatively sensitive in Caltech-2015 at the simulation of RCM measurements, and the R10 rate coefficient of Caltech-2015 is among the lowest ones in the whole temperature range. For $\mathrm{R} 11, \mathrm{CH}_{4}+\mathrm{O}=\mathrm{CH}_{3}+\mathrm{OH}$, the Arrhenius plots are close to each other, while the rate coefficient of Glarborg-2018 is slightly higher at both lower and higher temperatures. At low 
temperature, the rate coefficients of $\mathrm{R} 12, \mathrm{CH}_{4}+\mathrm{HO}_{2}=\mathrm{CH}_{3}+\mathrm{H}_{2} \mathrm{O}_{2}$, are close to each other for all mechanisms, while there are significant differences at high temperatures.

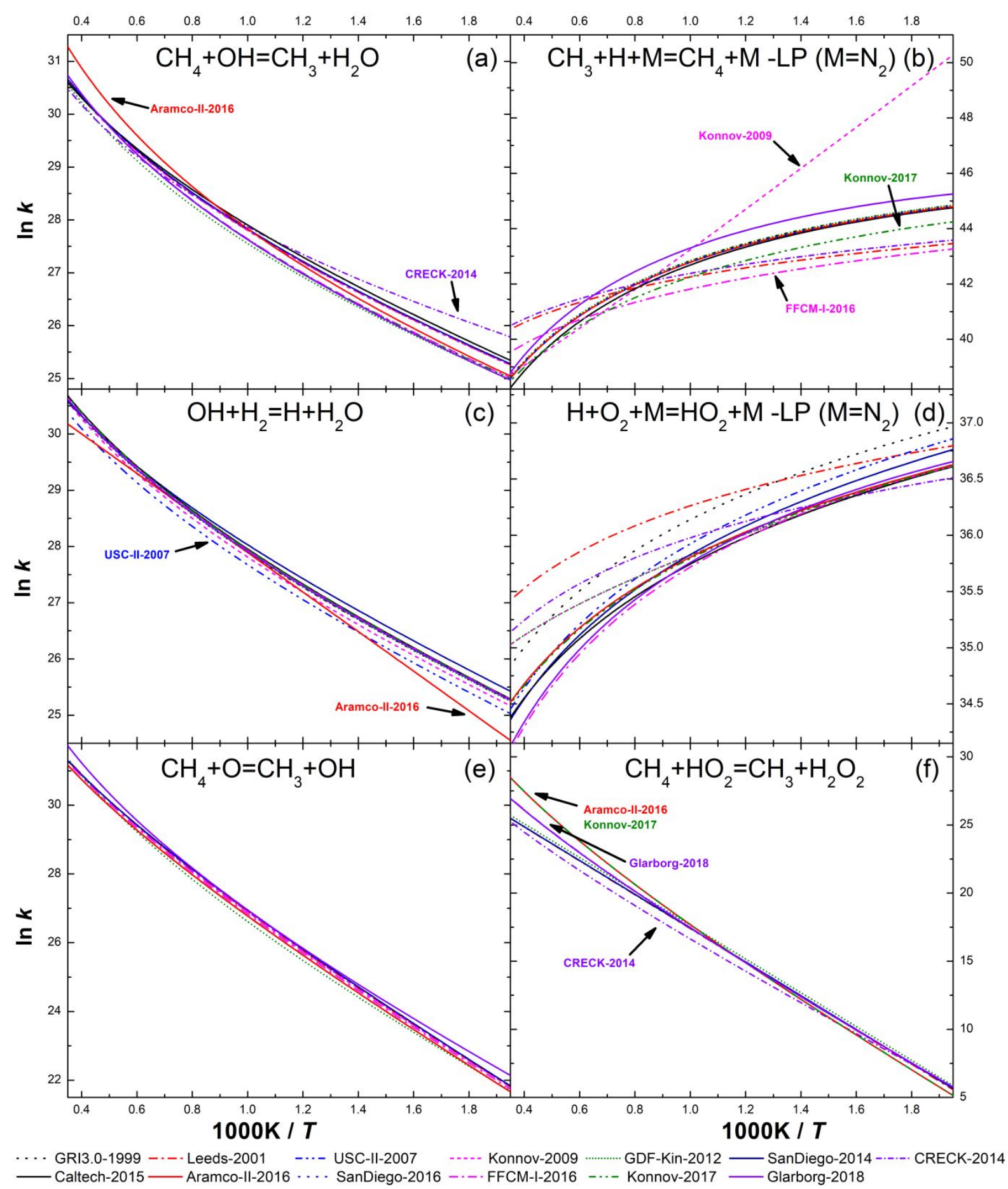


Figure. 12. Comparison of the rate coefficients of second-level sensitive reactions: $\mathrm{R} 7: \mathrm{CH}_{4}+\mathrm{OH}$ $=\mathrm{CH}_{3}+\mathrm{H}_{2} \mathrm{O}$ (a), R8: $\mathrm{CH}_{3}+\mathrm{H}+\mathrm{M}=\mathrm{CH}_{4}+\mathrm{M}$ (LP) (b), R9: OH $+\mathrm{H}_{2}=\mathrm{H}+\mathrm{H}_{2} \mathrm{O}$ (c), R10: $\mathrm{H}+$ $\mathrm{O}_{2}+\mathrm{M}=\mathrm{HO}_{2}+\mathrm{M}(\mathrm{LP})(\mathrm{d}), \mathrm{R} 11: \mathrm{CH}_{4}+\mathrm{O}=\mathrm{CH}_{3}+\mathrm{OH}(\mathrm{e}), \mathrm{R} 12: \mathrm{CH}_{4}+\mathrm{HO}_{2}=\mathrm{CH}_{3}+\mathrm{H}_{2} \mathrm{O}_{2}$ (f). The units of the rate coefficients are expressed in $\mathrm{cm}, \mathrm{mol}, \mathrm{s}$.

Figure 13 shows the frequencies of the sensitivity coefficients from R1 to R6. The sensitivity coefficients have little variation for the shock tube measurements (ST and ST-PRR), while for the RCM experiments, the highly sensitive coefficients of identical reactions in different mechanisms have significant discrepancy.

It can be seen from Fig. 13(a) that reaction R1 have strong promoting effect for most cases, but the promoting effect in SanDiego-2014 on RCM ignition is very weak. Fig. 13(b) shows that reaction R2 shortens the simulated RCM ignition delays in SanDiego-2014; R2 basically performs the role of $\mathrm{R} 1$ in this mechanism via the generation of $\mathrm{OH}$ from $\mathrm{O}_{2}$. Correspondingly, Fig. 11(b) indicates that the rate coefficient of R2 for SanDiego-2014 is large, and Table 5 shows that R2 has the highest average value of the absolute scaled sensitivity coefficients for the SanDiego-2014 mechanism under RCM conditions. This suggests that the role of reaction R2 at RCM ignition (that is at lower temperatures) deserves further investigations. Performances of mechanisms Caltech-2015, Aramco-II-2016, Glarborg-2018 are good for reproducing ST-IDT (see Fig. 5(a)), and Aramco-II-2016, Glarborg-2018 and Konnov-2017 well reproduce RCM-IDT (see Fig. 5(c)). Reaction R2 is the only reaction that exhibits much inconsistency at low temperatures $(<1200 \mathrm{~K})$ among the mechanisms, which indicates that the $\ln k$ curves for reaction $\mathrm{R} 2$ must be within the framed region in Fig. 11(b) in the corresponding temperature region.

Fig. 13(c) shows that increasing the rate coefficient of reaction R3 extends the shock tube ignition delays, while under RCM conditions it shortens the ignition delays, especially for Aramco- 
II-2016. Reaction R4 is able to accelerate the shock tube ignition, while for RCM ignitions the effect is negligible, as seen from Fig. 13(d). Based on Fig. 13(e) and Fig. 13(f), the two channels of the reaction $\mathrm{HO}_{2}+\mathrm{HO}_{2}=\mathrm{H}_{2} \mathrm{O}_{2}+\mathrm{O}_{2}$ have inhibiting ability to ignition on various extent for all the mechanisms in RCM simulations, while the scaled sensitivity coefficients for shock tube ignitions are very low.

Similar results of sensitivity analysis for reactions R7-R12 are shown in Fig. S7 in the Supplementary Material. For reactions R8, R9 and R10 in Figs. S7 (b), (c), and (d), respectively, it is easy to see that these reactions have slight promoting or depressing influence, in good accordance for all mechanisms and reaction types. However, it is interesting that reaction $\mathrm{R} 7\left(\mathrm{CH}_{4}\right.$ $+\mathrm{OH}=\mathrm{CH}_{3}+\mathrm{H}_{2} \mathrm{O}$ ) has an opposite effect for ignitions in RCM and shock tube. It is worth noting that increasing the rate coefficient of R7 (see Fig. S7(a)) and R11 (Fig. S7(e)) can accelerate the ignition in the RCM simulations using Aramco-II-2016, while this effect is insignificant in the other mechanisms. Moreover, Fig. S7(f) shows that increasing the rate coefficient of R12 $\left(\mathrm{CH}_{4}+\right.$ $\mathrm{HO}_{2}=\mathrm{CH}_{3}+\mathrm{H}_{2} \mathrm{O}_{2}$ ) have opposite effect on the RCM ignition delay times using SanDiego-2014 and Aramco-II-2016. 


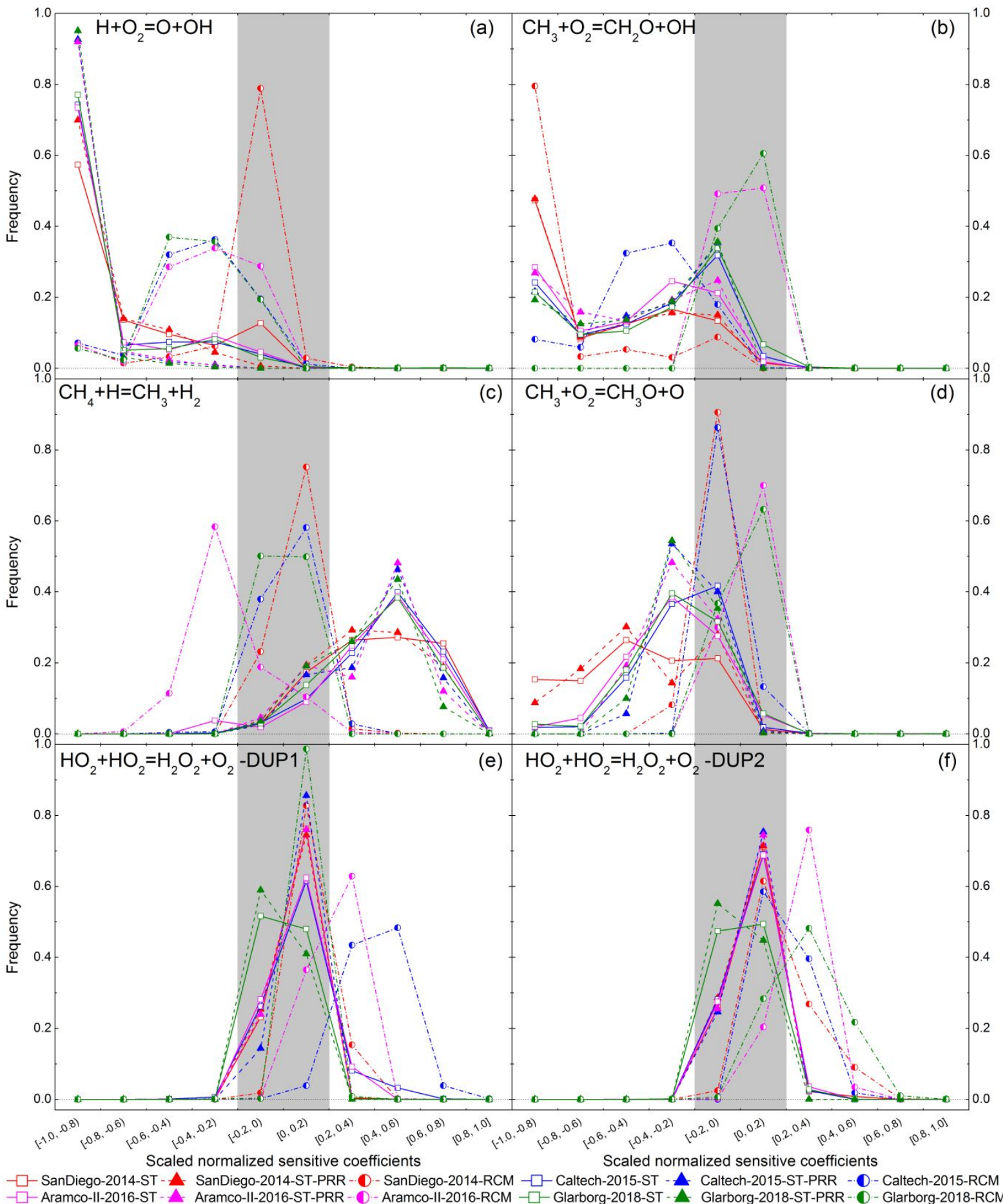

Figure. 13. Frequencies of sensitivity coefficients of $\mathrm{R} 1: \mathrm{H}+\mathrm{O}_{2}=\mathrm{O}+\mathrm{OH}(\mathrm{a}), \mathrm{R} 2: \mathrm{CH}_{3}+\mathrm{O}_{2}=$ $\mathrm{CH}_{2} \mathrm{O}+\mathrm{OH}(\mathrm{b}), \mathrm{R} 3: \mathrm{CH}_{4}+\mathrm{H}=\mathrm{CH}_{3}+\mathrm{H}_{2}$ (c), R4: $\mathrm{CH}_{3}+\mathrm{O}_{2}=\mathrm{CH}_{3} \mathrm{O}+\mathrm{O}(\mathrm{d}), \mathrm{R} 5: \mathrm{HO}_{2}+\mathrm{HO}_{2}=$ $\mathrm{H}_{2} \mathrm{O}_{2}+\mathrm{O}_{2}$ (Duplicate 1) (e), R6: $\mathrm{HO}_{2}+\mathrm{HO}_{2}=\mathrm{H}_{2} \mathrm{O}_{2}+\mathrm{O}_{2}$ (Duplicate 2) (f), for the three types of 
measurements (ST, ST-PRR, RCM). The sensitivity analyses were carried out using mechanisms SanDiego-2014, Caltech-2015, Aramco-II-2016 and Glarborg-2018. The experimental conditions are given for each type of measurements. The grey shaded rectangle is the domain of low sensitivity of reactions.

To sum up, at high temperatures (i.e. for shock tube measurements), the sensitivity analysis results obtained from the four best performing mechanisms have significant consistency. The rate coefficients of the most sensitive reactions of all mechanisms are similar with each other. The only significant exception is reaction $\mathrm{R} 2\left(\mathrm{CH}_{3}+\mathrm{O}_{2}=\mathrm{CH}_{2} \mathrm{O}+\mathrm{OH}\right)$. Based on the performance of the various mechanisms, the present study indicated that the proper selection of the rate parameters of $\mathrm{R} 2$ reaction is important and the rate coefficient of this reaction has to be determined in further experimental and theoretical studies at low temperatures.

The case of low temperature conditions (corresponding mainly to RCM measurements) is very different. There is an inconsistency of sensitivity analysis results among the various mechanisms and there are only a few reactions which have high sensitivity according to all the mechanisms. A better description of the low temperature ignition of methane requires a more accurate determination of the rate parameters of several reaction steps. As the sensitivity analysis results indicate, these are mainly the reactions of $\mathrm{HO}_{2}, \mathrm{H}_{2} \mathrm{O}_{2}$, and alkylperoxides.

6.3 Main differences between the four best mechanisms

The four best mechanisms are Aramco-II-2016, Caltech-2015, Glarborg-2018 and SanDiego2014 (in the order of increasing error) on average for the reproduction of ignition delay times of methane combustion, noting that Aramco-II-2016 was the only one that reproduced well the RCM measurements. In this section these four mechanisms are compared, using Figs. S8 to S11 in the 
Supplementary Material. These figures summarize the simulation and sensitivity analysis results in various intervals of temperature, pressure, equivalence ratio and diluent ratio in measurement categories ST without PRR, ST with PRR and RCM. The bottom of each figure shows the error function value $E$ for these four mechanisms, averaged for each interval. The upper four rows of panels plot the scaled normalized sensitivity coefficients, calculated by using each of the four mechanisms. The sensitivity coefficients are given for those 99 reactions for which the absolute scaled normalized sensitive coefficient is larger than 0.1 in any condition interval. The same reaction step is indicated with the same legend in each figure and each panel, which allows a transparent comparison of the sensitivity analysis results. Figures $\mathbf{S 8}$ to $\mathbf{S 1 1}$ have a common legend table after Fig. S11. It is immediately obvious, that even if the performance of the four mechanisms is very similar in some intervals, the indicated important reactions may be different.

Fig. S8 shows that the performance of the four mechanisms is similarly good for the ST with PRR measurements in the whole temperature range. Considering the ST without PRR measurements, all mechanisms have a good performance, except for SanDiego-2014 at low temperatures. For SanDiego-2014 at low temperatures, reaction $\mathrm{R} 2: \mathrm{CH}_{3}+\mathrm{O}_{2}=\mathrm{CH}_{2} \mathrm{O}+\mathrm{OH}$ has a considerable promoting effect on ignition (the scaled sensitivity coefficient is nearly -1 , see panel (a)) and this reaction has low sensitivity for the other mechanisms. Fig. S5(a) shows that the SanDiego-2014 mechanism tends to estimate shorter IDTs if the temperature is lower than 1400K. The rate coefficient of this reaction in SanDiego-2014 is much higher than in the other mechanisms (see Fig. 11(b)) in the whole temperature range. However, decreasing this rate coefficient alone does not improve the performance of the SanDiego-2014 mechanism at low temperatures.

Under high temperature conditions $(T>2200 \mathrm{~K})$, all the four mechanisms are relatively inaccurate. Reaction $\mathrm{R} 8: \mathrm{CH}_{3}+\mathrm{H}+\mathrm{M}=\mathrm{CH}_{4}+\mathrm{M}(\mathrm{LP})$ is the only reaction that has large sensitivity 
above $2200 \mathrm{~K}$, but much lower sensitivity under other conditions. The rate parameters of this reaction deserve a closer look.

Fig. S8(o) shows that only Aramco-II-2016 simulates well the low temperature RCM measurements. Aramco-II-2016 is different from the other three mechanisms, since the sensitivity analysis results show (see panel (i)) that four reactions, $\mathrm{CH}_{4}+\mathrm{O}=\mathrm{CH}_{3}+\mathrm{OH}(\mathrm{R} 11), \mathrm{CH}_{4}+\mathrm{OH}=$ $\mathrm{CH}_{3}+\mathrm{H}_{2} \mathrm{O}(\mathrm{R} 7), \mathrm{C}_{2} \mathrm{H}_{5} \mathrm{OH}+\mathrm{CH}_{3} \mathrm{O}_{2}=\mathrm{C}_{2} \mathrm{H}_{5} \mathrm{O}+\mathrm{CH}_{3} \mathrm{O}_{2} \mathrm{H}\left({ }^{*}\right)$, and $\mathrm{CH}_{3}+\mathrm{O}=\mathrm{CH}_{2} \mathrm{O}+\mathrm{H}$ are the main ignition promoting reactions under $\mathrm{RCM}$ conditions. Also, $\mathrm{HOCHO}+\mathrm{H}=>\mathrm{H}_{2}+\mathrm{CO}+\mathrm{OH}$ (*) is an important ignition hindering reaction in Aramco-II-2016. These reaction steps either do not exist in the other three mechanisms (indicated by asterisk), or have a minor role in them.

Regarding different pressure conditions, Fig. S9 shows that the four mechanisms reproduce well the shock tube experimental data, except for the SanDiego-2014 mechanism above 80 atm for the ST data, and the Aramco-II-2016 mechanism near 20 atm for all ST data. In ST measurements with PRR, Aramco-II-2016 has the poorest performance. Again, Aramco-II-2016 is the best performing mechanism at all pressures under RCM conditions.

Figures S10 and S11 present that the performance of the four mechanisms changes in good accordance with changing equivalence ratio and dilution, respectively. Figure $\mathbf{S 1 0}(\mathbf{m})$ shows that in the equivalence ratio range $[0.60,0.99)$, SanDiego-2014 is apparently better than the other mechanisms. According to Fig. S11(m), the errors of Aramco-II-2016 and SanDiego-214 are much higher than that of Caltech-2015, if the diluent ratio is less than 0.5. The obvious difference among all mechanisms is that the sensitivity coefficient of $\mathrm{CH}_{3}+\mathrm{CH}_{3}+\mathrm{M}=\mathrm{C}_{2} \mathrm{H}_{6}+\mathrm{M}$ is higher in Aramco-II-2016 than in Caltech-2015, and the origin of it is that Aramco-II-2016 uses higher rate coefficient for this reaction than the other mechanisms (see Fig. 14). 


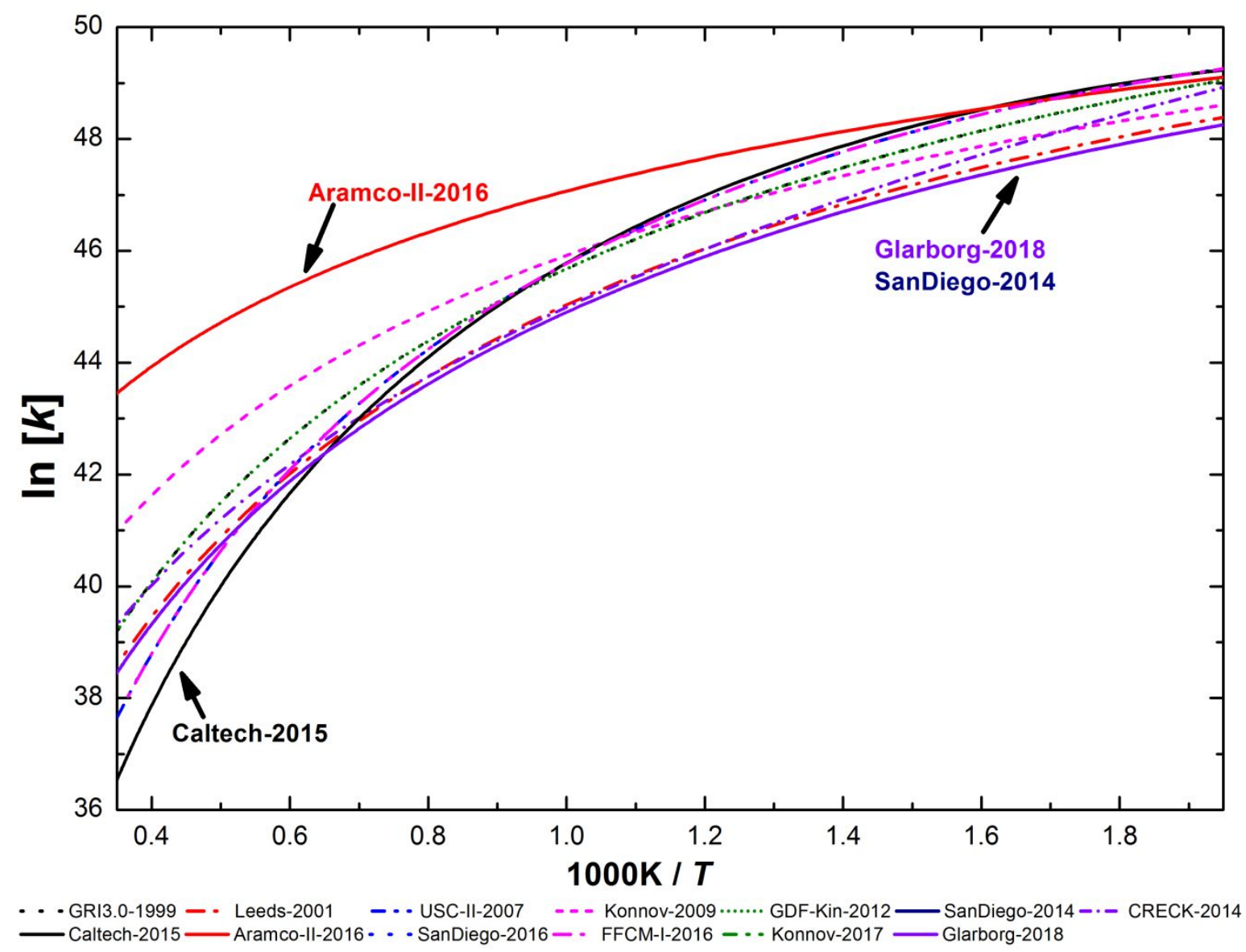

Figure. 14. Comparison of the rate coefficients for reaction $\mathrm{CH}_{3}+\mathrm{CH}_{3}+\mathrm{M}=\mathrm{C}_{2} \mathrm{H}_{6}+\mathrm{M}(\mathrm{M}=$ $\mathrm{N}_{2}$ ). The units of the rate coefficients are expressed in $\mathrm{cm}$, mol, $\mathrm{s}$. 


\section{Conclusion}

Methane is the main component of natural gas, which is a widely used clean fuel, thus accurate simulation of its combustion is of paramount importance. Furthermore, its kinetic mechanism is also an important part of the combustion mechanisms of larger hydrocarbons. Having reviewed the related experimental papers, large amount of measurements of ignition delay times in shock tubes (4939 data points in 574 datasets) and rapid compression machines (582/69) were collected from 73 publications. The initial mixtures included oxygen, diluent $\left(\mathrm{N}_{2}, \mathrm{Ar}, \mathrm{He}, \mathrm{CO}_{2}\right.$ or $\left.\mathrm{H}_{2} \mathrm{O}\right)$, and neat methane or blends of $\mathrm{CH}_{4}$ with $\mathrm{H}_{2}$ and/or $\mathrm{CO}$. The details of the experimental datasets are given in the Supplementary Material. All the experimental data were encoded in ReSpecTh Kinetics Data Format v2.3 (RKDF 2.3) XML files, which are freely available at the ReSpecTh Information Site ${ }^{5}$. From this site one can also download code Optima++ ${ }^{110}$, a simulation framework that allows convenient automatic testing of reaction mechanisms against large amount of experimental data by using simulation packages FlameMaster ${ }^{111}$ and OpenSMOKE++ ${ }^{112,113}$. The collected ignition delay data were used for mechanism comparison in this study, and these data files may also promote methane mechanism development studies in the future.

We found that 37 different ignition delay time (IDT) definitions have been applied in shock tube measurements. The corresponding IDT definitions were stored in the RKD data files and Optima++ can employ the appropriate IDT definition at the simulations. The only exception was when the experimental ignition delay time was determined based on the vibration relaxation of the produced CO, which would have required the inclusion of an additional detailed submodel, thus the related experimental data were omitted from the comparison.

The shock tube measurement data were published with or without measured pressure rise rate. These were considered as two separate categories of measurements in our investigations and in 
general the IDTs of the latter group could be reproduced better. When slightly increasing pressure was detected but neglected by the experimentalist, we categorized the reasons. For the RCM measurements, in the various papers we found several different handlings of heat loss during the compression period, and we recalculated it based on the nonreactive pressure-time histories whenever these raw data were available. The obtained revised volume-time profiles are published in the corresponding RKD files.

We selected 13 widely used methane combustion mechanisms and presented the ranges of conditions at which these mechanisms had been validated by the original authors. In this study all mechanisms were tested under much wider ranges of conditions. We compared four excited $\mathrm{OH}$ submechanisms and two excited $\mathrm{CH}$ submechanisms that have been published as parts of methane combustion mechanisms. The excited OH submechanism of Aramco-II-2016 could significantly improve the performance of several mechanisms, thus it was selected and coupled with those mechanisms that did not contain such a reaction block. Also, the excited $\mathrm{CH}$ submechanism of Aramco-II-2016 was used in a similar way for the related shock tube experiments.

Agreement between the experimental data and the simulation results was investigated using the mean squared and the mean signed errors. Furthermore, Pearson correlation coefficients were used to characterize the pairwise similarity of the simulation results obtained by the mechanisms. Whenever it was possible, the published experimental uncertainties were used for the calculation of the metrics above. In the lack of such information, the uncertainty of the ignition delay time was estimated from the published uncertainties of temperature and/or pressure using error propagation. Also, the statistical scatter of the data points in each data series was taken into account. The derived uncertainty of the experimental data was stored in the RKD data files. 
The results of mechanism comparison studies show that almost all mechanisms reproduced the high-temperature ignition delay times well, while ignition delay times measured in shock tubes and rapid compression machines at low temperatures (below $1000 \mathrm{~K}$ ) could also be wellreproduced by several mechanisms. It should be noted that Olm et al. ${ }^{1} 2$ excluded the low temperature $(T<1000 \mathrm{~K}) \mathrm{H}_{2}$ and $\mathrm{H}_{2} / \mathrm{CO}$ shock tube ignition delay data without measured pressure-time profiles since the mechanisms could reproduce these data poorly. However, in the present work we found that most mechanisms were able to give reasonable prediction of even the low temperature ignition delay times. The error function values of Aramco-II-2016 and Glarborg2018 were lower than $E=9$ (i.e. agreement within $3 \sigma$ on average) for the low initial temperature $(T$ $<900 \mathrm{~K})$ shock tube measurements. On the other hand, almost half of the mechanisms could reproduce the long ignition delays $\left(>10^{5} \mu \mathrm{s}\right)$ measured in shock tubes accurately.

The performance of the mechanisms was investigated in various ranges of temperature, pressure, equivalence ratio and diluent ratio. Four mechanisms, Aramco-II-2016, Caltech-2015, Glarborg2018 and SanDiego-2014 proved to be generally the best mechanisms, and additionally AramcoII-2016 had the smallest prediction error under RCM conditions. We recommend Aramco-II-2016 as the most robust mechanism as it performs reliably under wide range of conditions. However, it does not mean that Aramco-II-2016 has the best performance under all conditions, since for example Caltech-2015 has the lowest error in the initial temperature range 1300-1900 K. Therefore, if an accurate methane combustion mechanism is needed under a specific range of conditions, it can be selected based on the content of Figs. 5 to 8 .

Local sensitivity analysis was carried out for the best four mechanisms. The 15 most sensitive reactions of each mechanism in each measurement category were identified and compared. For high temperature ignitions, the results of sensitivity analysis of the best performing mechanisms 
were similar and the rate coefficients of the most sensitive reactions of all the four mechanisms were close to each other. The only exception was reaction $\mathrm{CH}_{3}+\mathrm{O}_{2}=\mathrm{CH}_{2} \mathrm{O}+\mathrm{OH}$, which was highly sensitive according to all mechanisms, but used with very different rate parameters. In the case of RCM measurements, there is an inconsistency among the sensitivity analysis results obtained for the various mechanisms. The sensitivity analysis results of RCM simulations show that the rate parameters of reactions involving peroxides, $\mathrm{HO}_{2}$ and $\mathrm{H}_{2} \mathrm{O}_{2}$ have to be known more accurately in order to improve the performance of the mechanisms at low temperatures.

\section{ASSOCIATED CONTENT}

The following files are available free of charge.

Lists for the details of all collected experimental data collected in this study, method for deriving experimental IDT uncertainty, comparison results for OHEX submechanisms, relevant figures and tables for sensitivity analysis result. (IDT_R1_Supp1_v01.docx)

Detailed estimated standard deviations for some experimental data points used for mechanism comparison (IDT_R1_Supp2_v01.txt)

\section{AUTHOR INFORMATION}

\section{Full contact information for authors}

Peng Zhang

Institution: Institute of Chemistry, ELTE Eötvös Loránd University

City: Budapest 
2

3

4

5

6

8

9

10

11

12

Postal code: 1117

Country: Hungary

ORCID ID: https://orcid.org/0000-0002-6376-1232

* István Gy. Zsély (E-mail address: zsigy@,chem.elte.hu)

Institution: Institute of Chemistry, ELTE Eötvös Loránd University

City: Budapest

Postal code: 1117

Country: Hungary

ORCID ID: https://orcid.org/0000-0002-6512-670X

Viktor Samu

Institution: Institute of Chemistry, ELTE Eötvös Loránd University

City: Budapest

Postal code: 1117

Country: Hungary

ORCID ID: https://orcid.org/0000-0002-5130-8174

Tibor Nagy

Institution: Institute of Materials and Environmental Chemistry (IMEC), Research Centre for Natural Sciences (RCNS), Eötvös Loránd Research Network 
City: Budapest

Postal code: 1117

Country: Hungary

ORCID ID: https://orcid.org/0000-0002-1412-3007

Tamás Turányi

Institution: Institute of Chemistry, ELTE Eötvös Loránd University

City: Budapest

Postal code: 1117

Country: Hungary

ORCID ID: https://orcid.org/0000-0002-1461-165X

\section{Corresponding Author}

* István Gy. Zsély (E-mail address: zsigy@chem.elte.hu)

\section{Author Contributions}

The manuscript was written through contributions from all authors. All authors have given approval to the final version of the manuscript.

\section{Funding Sources}


The authors acknowledge the financial support of the Hungarian National Research, Development and Innovation Office via NKFIH grants KH126515 and FK134332. Mr. Peng Zhang was sponsored by China Scholarship Council.

\section{Acknowledgements}

The authors thank the continuous support of Mr. Máté Papp and Ms. Ágota Busai with code Optima++, and are indebted to Drs. Sander Gersen and Yi Yu for providing their large amount of experimental data. The authors are also grateful for the supportive comments of the partners in COST collaboration CM1404 (SmartCats). 


\section{REFERENCES}

(1) Olm, C.; Zsély, I. G.; Pálvölgyi, R.; Varga, T.; Nagy, T.; Curran, H. J.; Turányi, T.

Comparison of the Performance of Several Recent Hydrogen Combustion Mechanisms.

Combust. Flame 2014, 161 (9), 2219-2234.

https://doi.org/10.1016/j.combustflame.2014.03.006.

(2) Olm, C.; Zsély, I. G.; Varga, T.; Curran, H. J.; Turányi, T. Comparison of the

Performance of Several Recent Syngas Combustion Mechanisms. Combust Flame 2015, 162 (5), 1793-1812. https://doi.org/10.1016/j.combustflame.2014.12.001.

(3) Olm, C.; Varga, T.; Valkó, É.; Curran, H. J.; Turányi, T. Uncertainty Quantification of a Newly Optimized Methanol and Formaldehyde Combustion Mechanism. Combust Flame 2017, 186, 45-64. https://doi.org/10.1016/j.combustflame.2017.07.029.

(4) Olm, C.; Varga, T.; Valkó, É.; Hartl, S.; Hasse, C.; Turányi, T. Development of an Ethanol Combustion Mechanism Based on a Hierarchical Optimization Approach. Int J Chem Kinet 2016, 48 (8), 423-441. https://doi.org/10.1002/kin.20998.

(5) ReSpecTh Information System, (http://respecth.hu/).

(6) Lu, T.; Law, C. K. Toward Accommodating Realistic Fuel Chemistry in Large-Scale Computations. Prog Energy Combust Sci 2009, 35, 192-215. https://doi.org/10.1016/j.pecs.2008.10.002.

(7) Jach, A.; Cislak, I.; Rudy, W.; Pekalski, A. A.; Teodorczyk, A. Comparison of the Performance of Several Hydrocarbon Combustion Mechanisms in Reproduction of 
Ignition Delay Times of C1-C4 Hydrocarbons. Proc 8th Eur. Combust Meet. 2017, 15131518.

(8) Baigmohammadi, M.; Patel, V.; Martinez, S.; Panigrahy, S.; Ramalingam, A.; Burke, U.; Somers, K. P.; Heufer, K. A.; Pekalski, A.; Curran, H. J. A Comprehensive Experimental and Simulation Study of Ignition Delay Time Characteristics of Single Fuel C1-C2 Hydrocarbons over a Wide Range of Temperatures, Pressures, Equivalence Ratios, and Dilutions. Energy \& Fuels 2020, 34 (3), 3755-3771. https://doi.org/10.1021/acs.energyfuels.9b04139.

(9) Jach, A.; Rudy, W.; Pękalski, A.; Teodorczyk, A. Assessment of Detailed Reaction Mechanisms for Reproduction of Ignition Delay Times of C2-C6 Alkenes and Acetylene. Combust. Flame 2019, 206, 37-50.

https://doi.org/https://doi.org/10.1016/j.combustflame.2019.04.022.

(10) Lee, H. C.; Mohamad, A. A.; Jiang, L. Y. Comprehensive Comparison of Chemical Kinetics Mechanisms for Syngas/Biogas Mixtures. Energy \& Fuels 2015, 29 (9), 61266145. https://doi.org/10.1021/acs.energyfuels.5b01136.

(11) Samu, V.; Varga, T.; Rahinov, I.; Cheskis, S.; Turányi, T. Determination of Rate Parameters Based on $\mathrm{NH}_{2}$ Concentration Profiles Measured in Ammonia-Doped MethaneAir Flames. Fuel 2018, 212, 679-683. https://doi.org/10.1016/j.fuel.2017.10.019.

(12) Kovács, M.; Papp, M.; Zsély, I. G.; Turányi, T. Determination of Rate Parameters of Key N/H/O Elementary Reactions Based on H2/O2/NOx Combustion Experiments. Fuel 2020, 264, 116720. https://doi.org/https://doi.org/10.1016/j.fuel.2019.116720. 
(13) Kawka, L.; Juhász, G.; Papp, M.; Nagy, T.; Gy. Zsély, I.; Turányi, T. Comparison of Detailed Reaction Mechanisms for Homogeneous Ammonia Combustion. Zeitscrift für Phys. Chemie 2020, 234, 1329-1357.

(14) Turányi, T.; Nagy, T.; Zsély, I. G.; Cserháti, M.; Varga, T.; Szabó, B. T.; Sedyó, I.; Kiss, P. T.; Zempléni, A.; Curran, H. J. Determination of Rate Parameters Based on Both Direct and Indirect Measurements. Int J Chem Kinet 2012, 44 (5), 284-302. https://doi.org/10.1002/kin.20717.

(15) Zsély, I. G.; Varga, T.; Nagy, T.; Cserháti, M.; Turányi, T.; Peukert, S.; Braun-Unkhoff, M.; Naumann, C.; Riedel, U. Determination of Rate Parameters of Cyclohexane and 1Hexene Decomposition Reactions. Energy 2012, 43, 85-93. https://doi.org/10.1016/j.energy.2012.01.004.

(16) Varga, T.; Zsély, I. G.; Turányi, T.; Bentz, T.; Olzmann, M. Kinetic Analysis of Ethyl Iodide Pyrolysis Based on Shock Tube Measurements. Int J Chem Kinet 2014, 46, 295304. https://doi.org/10.1002/kin.20829.

(17) Varga, T.; Nagy, T.; Olm, C.; Zsély, I. G.; Pálvölgyi, R.; Valkó, É.; Vincze, G.; Cserháti, M.; Curran, H. J.; Turányi, T. Optimization of a Hydrogen Combustion Mechanism Using Both Direct and Indirect Measurements. Proc Combust Inst 2015, 35 (1), 589-596. https://doi.org/10.1016/j.proci.2014.06.071.

(18) Samu, V.; Varga, T.; Brezinsky, K.; Turányi, T. Investigation of Ethane Pyrolysis and Oxidation at High Pressures Using Global Optimization Based on Shock Tube Data. Proc Combust Inst 2017, 36, 691-698. https://doi.org/10.1016/j.proci.2016.05.039. 
(19) Buczkó, N. A.; Varga, T.; Zsély, I. G.; Turányi, T. Formation of NO in High-Temperature $\mathrm{N}_{2} / \mathrm{O}_{2} / \mathrm{H}_{2} \mathrm{O}$ Mixtures: Re-Evaluation of Rate Coefficients. Energy and Fuels 2018, 32 (10), 10114-10120. https://doi.org/10.1021/acs.energyfuels.8b00999.

(20) Nagy, T.; Turányi, T. Minimal Spline Fit: A Model-Free Method for Determining Statistical Noise of Experimental Data Series. In Proceedings of the European Combustion Meeting; 2021.

(21) Zhang, Z.; Hu, E.; Pan, L.; Chen, Y.; Gong, J.; Huang, Z. Shock-Tube Measurements and Kinetic Modeling Study of Methyl Propanoate Ignition. Energy \& Fuels 2014, 28 (11), 7194-7202. https://doi.org/10.1021/ef501527z.

(22) Smith, G. P.; Golden, D. M.; Frenklach, M.; Moriarty, N. W.; Eiteneer, B.; Goldenberg, M.; Bowman, C. T.; Hanson, R. K.; Song, S.; Gardiner Jr, W. C.; Lissianski, V. V; Qin, Z. GRI-Mech 3.0, 1999, (http://www.me.berkeley.edu/gri_mech/).

(23) Hughes, K. J.; Turányi, T.; Clague, A. R.; Pilling, M. J. Development and Testing of a Comprehensive Chemical Mechanism for the Oxidation of Methane. Int J Chem Kinet 2001, 33, 513-538. https://doi.org/10.1002/kin.1048.

(24) Wang, H.; You, X.; Joshi, A. V; Davis, S. G.; Laskin, A.; Egolfopoulos, F.; Law, C. K. USC Mech Version II. High-temperature combustion reaction model of $\mathrm{H} 2 / \mathrm{CO} / \mathrm{C} 1-\mathrm{C} 4$ compounds, 2007, (http://ignis.usc.edu/USC_Mech_II.htm).

(25) Konnov, A. A. Implementation of the NCN Pathway of Prompt-NO Formation in the Detailed Reaction Mechanism. Combust Flame 2009, 156, 2093-2105. https://doi.org/10.1016/j.combustflame.2009.03.016. 
(26) Yu, Y. Cinétique d'auto-Inflammation de Carburants Gazeux a Haute Pression: Etude Experimentale et de Modelisation, L’Universite des Sciences et Technologies de Lille, 2012.

(27) Mechanical and Aerospace Engineering (Combustion Research) University of California at San Diego. Chemical-kinetic mechanisms for combustion applications, San Diego Mechanism, 2014, (https://web.eng.ucsd.edu/mae/groups/combustion/mechanism.html).

(28) CRECK modeling Group C1-C3 kinetic mechanism Version 1412, 2014, (http://creckmodeling.chem.polimi.it/index.php).

(29) The FORCE - California Institute of Technology. CaltechMech detailed kinetic model (version 2.3), 2015, (https://www.theforce.caltech.edu/CaltechMech/).

(30) NUI Galway Combustion Chemistry Centre. AramcoMech 2.0, 2017, (http://www.nuigalway.ie/combustionchemistrycentre/mechanismdownloads/aramcomech 20/).

(31) Mechanical and Aerospace Engineering (Combustion Research) University of California at San Diego. Chemical-kinetic mechanisms for combustion applications, San Diego Mechanism, 2016, (https://web.eng.ucsd.edu/mae/groups/combustion/mechanism.html).

(32) Smith, G. P.; Tao, Y.; Wang, H. Foundational fuel chemistry model Version 1.0, 2016, (https://web.stanford.edu/group/haiwanglab/FFCM1/pages/FFCM1.html).

(33) Christensen, M.; Konnov, A. A. Laminar Burning Velocity of Diacetyl + Air Flames. Further Assessment of Combustion Chemistry of Ketene. Combust. Flame 2017, 178, 97110. https://doi.org/https://doi.org/10.1016/j.combustflame.2016.12.026. 
(34) Glarborg, P.; Miller, J. A.; Ruscic, B.; Klippenstein, S. J. Modeling Nitrogen Chemistry in Combustion. Prog. Energy Combust. Sci. 2018, 67, 31-68.

https://doi.org/https://doi.org/10.1016/j.pecs.2018.01.002.

(35) Seery, D. J.; Bowman, C. T. An Experimental and Analytical Study of Methane Oxidation behind Shock Waves. Combust Flame 1970, 14, 34-47. https://doi.org/10.1016/s00102180(70)80008-6.

(36) Spadaccini, L. J.; Colket, M. B. Ignition Delay Characteristics of Methane Fuels. Prog Energy Combust Sci 1994, 20 (5), 431-460. https://doi.org/10.1016/0360-1285(94)900116.

(37) Asaba, T.; Yoneda, K.; Kakihara, N.; Hikita, T. A Shock Tube Study of Ignition of Methane-Oxygen Mixtures. Symp Combust 1963, 9, 193-200. https://doi.org/10.1016/b978-1-4832-2759-7.50028-5.

(38) Burcat, A.; Scheller, K.; Lifshitz, A. Shock-Tube Investigation of Comparative Ignition Delay Times for $\mathrm{C}_{1}-\mathrm{C}_{5}$ Alkanes. Combust Flame 1971, 16, 29-33. https://doi.org/10.1016/s0010-2180(71)80007-x.

(39) Cooke, D. F.; Williams, A. Shock-Tube Studies of the Ignition and Combustion of Ethane and Slightly Rich Methane Mixtures with Oxygen. Symp Combust 1971, 13, 757-766. https://doi.org/10.1016/s0082-0784(71)80078-4.

(40) Cooke, D. F.; Williams, A. Shock Tube Studies of Methane and Ethane Oxidation. Combust Flame 1975, 24, 245-256. https://doi.org/10.1016/0010-2180(75)90154-6. 
(41) Dabora, E. K. Effect of $\mathrm{NO}_{2}$ on the Ignition Delay of $\mathrm{CH}_{4}$-Air Mixtures. Combust Flame 1975, 24, 181-184. https://doi.org/10.1016/0010-2180(75)90146-7.

(42) de Vries, J.; Petersen, E. L. Autoignition of Methane-Based Fuel Blends under Gas Turbine Conditions. Proc Combust Inst 2007, 31, 3163-3171. https://doi.org/10.1016/j.proci.2006.07.206.

(43) Donohoe, N.; Heufer, A.; Metcalfe, W. K.; Curran, H. J.; Davis, M. L.; Mathieu, O.; Plichta, D.; Morones, A.; Petersen, E. L.; Güthe, F. Ignition Delay Times, Laminar Flame Speeds, and Mechanism Validation for Natural Gas/Hydrogen Blends at Elevated Pressures. Combust Flame 2014, 161, 1432-1443. https://doi.org/10.1016/j.combustflame.2013.12.005.

(44) Eubank, C. S.; Rabinowitz, M. J.; Gardiner Jr, W. C.; Zellner, R. E. Shock-Initiated Ignition of Natural Gas-Air Mixtures. Symp Combust 1981, 18, 1767-1774. https://doi.org/10.1016/s0082-0784(81)80181-6.

(45) Frenklach, M.; Bornside, D. E. Shock-Initiated Ignition in Methane-Propane Mixtures. Combust Flame 1984, 56, 1-27. https://doi.org/10.1016/0010-2180(84)90002-6.

(46) Higgin, R. M. R.; Williams, A. A Shock-Tube Investigation of the Ignition of Lean Methane and n-Butane Mixtures with Oxygen. Symp Combust 1969, 12, 579-590. https://doi.org/10.1016/s0082-0784(69)80439-x.

(47) Brabbs, T. A.; Robertson, T. F. Methane oxidation behind reflected shock waves -Ignition delay times measured by pressure and flame band emission. NASA Technical Memorandum 87268, 1986, (https://ntrs.nasa.gov/citations/19860012164). 
(48) Huang, J.; Hill, P. G.; Bushe, W. K.; Munshi, S. R. Shock-Tube Study of Methane Ignition under Engine-Relevant Conditions: Experiments and Modeling. Combust Flame 2004, 136, 25-42. https://doi.org/10.1016/j.combustflame.2003.09.002.

(49) Krishnan, K. S.; Ravikumar, R.; Bhaskaran, K. A. Experimental and Analytical Studies on the Ignition of Methane-Acetylene Mixtures. Combust Flame 1983, 49, 41-50. https://doi.org/10.1016/0010-2180(83)90149-9.

(50) Lifshitz, A.; Scheller, K.; Burcat, A.; Skinner, G. B. Shock-Tube Investigation of Ignition in Methane-Oxygen-Argon Mixtures. Combust Flame 1971, 16, 311-321. https://doi.org/10.1016/s0010-2180(71)80102-5.

(51) Slack, M. W.; Grillo, A. R. Shock Tube Investigation of Methane-Oxygen Ignition Sensitized by $\mathrm{NO}_{2}$. Combust Flame 1981, 40, 155-172. https://doi.org/10.1016/00102180(81)90120-6.

(52) Tang, C.; Wei, L.; Zhang, J.; Man, X.; Huang, Z. Shock Tube Measurements and Kinetic Investigation on the Ignition Delay Times of Methane/Dimethyl Ether Mixtures. Energy Fuels 2012, 26, 6720-6728. https://doi.org/10.1021/ef301339m.

(53) Tsuboi, T.; Wagner, H. G. Homogeneous Thermal Oxidation of Methane in Reflected Shock Waves. Symp Combust 1974, 15, 883-890. https://doi.org/10.1016/s00820784(75)80355-9.

(54) Tsuboi, T.; Katoh, M. On Induction Periods of Shock-Heated Methane-Oxygen-ArgonMixtures. Jpn. J. Appl. Phys. 1985, 24 (12), 1697-1702. https://doi.org/10.1143/jjap.24.1697. 
(55) Zhang, Y.; Jiang, X.; Wei, L.; Zhang, J.; Tang, C.; Huang, Z. Experimental and Modeling Study on Auto-Ignition Characteristics of Methane/Hydrogen Blends under Engine Relevant Pressure. Int J Hydrog. Energy 2012, 37, 19168-19176.

https://doi.org/10.1016/j.ijhydene.2012.09.056.

(56) Zhukov, V. P.; Sechenov, V. A.; Starikovskii, A. Y. Spontaneous Ignition of Methane-Air Mixtures in a Wide Range of Pressures. Combust Explos Shock Waves 2003, 39, 487-495. https://doi.org/10.1023/A:1026186231905.

(57) Bowman, C. T. Non-Equilibrium Radical Concentrations in Shock-Initiated Methane Oxidation. Symp Combust 1975, 15 (1), 869-882. https://doi.org/10.1016/S00820784(75)80354-7.

(58) Lamoureux, N.; Paillard, C. E.; Vaslier, V. Low Hydrocarbon Mixtures Ignition Delay Times Investigation behind Reflected Shock Waves. Shock Waves 2002, 11, 309-322. https://doi.org/10.1007/s001930100108.

(59) Cheng, R. K.; Oppenheim, A. K. Autoignition in Methane-Hydrogen Mixtures. Combust Flame 1984, 58, 125-139. https://doi.org/10.1016/0010-2180(84)90088-9.

(60) Hidaka, Y.; Sato, K.; Henmi, Y.; Tanaka, H.; Inami, K. Shock-Tube and Modeling Study of Methane Pyrolysis and Oxidation. Combust Flame 1999, 118, 340-358. https://doi.org/10.1016/s0010-2180(99)00010-3.

(61) Bowman, C. T. An Experimental and Ananytical Investigation of the High Temperature Exidation Mechanisms of Hydrocarbon Fuels. Combust Sci Technol 1970, 2, 161-172. https://doi.org/10.1080/00102207008952244. 
(62) Bozhenkov, S. A.; Starikovskaia, S. M.; Starikovskii, A. Y. Nanosecond Gas Discharge Ignition of $\mathrm{H}_{2}-$ and $\mathrm{CH}_{4}-$ Containing Mixtures. Combust Flame 2003, 133, 133-146. https://doi.org/10.1016/S0010-2180(02)00564-3.

(63) Burke, U.; Somers, K. P.; O’Toole, P.; Zinner, C. M.; Marquet, N.; Bourque, G.; Petersen, E. L.; Metcalfe, W. K.; Serinyel, Z.; Curran, H. J. An Ignition Delay and Kinetic Modeling Study of Methane, Dimethyl Ether, and Their Mixtures at High Pressures. Combust Flame 2015, 162, 315-330. https://doi.org/10.1016/j.combustflame.2014.08.014.

(64) Hu, E.; Li, X.; Meng, X.; Chen, Y.; Cheng, Y.; Xie, Y.; Huang, Z. Laminar Flame Speeds and Ignition Delay Times of Methane-Air Mixtures at Elevated Temperatures and Pressures. Fuel 2015, 158, 1-10. https://doi.org/10.1016/j.fuel.2015.05.010.

(65) Jachimowski, C. J. Kinetics of Oxygen Atom Formation during the Oxidation of Methane behind Shock Waves. Combust Flame 1974, 23, 233-248. https://doi.org/10.1016/00102180(74)90061-3.

(66) Kistiakowsky, G. B.; Willard Richards, L. Emission of Vacuum Ultraviolet Radiation from the Acetylene-Oxygen and the Methane-Oxygen Reactions in Shock Waves. J Chem Phys 1962, 36 (7), 1707-1714. https://doi.org/10.1063/1.1701256.

(67) Levy, Y.; Olchanski, E.; Sherbaum, V.; Erenburg, V.; Burcat, A. Shock-Tube Ignition Study of Methane in Air and Recirculating Gases Mixtures. J Propul Power 2006, 22 (3), 669-676. https://doi.org/10.2514/1.12511. 
(68) Mathieu, O.; Pemelton, J. M.; Bourque, G.; Petersen, E. L. Shock-Induced Ignition of Methane Sensitized by $\mathrm{NO}_{2}$ and $\mathrm{N}_{2} \mathrm{O}$. Combust Flame 2015, 162, 3053-3070. https://doi.org/10.1016/j.combustflame.2015.03.024.

(69) Beerer, D. J.; McDonell, V. G. An Experimental and Kinetic Study of Alkane Autoignition at High Pressures and Intermediate Temperatures. Proc Combust Inst 2011, 33, 301-307. https://doi.org/10.1016/j.proci.2010.05.015.

(70) Petersen, E. L.; Davidson, D. F.; Hanson, R. K. Kinetics Modeling of Shock-Induced Ignition in Low-Dilution $\mathrm{CH}_{4} / \mathrm{O}_{2}$ Mixtures at High Pressures and Intermediate Temperatures. Combust Flame 1999, 117 (1-2), 272-290. https://doi.org/10.1016/s00102180(98)00111-4.

(71) Petersen, E. L.; Davidson, D. F.; Hanson, R. K. Ignition Delay Times of Ram Accelerator $\mathrm{CH}_{4} / \mathrm{O}_{2} /$ Diluent Mixtures. J. Propuls. Power 1999, 15, 82-91. https://doi.org/10.2514/2.5394.

(72) Petersen, E. L.; Röhrig, M.; Davidson, D. F.; Hanson, R. K.; Bowman, C. T. HighPressure Methane Oxidation behind Reflected Shock Waves. Proc. Combust. Inst. 1996, 26, 799-806. https://doi.org/10.1016/s0082-0784(96)80289-x.

(73) Grillo, A.; Slack, M. W. Shock Tube Study of Ignition Delay Times in Methane - Oxygen - Nitrogen - Argon Mixtures. Combust Flame 1976, 27, 377-381. https://doi.org/10.1016/0010-2180(76)90042-0.

(74) Huang, J.; Bushe, W. K. Experimental and Kinetic Study of Autoignition in Methane/Ethane/Air and Methane/Propane/Air Mixtures under Engine-Relevant 
Conditions. Combust Flame 2006, 144, 74-88.

https://doi.org/10.1016/j.combustflame.2005.06.013.

(75) Suzuki, A.; Inomata, T.; Jinno, H.; Moriwaki, T. Effect of Bromotrifluoromethane on the Ignition in Methane and Ethane-Oxygen-Argon Mixtures behind Shock Waves. Bull Chem Soc Jpn 1991, 64, 3345-3354. https://doi.org/10.1246/bcsj.64.3345.

(76) Takahashi, K.; Inomata, T.; Moriwaki, T.; Okazaki, S. The Addition Effect of $\mathrm{CH}_{3} \mathrm{Br}$ and $\mathrm{CH}_{3} \mathrm{Cl}$ on Ignition of $\mathrm{CH}_{4}$ by Shock Wave. Bull Chem Soc Jpn 1988, 61, 3307-3313. https://doi.org/10.1246/bcsj.61.3307.

(77) Walker, B. C. Shock-Tube Investigation of Ignition Delay Times of Blends of Methane and Ethane with Oxygen, B.S. University of Tennessee, 2000.

(78) Huang, J.; Bushe, W. K.; Hill, P. G.; Munshi, S. R. Experimental and Kinetic Study of Shock Initiated Ignition in Homogeneous Methane-Hydrogen-Air Mixtures at EngineRelevant Conditions. Int J Chem Kinet 2006, 38, 221-233. https://doi.org/10.1002/kin.20157.

(79) Petersen, E. L.; Hall, J. M.; Smith, S. D.; de Vries, J.; Amadio, A. R.; Crofton, M. W. Ignition of Lean Methane-Based Fuel Blends at Gas Turbine Pressures. J Eng Gas Turbines Power 2007, 129, 937-944. https://doi.org/10.1115/1.2720543.

(80) Aul, C. J.; Metcalfe, W. K.; Burke, S. M.; Curran, H. J.; Petersen, E. L. Ignition and Kinetic Modeling of Methane and Ethane Fuel Blends with Oxygen: A Design of Experiments Approach. Combust Flame 2013, 160, 1153-1167. https://doi.org/10.1016/j.combustflame.2013.01.019. 
(81) Yu, C. L.; Wang, C.; Frenklach, M. Chemical Kinetics of Methyl Oxidation by Molecular Oxygen. J Phys Chem 1995, 99, 14377-14387. https://doi.org/10.1021/j100039a027.

(82) Dean, A. M.; Kistiakowsky, G. B. Oxidation of Carbon Monoxide/Methane Mixtures in Shock Waves. J Chem Phys 1971, 54 (4), 1718-1725. https://doi.org/:10.1063/1.1675077.

(83) Chaumeix, N.; Pichon, S.; Lafosse, F.; Paillard, C. E. Role of Chemical Kinetics on the Detonation Properties of Hydrogen /Natural Gas/Air Mixtures. Int J Hydrog. Energy 2007, 32 (13), 2216-2226. https://doi.org/10.1016/j.ijhydene.2007.04.008.

(84) Heufer, K. A.; Olivier, H. Determination of Ignition Delay Times of Different Hydrocarbons in a New High Pressure Shock Tube. Shock Waves 2010, 20, 307-316. https://doi.org/10.1007/s00193-010-0262-2.

(85) Seery, D. J.; Bowman, C. T. A Shock Tube Study of Methane Oxidation. Div Fuel Chem $1967,11(4), 82-95$.

(86) Hidaka, Y.; Nagayama, M.; Suga, M. The Application of a Quadrupole Mass Spectrometer to a Study of Methane Oxidation in Shock Waves. Bull Chem Soc Jpn 1978, 51 (6), 1644-1659. https://doi.org/10.1246/bcsj.51.1659.

(87) Skinner, G. B.; Ruehrwein, R. A. Shock Tube Studies on the Pyrolysis and Oxidation of Methane. J Phys Chem 1959, 63, 1736-1742. https://doi.org/10.1021/j150580a040.

(88) Gurentsov, E. V; Divakov, O. G.; Eremin, A. V. Ignition of Multicomponent Hydrocarbon/Air Mixtures behind Shock Waves. High Temp. 2002, 40, 379-386. https://doi.org/10.1023/A:1016012007493. 
(89) Koroglu, B.; Pryor, O. M.; Lopez, J.; Nash, L.; Vasu, S. S. Shock Tube Ignition Delay Times and Methane Time-Histories Measurements during Excess $\mathrm{CO}_{2}$ Diluted OxyMethane Combustion. Combust Flame 2016, 164, 152-163. https://doi.org/10.1016/j.combustflame.2015.11.011.

(90) Zeng, W.; Ma, H.; Liang, Y.; Hu, E. Experimental and Modeling Study on Effects of $\mathrm{N}_{2}$ and $\mathrm{CO}_{2}$ on Ignition Characteristics of Methane/Air Mixture. J. Adv. Res. 2015, 6, 189201. https://doi.org/10.1016/j.jare.2014.01.003.

(91) Zhang, Y.; Huang, Z.; Wei, L.; Niu, S. Experimental and Kinetic Study on Ignition Delay Times of Methane/Hydrogen/Oxygen/Nitrogen Mixtures by Shock Tube. Chinese Sci. Bull. 2011, 56 (26), 2853-2861. https://doi.org/10.1007/s11434-011-4635-4.

(92) Chang, E. J. Shock Tube Experiments for the Development and Validation of Models of Hydrocarbon Combustion, Stanford University, 1995.

(93) Merhubi, H. El; Kéromnès, A.; Catalano, G.; Lefort, B.; Moyne, L. Le. A High Pressure Experimental and Numerical Study of Methane Ignition. Fuel 2016, 177, 164-172. https://doi.org/https://doi.org/10.1016/j.fuel.2016.03.016.

(94) Leschevich, V. V; Martynenko, V. V; Penyazkov, O. G.; Sevrouk, K. L.; Shabunya, S. I. Auto-Ignitions of a Methane/Air Mixture at High and Intermediate Temperatures. Shock Waves 2016, 26, 657-672. https://doi.org/10.1007/s00193-016-0665-9.

(95) Deng, F.; Yang, F.; Zhang, P.; Pan, Y.; Zhang, Y.; Huang, Z. Ignition Delay Time and Chemical Kinetic Study of Methane and Nitrous Oxide Mixtures at High Temperatures. Energy Fuels 2016, 30, 1415-1427. https://doi.org/10.1021/acs.energyfuels.5b02581. 
(96) Deng, F.; Yang, F.; Zhang, P.; Pan, Y.; Bugler, J.; Curran, H. J.; Zhang, Y.; Huang, Z. Towards a Kinetic Understanding of the $\mathrm{NO}_{\mathrm{x}}$ Promoting-Effect on Ignition of Coalbed Methane: A Case Study of Methane/Nitrogen Dioxide Mixtures. Fuel 2016, 181, 188198. https://doi.org/https://doi.org/10.1016/j.fuel.2016.04.090.

(97) Mathieu, O.; Kopp, M. M.; Petersen, E. L. Shock-Tube Study of the Ignition of MultiComponent Syngas Mixtures with and without Ammonia Impurities. Proc Combust Inst 2013, 34, 3211-3218. https://doi.org/10.1016/j.proci.2012.05.008.

(98) Pryor, O.; Barak, S.; Koroglu, B.; Ninnemann, E.; Vasu, S. S. Measurements and Interpretation of Shock Tube Ignition Delay Times in Highly $\mathrm{CO}_{2}$ Diluted Mixtures Using Multiple Diagnostics. Combust. Flame 2017, 180, 63-76. https://doi.org/10.1016/j.combustflame.2017.02.020.

(99) Liu, Y.; Zou, C.; Cheng, J.; Jia, H.; Zheng, C. Experimental and Numerical Study of the Effect of $\mathrm{CO}_{2}$ on the Ignition Delay Times of Methane under Different Pressures and Temperatures. Energy \& Fuels 2018, 32 (10), 10999-11009. https://doi.org/10.1021/acs.energyfuels.8b02443.

(100) Shao, J.; Davidson, D. F.; Hanson, R. K. A Shock Tube Study of Ignition Delay Times in Diluted Methane, Ethylene, Propene and Their Blends at Elevated Pressures. Fuel 2018, 225, 370-380. https://doi.org/https://doi.org/10.1016/j.fuel.2018.03.146.

(101) Zhang, Y.; Huang, Z.; Wei, L.; Zhang, J.; Law, C. K. Experimental and Modeling Study on Ignition Delays of Lean Mixtures of Methane, Hydrogen, Oxygen, and Argon at Elevated Pressures. Combust Flame 2012, 159 (3), 918-931. https://doi.org/10.1016/j.combustflame.2011.09.010. 
(102) Herzler, J.; Naumann, C. Shock-Tube Study of the Ignition of Methane/Ethane/Hydrogen Mixtures with Hydrogen Contents from 0\% to 100\% at Different Pressures. Proc Combust Inst 2009, 32, 213-220. https://doi.org/10.1016/j.proci.2008.07.034.

(103) Krishnan, S.; Ravikumar, R. Ignition Delay of Methane in Reflected Shock Waves. Combust. Sci. Technol. 1980, 24, 239-245. https://doi.org/10.1080/00102208008952443.

(104) Ramalingam, A.; Zhang, K.; Dhongde, A.; Virnich, L.; Sankhla, H.; Curran, H.; Heufer, A. An RCM Experimental and Modeling Study on $\mathrm{CH}_{4}$ and $\mathrm{CH}_{4} / \mathrm{C}_{2} \mathrm{H}_{6}$ Oxidation at Pressures up to 160 Bar. Fuel 2017, 206, 325-333. https://doi.org/10.1016/j.fuel.2017.06.005.

(105) Hashemi, H.; Christensen, J. M.; Gersen, S.; Levinsky, H.; Klippenstein, S. J.; Glarborg, P. High-Pressure Oxidation of Methane. Combust Flame 2016, 172, 349-364. https://doi.org/10.1016/j.combustflame.2016.07.016.

(106) Gersen, S.; Darmeveil, H.; Levinsky, H. The Effects of CO Addition on the Autoignition of $\mathrm{H}_{2}, \mathrm{CH}_{4}$ and $\mathrm{CH}_{4} / \mathrm{H}_{2}$ Fuels at High Pressure in an RCM. Combust Flame 2012, 159, 3472-3475. https://doi.org/10.1016/j.combustflame.2012.06.021.

(107) Liu, C.; Song, H.; Zhang, P.; Wang, Z.; Wooldridge, M. S.; He, X.; Suo, G. A Rapid Compression Machine Study of Autoignition, Spark-Ignition and Flame Propagation Characteristics of $\mathrm{H}_{2} / \mathrm{CH}_{4} / \mathrm{CO} /$ Air Mixtures. Combust. Flame 2018, 188, 150-161. https://doi.org/10.1016/j.combustflame.2017.09.031.

(108) Varga, T.; Olm, C.; Máté, P.; Ágota, B.; Zsély, I. G. ReSpecTh Kinetics Data Format Specification v2.3; 2020. 
https://doi.org/http://respecth.chem.elte.hu/respecth/reac/ReSpecTh_Kinetics_Data_Forma t_Specification_v2.3.pdf.

(109) Frenklach, M.; Packard, A.; Seiler, P.; Feeley, R. Collaborative Data Processing in Developing Predictive Models of Complex Reaction Systems. Int J Chem Kinet 2004, 36, 57-66. https://doi.org/10.1002/kin.10172.

(110) Papp, M.; Varga, T.; Busai, Á.; Zsély, I. G.; Nagy, T.; Turányi, T. Optima++ Package v2.1.0: A General C++ Framework for Performing Combustion Simulations and Mechanism Optimization. 2021.

(111) Pitsch, H. FlameMaster v4.0 BETA: A C++ Computer Program for 0D Combustion and 1D Laminar Flame Calculations. 2016.

(112) Cuoci, A.; Frassoldati, A.; Faravelli, T.; Ranzi, E. OpenSMOKE++: An Object-Oriented Framework for the Numerical Modeling of Reactive Systems with Detailed Kinetic Mechanisms. Comput Phys Commun 2015, 192, 237-264. https://doi.org/10.1016/j.cpc.2015.02.014.

(113) OpenSMOKE++, (https://www.opensmokepp.polimi.it/).

(114) Mathieu, O.; Mulvihill, C. R.; Petersen, E. L. Assessment of Modern Detailed Kinetics Mechanisms to Predict CO Formation from Methane Combustion Using Shock-Tube Laser-Absorption Measurements. Fuel 2019, 236, 1164-1180. https://doi.org/https://doi.org/10.1016/j.fuel.2018.09.029. 
(115) Tanaka, S.; Ayala, F.; Keck, J. C. A Reduced Chemical Kinetic Model for HCCI Combustion of Primary Reference Fuels in a Rapid Compression Machine. Combust. Flame 2003, 133 (4), 467-481. https://doi.org/10.1016/S0010-2180(03)00057-9.

(116) Mittal, G.; Sung, C. J. A Rapid Compression Machine for Chemical Kinetics Studies at Elevated Pressures and Temperatures. Combust. Sci. Technol. 2007, 179, 497-530. https://doi.org/10.1080/00102200600671898.

(117) Kéromnès, A.; Metcalfe, W. K.; Heufer, K. A.; Donohoe, N.; Das, A. K.; Sung, C.-J.; Herzler, J.; Naumann, C.; Griebel, P.; Mathieu, O.; Krejci, M. C.; Petersen, E. L.; Pitz, W. J.; Curran, H. J. An Experimental and Detailed Chemical Kinetic Modeling Study of Hydrogen and Syngas Mixture Oxidation at Elevated Pressures. Combust. Flame 2013, 160 (6), 995-1011. https://doi.org/10.1016/J.COMBUSTFLAME.2013.01.001.

(118) He, X.; Walton, S. M.; Zigler, B. T.; Wooldridge, M. S.; Atreya, A. Experimental Investigation of the Intermediates of Isooctane during Ignition. Int. J. Chem. Kinet. 2007, 39 (9), 498-517. https://doi.org/10.1002/kin.20254.

(119) Brett, L.; Macnamara, J.; Musch, P.; Simmie, J. M. Simulation of Methane Autoignition in a Rapid Compression Machine with Creviced Pistons. Combust Flame 2001, 124, 326329. https://doi.org/10.1016/s0010-2180(00)00193-0.

(120) Gersen, S.; Anikin, N. B.; Mokhov, A. V; Levinsky, H. B. Ignition Properties of Methane/Hydrogen Mixtures in a Rapid Compression Machine. Int J Hydrog. Energy 2008, 33, 1957-1964. https://doi.org/10.1016/j.ijhydene.2008.01.017. 
(121) Srinivasan, N. K.; Su, M. C.; Sutherland, J. W.; Michael, J. V. Reflected Shock Tube Studies of High-Temperature Rate Constants for $\mathrm{CH}_{3}+\mathrm{O}_{2}, \mathrm{H}_{2} \mathrm{CO}+\mathrm{O}_{2}$, and $\mathrm{OH}+\mathrm{O}_{2} . J$ Phys Chem A 2005, 109 (35), 7902-7914. https://doi.org/10.1021/jp0581330.

(122) Srinivasan, N. K.; Su, M.-C.; Michael, J. V. $\mathrm{CH}_{3}+\mathrm{O}_{2} \rightarrow \mathrm{H}_{2} \mathrm{CO}+\mathrm{OH}$ Revisited. J. Phys. Chem. A 2007, 111 (45), 11589-11591. https://doi.org/10.1021/jp0757210.

(123) Saito, K.; Ito, R.; Kakumoto, T.; Imamura, A. The Initial Process of the Oxidation of the Methyl Radical in Reflected Shock Waves. J. Phys. Chem. 1986, 90 (7), 1422-1427. https://doi.org/10.1021/j100398a042. 